\title{
NUMERICAL INSTABILITY STUDY OF SUPERCRITICAL WATER FLOWING UPWARD IN TWO HEATED PARALLEL CHANNELS
}

BY

SUJUAN LI

A Thesis

Submitted to the Faculty of Graduate Studies In Partial Fulfillment of the Requirements for the Degree of

\section{MASTER OF SCIENCE}

Department of Mechanical and Manufacturing Engineering University of Manitoba

Winnipeg, Manitoba

(C) Sujuan Li, 2016 


\begin{abstract}
A three dimensional numerical investigation of supercritical water flowing upward in two heated parallel channels was developed using a RANS model in the Computational Fluid Dynamics (CFD) code ANSYS CFX. The standard k- $\varepsilon$ turbulence model with scalable wall functions was adopted throughout this numerical study.

The effects of spatial and temporal grid sizes on flow instability were studied first. Then oscillatory instabilities of nine experimental cases were predicted using the CFX code. For comparison purposes, Chatoorgoon's 1-D non-linear SPORTS code was also used to determine the instability boundary. These new numerical results were compared with the experimental data and previous numerical results by other investigators.

Additionally, the effects of changing the outlet plenum volume, the turbulent Prandtl number, the turbulence inlet conditions, the outlet $\mathrm{K}$ factor, the maximum iterations per time step in the transient analysis and the order of the transient scheme on the instability thresholds were examined.
\end{abstract}




\section{ACKNOWLEDGEMENTS}

Firstly, I would like to express my sincere appreciation to my advisors, Dr. V. Chatoorgoon and Dr. S.J. Ormiston for giving me the chance to work on this project and for all of their valuable guidance during my M.Sc. study. I would also like to thank AECL for the financial support of this project. Last but not least, I am grateful for the support, understanding and patience from my husband, Lei and my parents. 


\section{TABLE OF CONTENTS}

ABSTRACT

ACKNOWLEDGEMENTS

TABLE OF CONTENTS III

LIST OF TABLES VI

LIST OF FIGURES VIII

NOMENCLATURE X

Greek Symbols xiv

Subscripts . $\mathrm{XV}$

Acronyms xvi

Abbreviation xvii

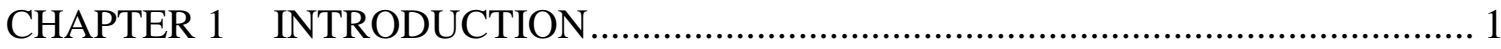

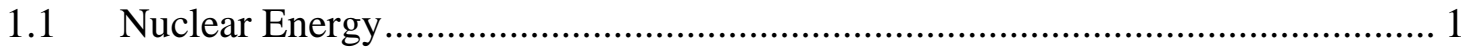

1.2 Supercritical Water Cooled Reactors ............................................................. 2

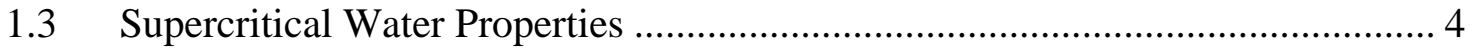

1.4 Supercritical Flow Instability ................................................................ 7

1.5 SCWR Modelling ................................................................................ 9

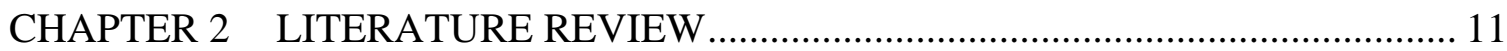

2.1 Instability Studies of Single Channel ................................................... 11

2.2 Instability Studies of Parallel Channels ........................................................ 13 
2.3 Instability Studies of Circulation Loop .......................................................... 16

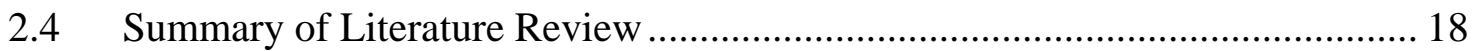

$2.5 \quad$ Objectives of Present Work.......................................................................... 19

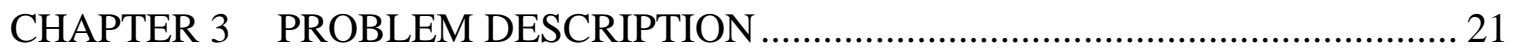

3.1 Xiong's Experimental Loop (Xiong et al., 2012)........................................... 21

3.2 Flow Conditions for the Xiong's Experiment (Xiong et al., 2012)................... 24

CHAPTER 4 NUMERICAL MODELING …………………………………….... 25

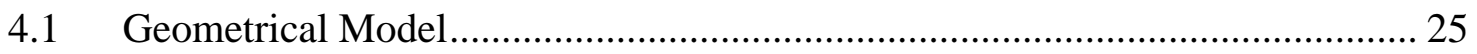

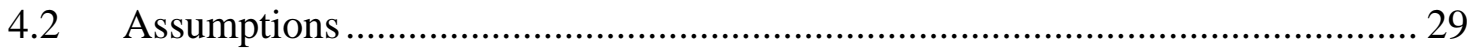

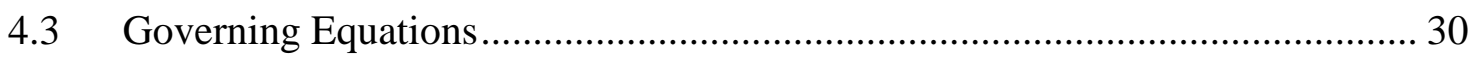

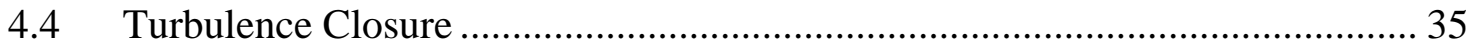

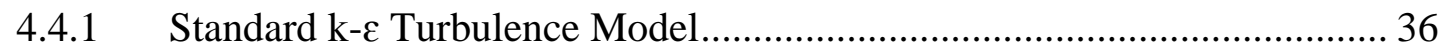

4.4.2 Scalable Wall Functions .......................................................................... 37

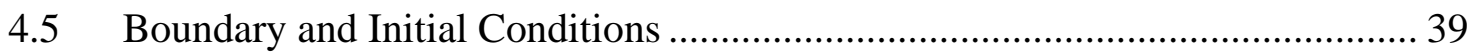

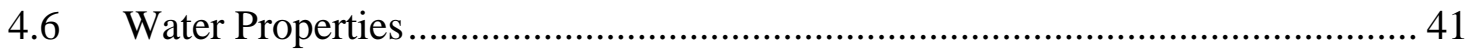

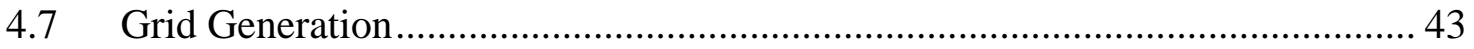

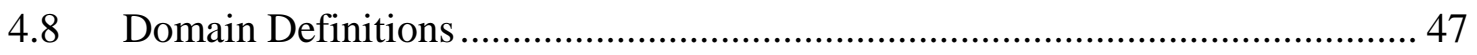

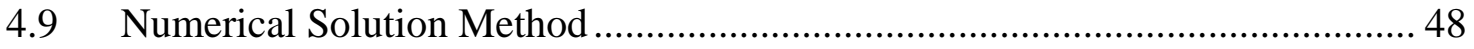

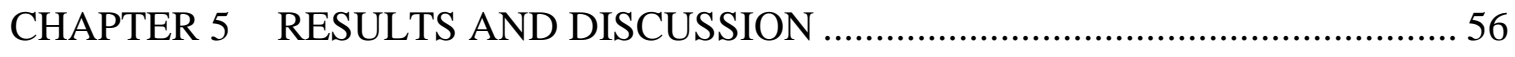

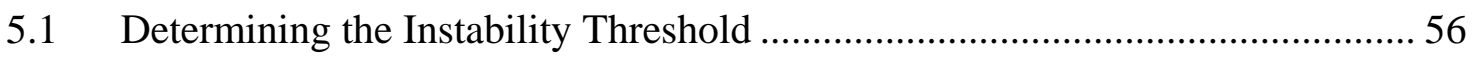

5.2 Spatial Resolution Independence Study ……............................................... 57

$5.3 \quad$ Temporal Resolution Independence Study ……………............................... 58

5.4 Present CFX Predictions of Threshold Mass Flow Rates ................................. 60 
5.5 1-D SPORTS Predictions of Threshold Mass Flow Rate ................................ 64

5.6 Comparisons between Numerical Simulations and the Experiment ................. 65

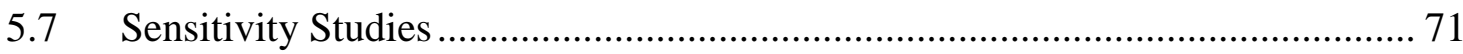

5.7.1 Effect of Changing the Outlet Plenum Volume ...................................... 71

5.7.2 Effect of Changing the Turbulent Prandtl Number.................................. 75

5.7.3 Effect of Changing the Turbulence Inlet Conditions ............................... 79

5.7.4 Effect of Changing the Outlet K Factor ................................................. 82

5.7.5 Effect of Changing the Maximum Iterations per Time Step...................... 83

5.7.6 Effect of Changing the Transient Scheme ............................................... 85

CHAPTER 6 SUMMARY, CONCLUSIONS, AND RECOMMENDATIONS .......... 93

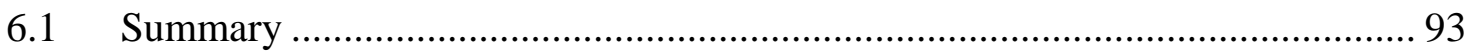

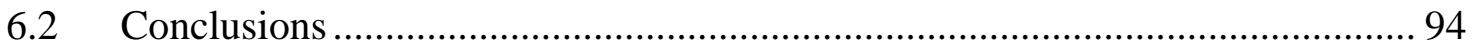

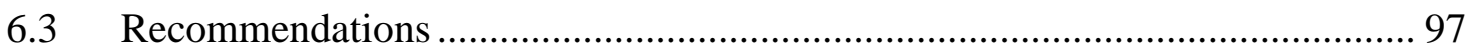

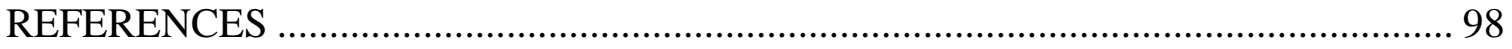




\section{LIST OF TABLES}

Table 3.1: Different flow conditions run using the Xiong et al. (2012) experimental loop, as obtained from $\mathrm{Xi}$ et al. (2014)

Table 5.1: Different meshes used for spatial independence study 57

Table 5.2: The threshold mass flow rate $(\mathrm{kg} / \mathrm{s})$ predicted with different meshes (mass flow rates are for the full geometry and discrepancies are relative to the mesh 3 results) 58

Table 5.3: The threshold mass flow rate $(\mathrm{kg} / \mathrm{s})$ predicted with different time steps (mass flow rates are for the full geometry and discrepancies are relative to the 0.01 s results) .. 59

Table 5.4: Threshold mass flow rates of nine experimental cases predicted by CFX ...... 63

Table 5.5: The Reynolds number at the inlet and outlet of both channels for nine experimental cases 64

Table 5.6: Threshold mass flow rates of nine experimental cases predicted by the 1-D non-linear SPORTS code 65

Table 5.7: $N_{T P C}$ comparisons between numerical simulations and experimental results.. 66

Table 5.8: Comparisons of threshold mass flow rates obtained with two different outlet plena volumes for Case 1 and Case 3

Table 5.9: Comparisons of total pressure drops in two channels obtained with two outlet plena at a same total mass flow rate of $0.0340 \mathrm{~kg} / \mathrm{s}$ for Case 1 75 
Table 5.10: Comparison of total pressure drops in two channels with different Prt values

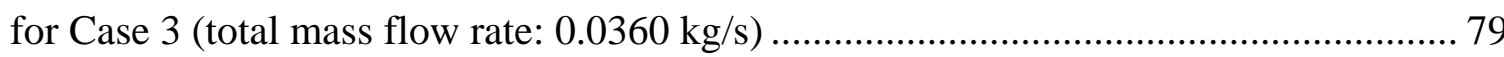

Table 5.11: Comparisons of Case 3 instability boundaries obtained with three different

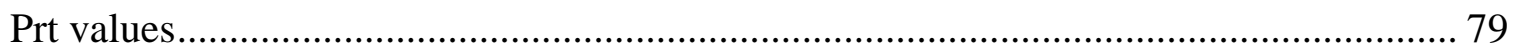

Table 5.12: Comparisons of total pressure drops in two channels with different turbulence

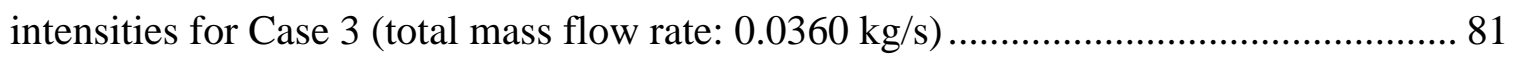

Table 5.13: Comparison of Case 3 instability boundaries obtained with different turbulence inlet conditions ............................................................................. 81

Table 5.14: Comparisons of Case 3 instability boundaries obtained with different outlet K

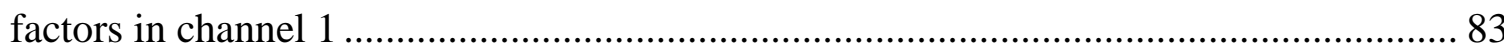

Table 5.15: Comparisons of Case 3 instability boundaries obtained with different outlet K

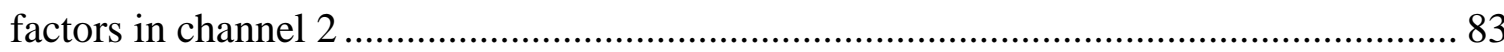

Table 5.16: Restart test results at different total inlet mass flow rates for Case 1 ........... 90

Table 5.17: Instability boundary of Case 1 under different test conditions..................... 91 


\section{LIST OF FIGURES}

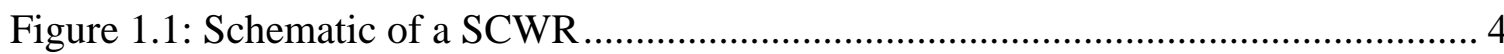

Figure 1.2: Scheme of the phase diagram for water …………………......................... 5

Figure 1.3: $C_{p}$ variations with temperature for supercritical water at constant pressures

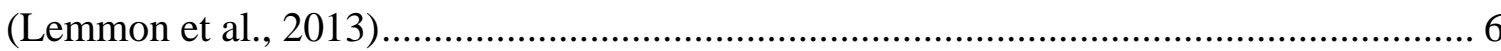

Figure 1.4: Thermo-physical property variations of water at a supercritical pressure of 25

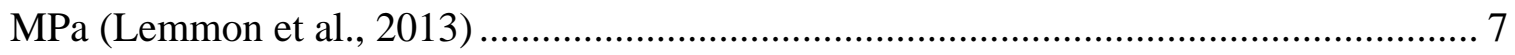

Figure 3.1: Schematic diagram of the Xiong et al. (2012) experimental loop.................. 22

Figure 3.2: Schematic diagram of the test section in Xiong's experiment (Xiong et al., 2012) 23

Figure 4.1: Schematic diagram of the numerical model used in simulation..................... 26

Figure 4.2: Part view of the numerical model used in simulation from CFX with partial enlargement 27

Figure 4.3: Regions and Equations of IAPWS-IF97 (ANSYS CFX-Solver Theory Guide, 2013) 42

Figure 4.4: A cross-sectional view of the half O-grid mesh used in the channel 44

Figure 4.5: Detailed views of the channel in the plenum region 44

Figure 4.6: Isometric view of the mesh that connects the plenum to the channel 45 
Figure 4.7: Fluid domains of the numerical model used in this study

Figure 4.8: 2D simplification of a typical control volume in CFX

Figure 5.1: Time responses of inlet mass flow rate in channel 1 at different time steps and a total mass flow rate of $0.0340 \mathrm{~kg} / \mathrm{s}$ for Case 1 60

Figure 5.2: Time responses of the normalized channel 1 inlet mass flow rate at two different total mass flow rates for Case 1

Figure 5.3: Time responses of the normalized inlet mass flow rate in two parallel channels at a same total mass flow rate of $0.0340 \mathrm{~kg} / \mathrm{s}$ for Case 1

Figure 5.4: Geometrical model used in Xi's simulation. 69

Figure 5.5: Comparisons of velocity field obtained with two outlet plena at a same total mass flow rate of $0.0340 \mathrm{~kg} / \mathrm{s}$ for Case 1 (outlets of two channels were magnified) ....... 74

Figure 5.6: Channel 1 average wall temperature variations with different Prt values for Case 3 at a total mass flow rate of $0.0360 \mathrm{~kg} / \mathrm{s}$ 77

Figure 5.7: Comparisons of the normalized channel 1 inlet mass flow rate transient responses at different maximum numbers of iterations per time step for Case 3 and at a total mass flow rate of $0.0360 \mathrm{~kg} / \mathrm{s}$ 85

Figure 5.8: Case 1 instability boundary predicted by different transient schemes 86

Figure 5.9: The normalized channel 1 inlet mass flow transient responses under Case 1 flow conditions with different transient schemes 89 


\section{NOMENCLATURE}

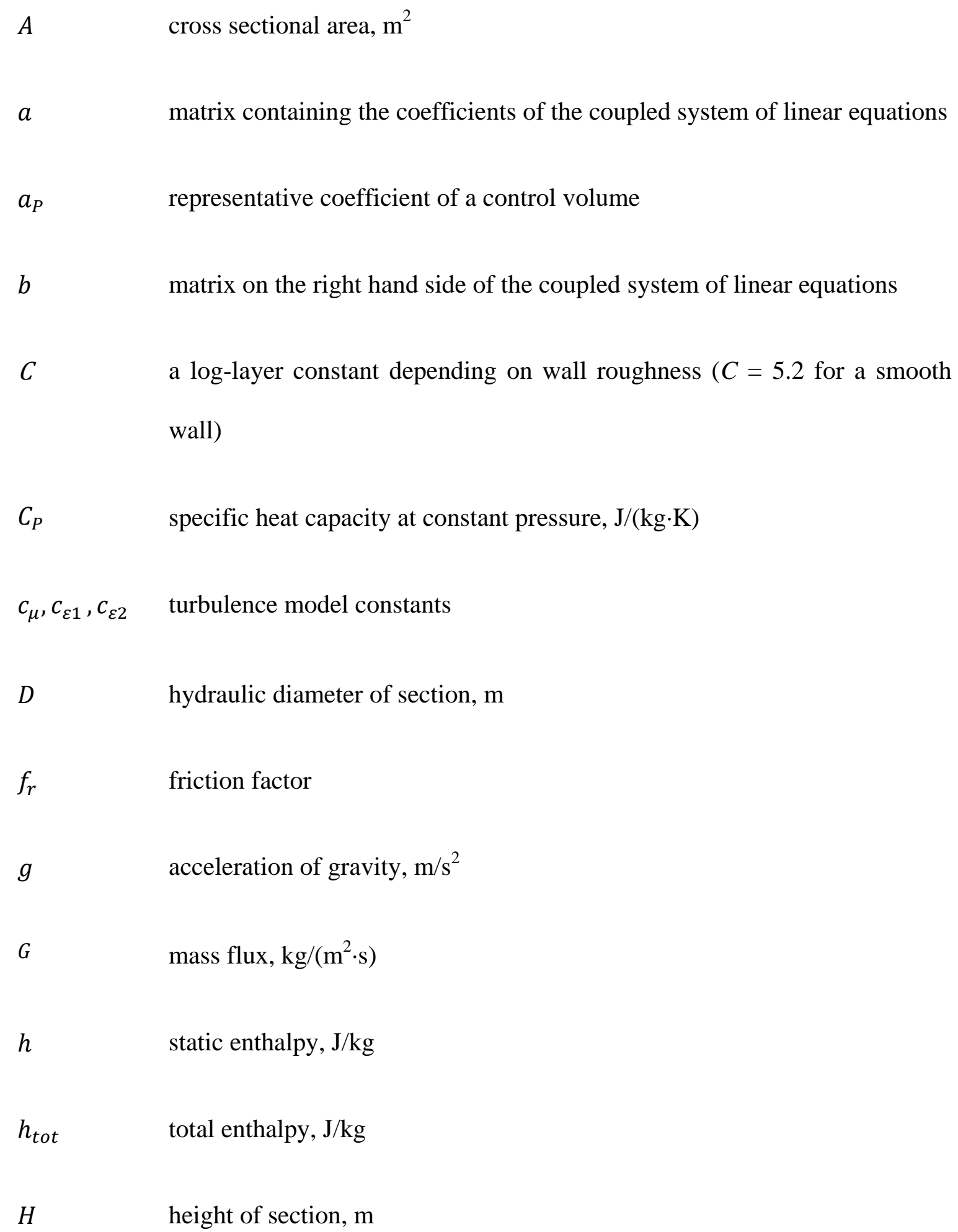




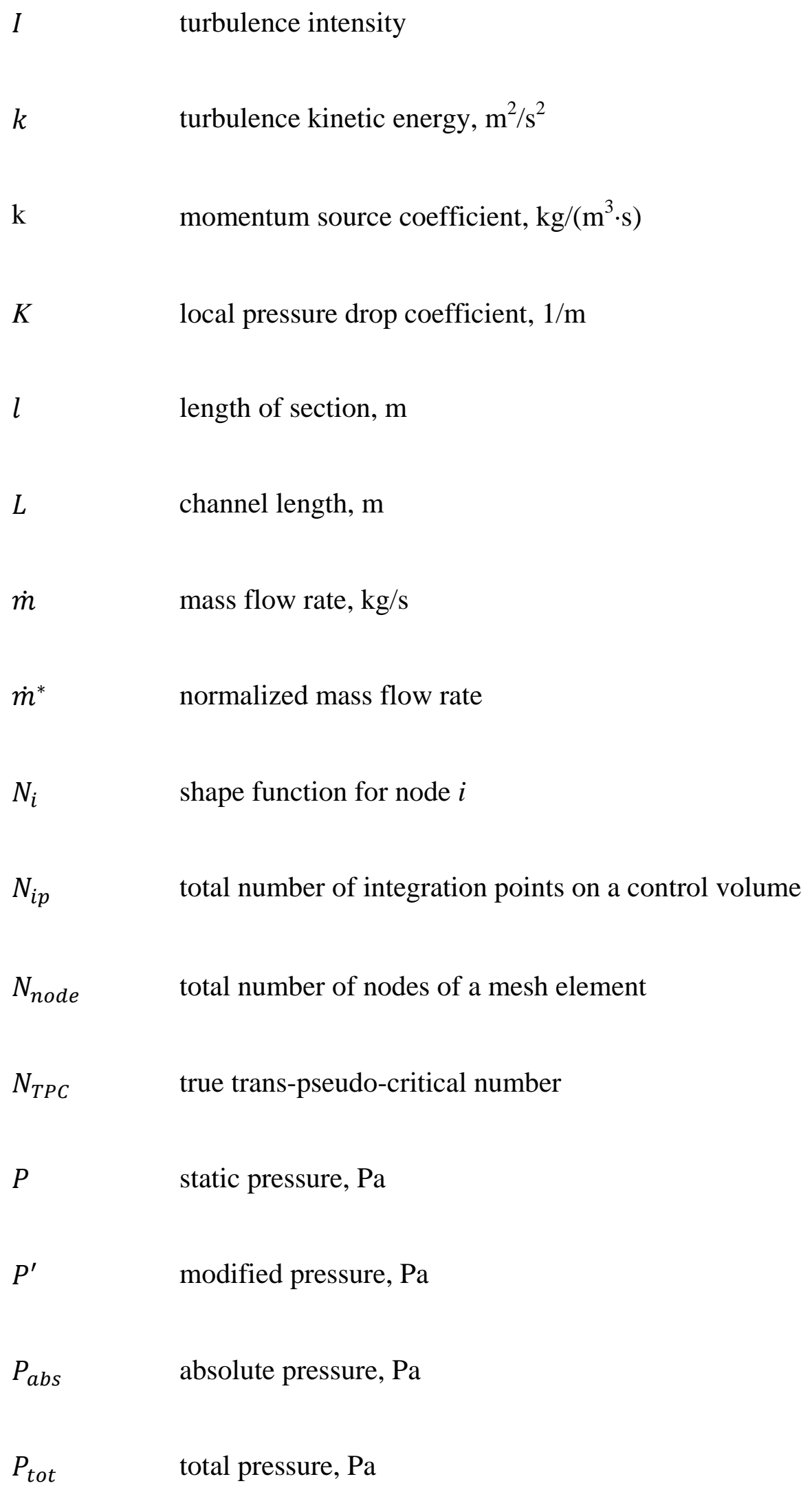




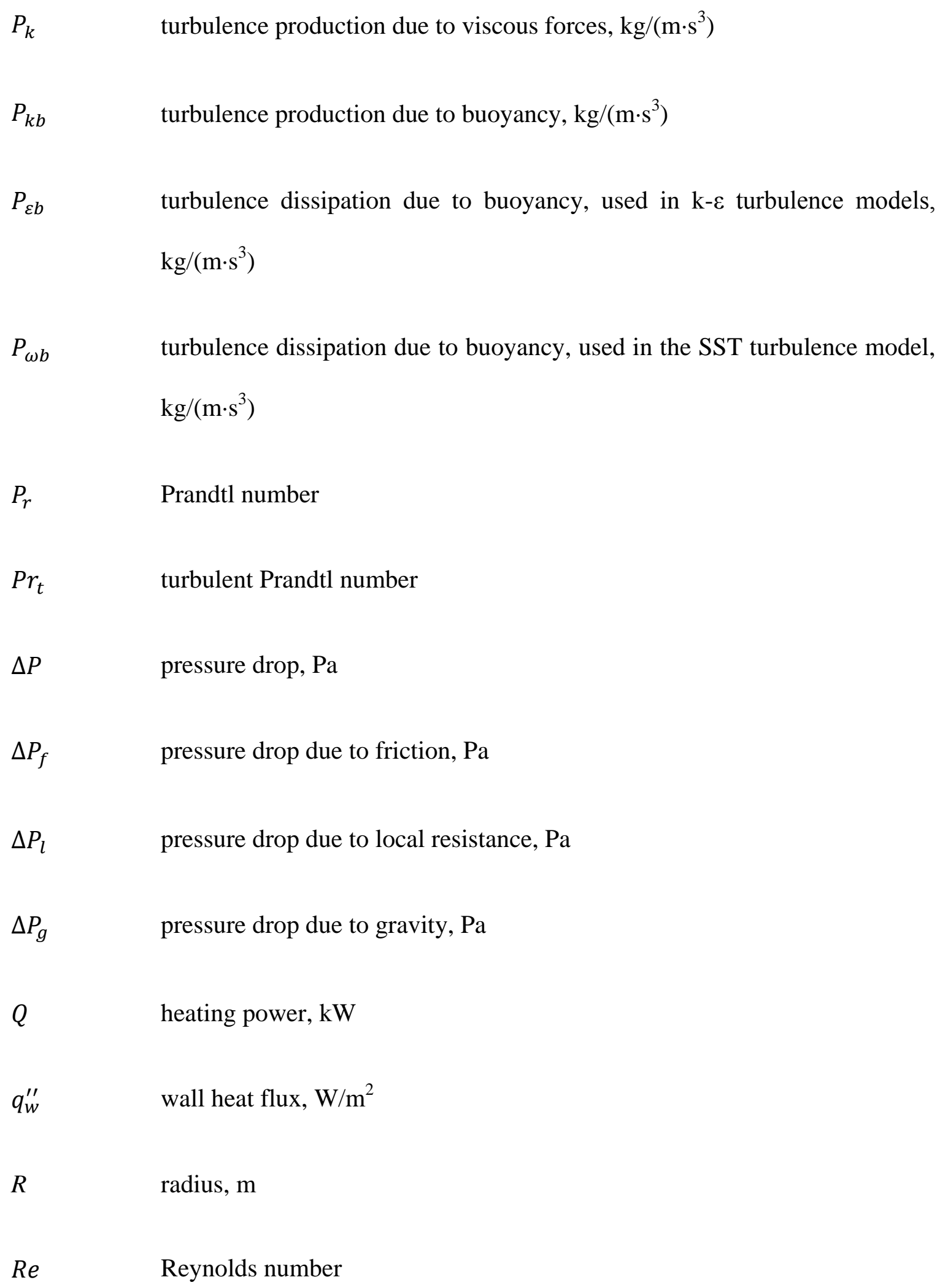


$\vec{r}$

$\vec{r}_{r e f}$

$r_{\psi}$

$\tilde{r}_{\psi}$

$S_{M, b u o y}$

$S_{M, f r i c t}$

$T$

$T_{\text {ref }}$

$T_{w}$

$\bar{T}_{w}$

$t$

$U$

$U_{i}, U_{j}, U_{k} \quad$ mean flow velocities relative to $i, j$, and $k$ in a three dimensional Cartesian

coordinate system, $\mathrm{m} / \mathrm{s}$

$U_{t} \quad$ velocity tangent to the wall at the distance of $\Delta y$ from the wall, $\mathrm{m} / \mathrm{s}$

position vector, $\mathrm{m}$

buoyancy reference location, specified at the centroid of the outlet, $\mathrm{m}$

raw residual

normalized residual

momentum source term due to buoyancy, $\mathrm{kg} /\left(\mathrm{m}^{2} \cdot \mathrm{s}^{2}\right)$

a general momentum source to model local friction pressure drops, $\mathrm{kg} /\left(\mathrm{m}^{2} \cdot \mathrm{s}^{2}\right)$

temperature, $\mathrm{K}$

reference temperature, $\mathrm{K}$

fluid temperature at the wall, $\mathrm{K}$

average fluid temperature at the wall, $\mathrm{K}$

time, $s$

mean flow velocity, $\mathrm{m} / \mathrm{s}$ 

$u^{*}$
dimensionless velocity scale
$u^{+}$
near-wall velocity
$u_{i}, u_{j}$
turbulent fluctuating velocities, $\mathrm{m} / \mathrm{s}$
$u_{\tau}$
friction velocity, $\mathrm{m} / \mathrm{s}$
w
velocity in $z$-direction, $\mathrm{m} / \mathrm{s}$
$x, y, z \quad$ position in a Cartesian coordinate system, $\mathrm{m}$
$y^{+}$
non-dimensional distance of the first node from the wall

\section{Greek Symbols}

$\beta$

$\sigma_{\varepsilon}, \sigma_{k}$

$\Delta$

$\nabla$

$\delta$

$\delta_{i j}$

$\varepsilon$

$\theta$

$\kappa$ isobaric thermal expansion coefficient, $\mathrm{K}^{-1}$

model constants for $k$ and $\varepsilon$ equations

difference between two quantities

vector differential operator

surface roughness, $\mathrm{m}$

Kronecker delta function

turbulence dissipation rate, $\mathrm{m}^{2} / \mathrm{s}^{3}$

angular position in a cylindrical coordinate system, rad

von Kármán constant 
thermal conductivity, $\mathrm{W} / \mathrm{m} \cdot \mathrm{K}$

$\lambda_{t} \quad$ turbulent thermal conductivity, $\mathrm{W} / \mathrm{m} \cdot \mathrm{K}$

$\mu$

dynamic viscosity, $\mathrm{Pa} \cdot \mathrm{S}$

$\mu_{t}$

eddy viscosity, $\mathrm{Pa} \cdot \mathrm{s}$

$v$

kinematic viscosity, $\mathrm{m}^{2} / \mathrm{s}$

$v_{t}$

turbulent kinematic viscosity, $\mathrm{m}^{2} / \mathrm{s}$

$\rho$

density, $\mathrm{kg} / \mathrm{m}^{3}$

$\rho_{\text {ref }}$

reference density, $\mathrm{kg} / \mathrm{m}^{3}$

$\rho \overline{u_{\imath} u_{\jmath}} \quad$ Reynolds stress, N/m 2

$\tau$

magnitude of shear stress, $\mathrm{N} / \mathrm{m}^{2}$

$\tau_{w}$

shear stress at the wall, $\mathrm{N} / \mathrm{m}^{2}$

$\tau_{i j}$

shear stress, $\mathrm{N} / \mathrm{m}^{2}$

$\varphi$

generic solution variable

$\varphi_{f} \quad$ generic face value of a solution variable

$\varphi_{\text {range }} \quad$ representative value of the overall range in the solution variable

$\varphi_{u p} \quad$ generic upwind cell centre value of a solution variable

\section{Subscripts}

1

channel 1 


\begin{tabular}{|c|c|}
\hline 2 & channel 2 \\
\hline$c$ & critical \\
\hline$f$ & friction \\
\hline$g$ & gravity \\
\hline in & inlet \\
\hline ip & integration point \\
\hline$l$ & local \\
\hline $\max$ & maximum \\
\hline $\min$ & minimum \\
\hline$n b$ & neighbour \\
\hline norm & normalized \\
\hline out & outlet \\
\hline$p c$ & pseudo-critical \\
\hline thold & threshold \\
\hline tot & total \\
\hline
\end{tabular}

\section{Acronyms}

$\begin{array}{ll}\text { BWR } & \text { Boiling Water Reactor } \\ \text { DNS } & \text { Direct Numerical Simulation }\end{array}$




$\begin{array}{ll}\text { DWO } & \text { Density Wave Oscillation } \\ \text { GFR } & \text { Gas-Cooled Fast Reactor } \\ \text { GIF } & \text { Generation IV International Forum } \\ \text { LFR } & \text { Lead-Cooled Fast Reactor } \\ \text { LWR } & \text { Light Water Reactor } \\ \text { MSR } & \text { Molten Salt Reactor } \\ \text { NPIC } & \text { Nuclear Power Institute of China } \\ \text { PWR } & \text { Pressurized Water Reactors } \\ \text { RANS } & \text { Reynolds Averaged Navier-Stokes } \\ \text { SCWR } & \text { Supercritical Water Cooled Reactor } \\ \text { SFR } & \text { Sodium-Cooled Fast Reactor } \\ \text { UDS } & \text { Upwind Difference Scheme } \\ \text { VHTR } & \text { Very High Temperature Reactor }\end{array}$




\section{CHAPTER 1 \\ INTRODUCTION}

\subsection{Nuclear Energy}

According to the Worldometers statistics (Worldometers.info, 2016), the world population presently is more than 7 billion, and is expected to reach 8 billion in 2024 and 10 billion in 2056. There is therefore a growing demand for energy due to the world population increase. So far, fossil fuels (initially mainly lignite and coal; later oil and natural gas) have always been the main energy source. However, it is unrealistic to indefinitely depend on the combustion of fossil fuels which are non-renewable and finite for human energy consumption. Continued large-scale combustion of fossil fuels increases the emission of greenhouse gases (mainly carbon dioxide), serious environmental consequences and health risks due to pollution. In addition, the extraction of fossil fuels is more and more difficult, energy-consuming and costly. Therefore, it is necessary to reduce the consumption of fossil fuels.

Electrical-energy generation is one of the most important consumers of energy in the world. Since nuclear energy has already been deployed worldwide for electricity generation, and what's more, rather satisfactory performances have been achieved, increasing the construction of nuclear power plants for electricity supply is the most viable, effective and logical way to reduce fossil-fuel-based energy consumption. Furthermore, nuclear energy is environmentally friendly and is able to economically supply electricity safely, reliably and sustainably (Brook et al., 2014). In 2012, 10.9\% of the world's electricity was supplied by nuclear power plants. In 2016, 444 nuclear 
reactors across 30 countries are being operated for electricity generation, and 63 new nuclear power plants in 15 countries are under construction (Nuclear Energy Institute, 2016). Currently, the majority of first generation nuclear reactor systems are retired, second generation reactor systems are the main reactors in operation and only about 12 Generation III reactors are in operation. In addition, a new and innovative generation of nuclear power reactors, Generation IV reactors, are proposed and being researched.

\subsection{Supercritical Water Cooled Reactors}

The Generation IV International Forum (GIF) was founded in 2001. It currently consists of ten active members (Canada, China, the European Atomic Energy Community (Euratom), France, Japan, Russia, South Korea, South Africa, Switzerland and the United States) and three non-active members (Argentina, Brazil and the United Kingdom). This forum is aimed at furthering research and development of the next generation of advanced nuclear reactors. Based on the four objectives of sustainability, safety and reliability, economics, and proliferation resistance and physical protection, the GIF identified the six most promising nuclear reactor designs to be focused on: the GasCooled Fast Reactor (GFR), the Sodium-Cooled Fast Reactor (SFR), the Lead-Cooled Fast Reactor (LFR), the Very High Temperature Reactor (VHTR), the Molten Salt Reactor (MSR), and the Supercritical Water Cooled Reactor (SCWR).

The Supercritical Water Cooled Reactor (SCWR) uses light water at supercritical conditions ( $\mathrm{P} \geq 22.06[\mathrm{MPa}]$ and $\left.\mathrm{T} \geq 373.946\left[{ }^{\circ} \mathrm{C}\right]\right)$ as the working fluid. The operation experience of Fossil Fired Power Plants (FFPP) indicates that increasing the system pressure and temperature can improve thermal efficiency significantly; thus, the 
application of supercritical water as the coolant is a good approach to achieve the goal of improving the plant efficiency economically. Making full use of the technologies in supercritical water-cooled fossil-fired power plants, the thermal efficiency of SCWRs is expected to reach $44 \%$ or more, compared to $34-36 \%$ for current reactors (OECD, 2014).

Supercritical Water Cooled Reactors (SCWRs), Boiling Water Reactors (BWRs) and Pressurized Water Reactors (PWRs) are all Light Water Reactors (LWRs). Different from the BWR whose exit temperature is limited by the Departure of Nuclear Boiling (DNB) problem, a SCWR would work at a high temperature level. Furthermore, because the water is superheated in the core, there is no need for the installation of the steam separators and dryers needed in BWRs, or the steam generators required in PWRs. Consequently, this compact design of SCWRs can not only simplify power plants significantly, but can also save some construction costs.

Figure 1.1 is the schematic of a SCWR design. The cold water is pumped into the reactor pressure vessel at a high pressure, and it subsequently flows through the reactor core where it is heated to be supercritical by the atom fission energy. Then the hot fluid is passed through the high pressure turbine directly, where the turbine drives the generator to produce electrical energy. The working fluid exiting the turbine is passed through the condenser to be cooled down. And then, the water from the condenser is fed back to the reactor pressure vessel by the pump and the cycle is repeated. 


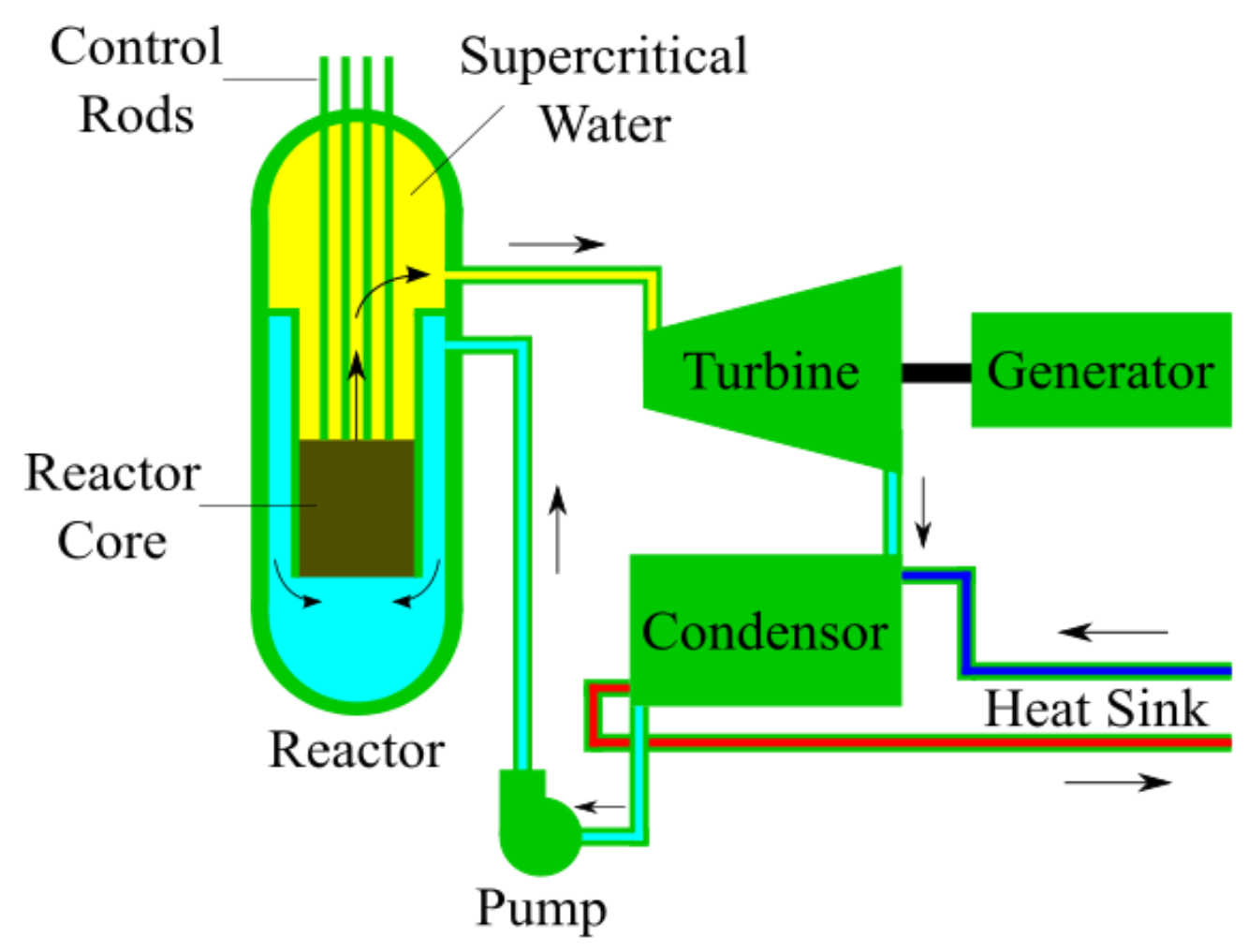

Figure 1.1: Schematic of a SCWR

Currently, the technological development of SCWRs is still unfolding. According to the system development timelines in the GIF 2014 Technology Roadmap, the licensing, construction and operation of a prototype or demonstration SCWR system are likely to start around 2025, followed by another 10 years to deal with details, and then SCWRs are anticipated to be available for commercial construction (OECD, 2014).

\subsection{Supercritical Water Properties}

The phase diagram of water is shown schematically in Figure 1.2. Solid ice is transformed into vapour directly along the sublimation line without any other intermediate processes, and is separated from the liquid water by the melting line. The boiling line separates the liquid phase and the gaseous phase of water. These three lines 
meet together at the triple point where all three states of water coexist. At the upper end of the boiling line, there is another important point: the critical point. For water, the pressure and temperature at the critical point is $22.06 \mathrm{MPa}$ and $373.9^{\circ} \mathrm{C}$, respectively. When a fluid is compressed above its critical pressure and heated above its critical temperature, the fluid is said to be supercritical and exists as a single phase. At the critical point, the densities of liquid and vapor are identical.

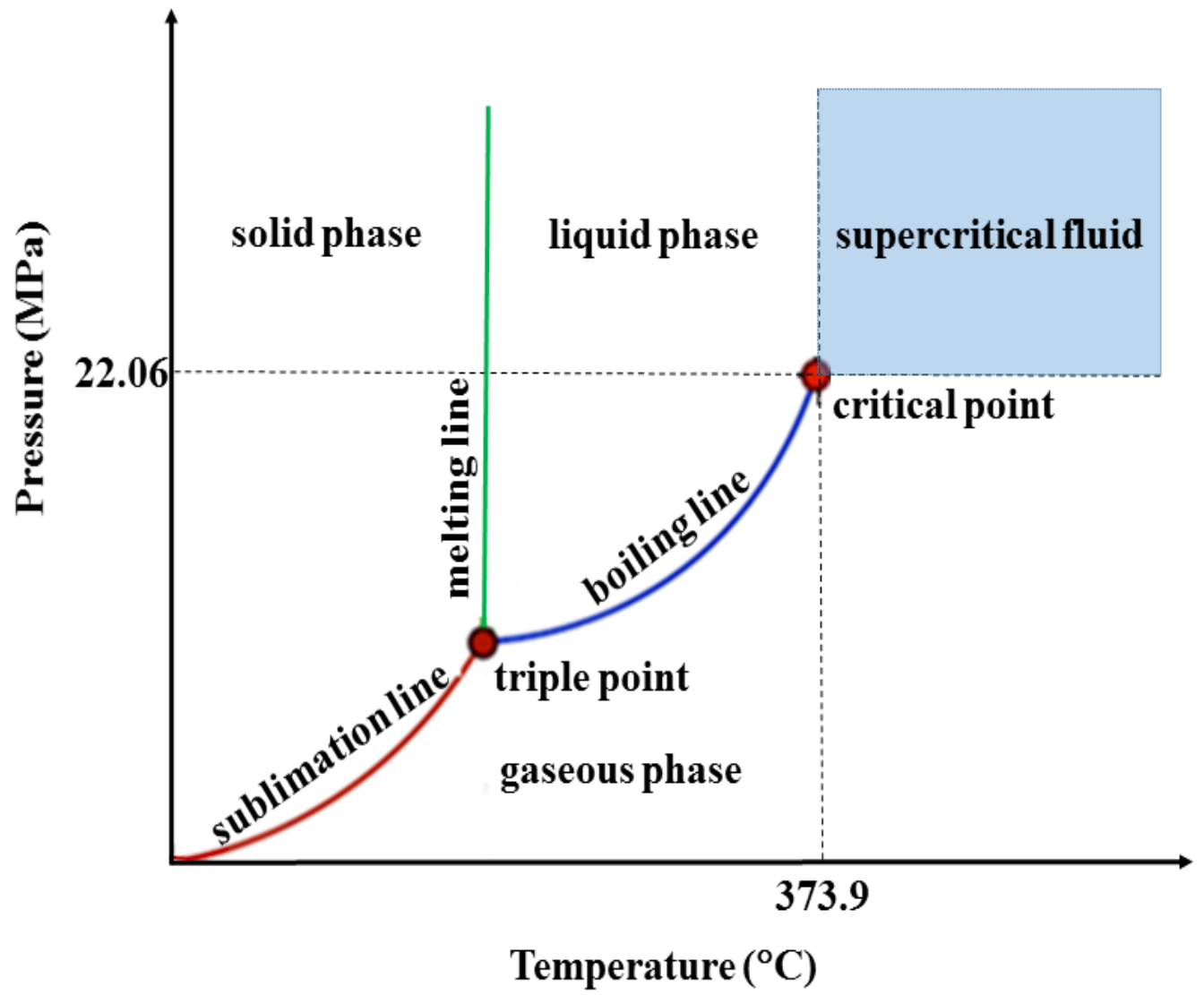

Figure 1.2: Scheme of the phase diagram for water

In the supercritical fluid region (blue region in Figure 1.2), at any given pressure there is a corresponding pseudocritical temperature. The pseudocritical temperature corresponds to the maximum value of the fluid specific heat capacity, $C_{p}$. As shown in Figure 1.3, at 
each supercritical pressure, there is a spike of $C_{p}$ at a unique pseudocritical temperature. In addition, the spike is largest in magnitude when the supercritical pressure is closed to the critical point. The magnitude of the spike decreases with an increase in the pressure.

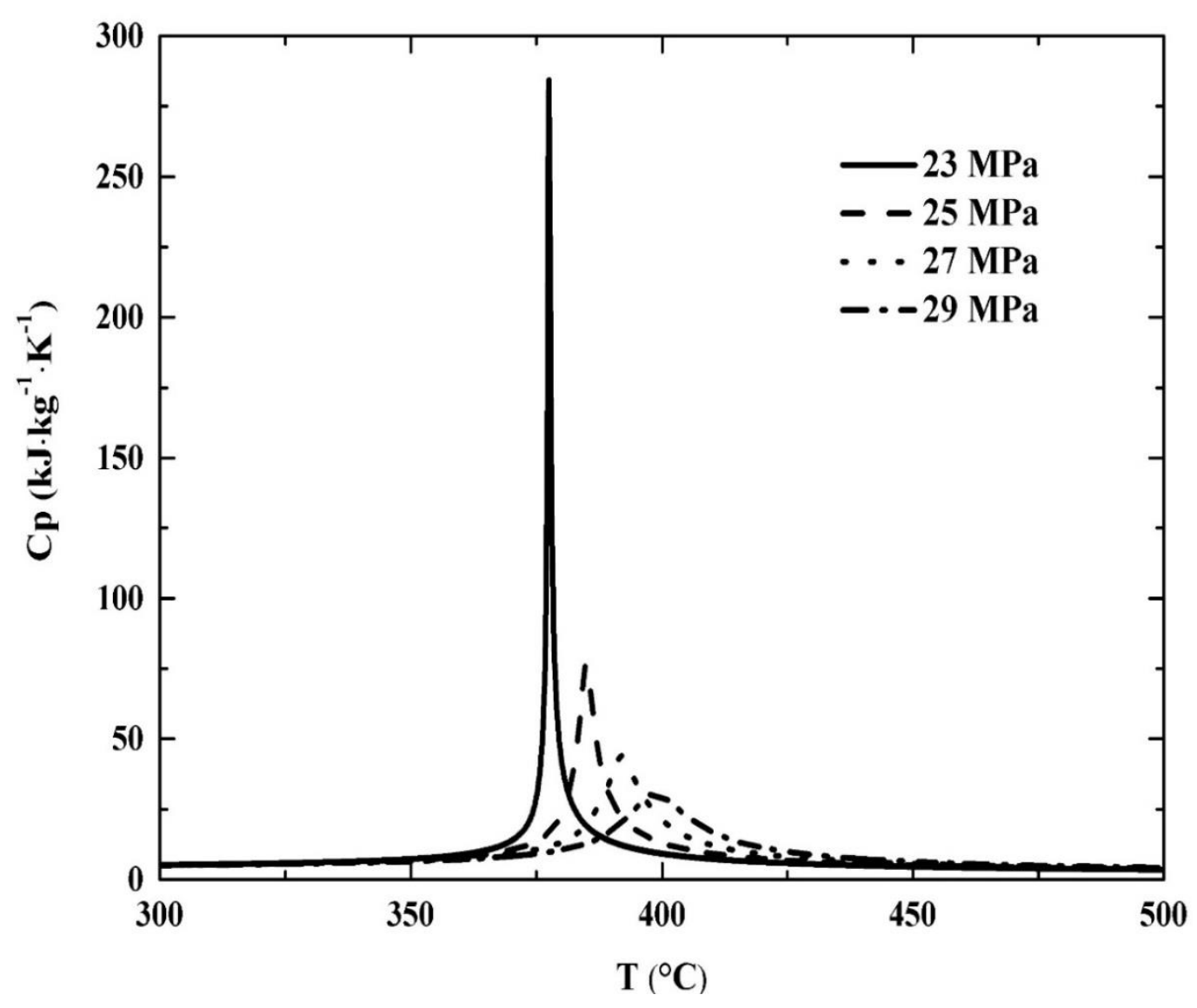

Figure 1.3: $C_{p}$ variations with temperature for supercritical water at constant pressures (Lemmon et al., 2013)

When the working condition approaches the critical or pseudocritical point, water properties undergo sharp changes. Figure 1.4 illustrates properties variations of supercritical water at a supercritical pressure of $25 \mathrm{MPa}$. It can be observed from this figure that, with an increase in the temperature, the specific heat capacity $\left(C_{p}\right)$ goes up sharply, goes through a sudden spike at the pseudocritical point, and then drops sharply to 
a value close to what it was before the pseudocritical point. The density $(\rho)$, viscosity $(\mu)$ and thermal conductivity $(\lambda)$, on the other hand, experience sharp drops at the pseudocritical point, followed by relatively constant values which are much lower than the values before the pseudocritical point.

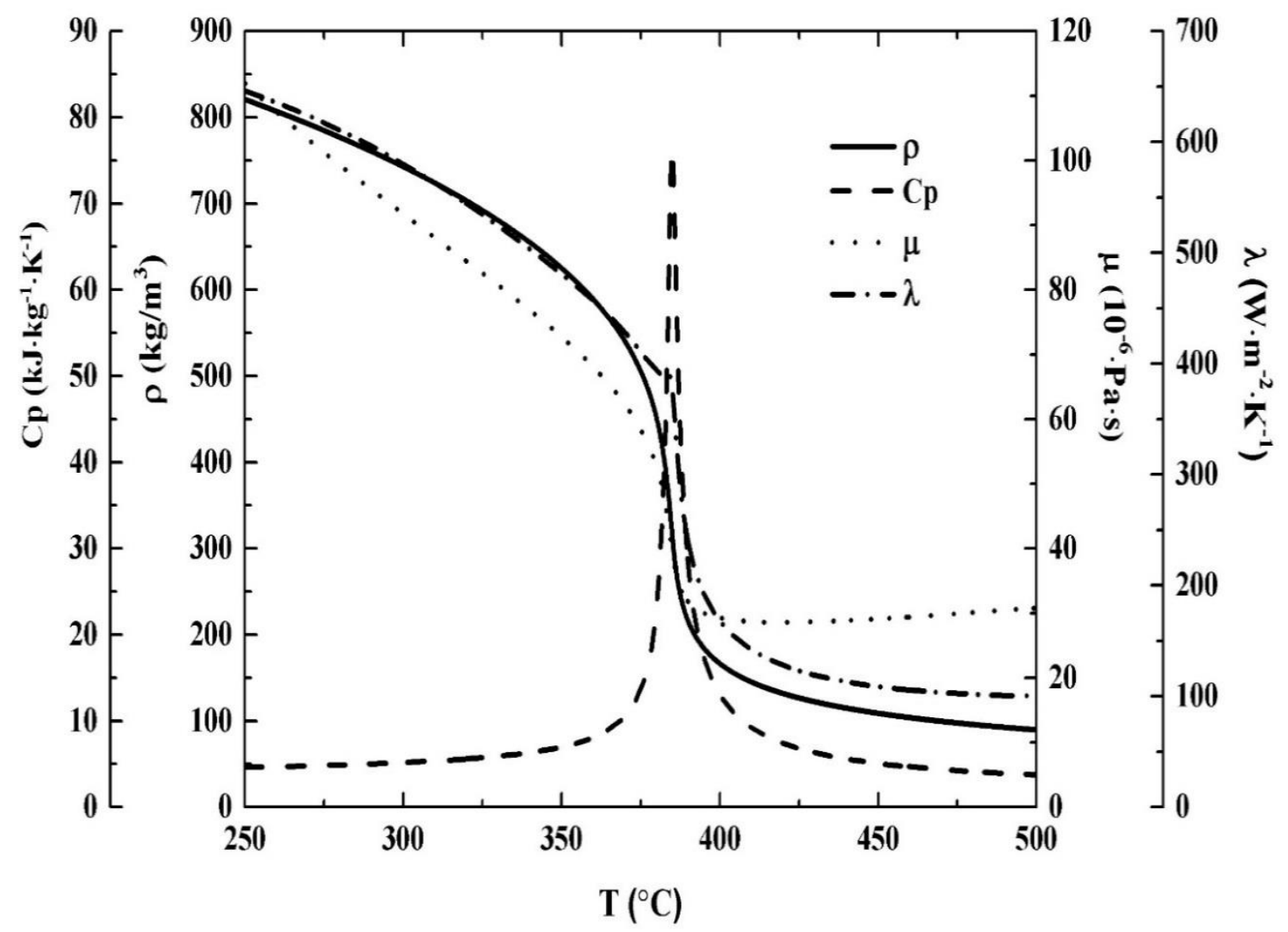

Figure 1.4: Thermo-physical property variations of water at a supercritical pressure of 25 MPa (Lemmon et al., 2013)

\subsection{Supercritical Flow Instability}

In spite of the benefits of SCWRs listed in section 1.2, sharp changes of water physical properties (mainly the large change of density) happen when the water temperature 
transitions through the pseudocritical point. This can trigger thermal hydraulic instabilities.

Flow instabilities in a nuclear reactor must be avoided, this is a mandatory safety requirement as the sustained oscillations in flow may lead to mechanical vibration of components and degrade system control, and may even result in mechanical damage of the whole nuclear reactor. With regards to the stable/unstable states of the flow, it is mainly distinguished by the fluid reaction after a disturbance in the initial state. If the disturbance has negligible influence on the initial state of the flow system and dies down gradually with time, then the flow is thought to be stable. Otherwise, the flow is unstable. Two main categories of flow instabilities are classified: static instabilities and dynamic instabilities (Boure et al., 1973). For the static instability (flow excursion or Ledinegg instability), the flow drifts away from its initial state in an excursive way, and finally stabilizes at a higher or lower position than the initial without returning to the initial state. Some researchers have shown that static instabilities can be explained by steady-state characteristics of the flow system, and that their onset can also be predicted by the steady-state pressure drop/flow rate analysis. Whereas, the dynamic instability (oscillatory or density-wave oscillation instability), is caused by the interaction and delayed feedback between the flow inertia and the fluid compressibility (Kakac, 2008). For an unstable flow with dynamic instabilities, the mass flow rate oscillates with growing amplitudes. To predict dynamic instability thresholds, it is not fully established that steady state solutions alone are sufficient to predict stabilities, so analyses of timedependent (transient) characteristics of the system are required. In the present study, 
oscillatory instabilities with mass flow rate oscillations are investigated. Both steady-state and transient analyses are performed to predict the instability boundaries.

\subsection{SCWR Modelling}

For oscillatory instabilities in SCWRs, three typical classifications were proposed by Zhao et al. (2005). The first case is a single channel or parallel-channel oscillations where only one channel or a small part of parallel channels in the fuel assemblies oscillate while the other channels stay steady. This kind of instability can be modeled by a single channel with constant pressure drop. The second case is named as out of phase or regionwide instability. During this case of oscillation, about half of the core oscillates with a $180^{\circ}$ shift to the other half (March-Leuba and Rey, 1993). A two-parallel-channel system with constant total mass flow rate can be used as the physical model for this kind of instability. The third case is called the core-wide in-phase instability, in which all channel flows oscillate in phase, leading to an oscillation throughout the core and the whole loop. This kind of oscillation can be modeled as circulation loop instability. Most investigations on supercritical flow instabilities are focused on the above three cases, and can be divided into three configurations: single channel, parallel-channel systems, and circulation loop. A review of the relevant experiments and numerical studies will be presented in the next chapter.

Numerical methods that have a good performance in modelling supercritical fluid flow instability experiments are used in the SCWRs design. These numerical methods mainly include direct numerical simulation (DNS), RANS models with commercial CFD codes, and one-dimensional codes. The use of CFD codes is becoming more common for the 
simulation of supercritical flows.

In this study, the second kind of instability with a two-parallel-channel system model is studied numerically with a CFD code. 


\section{CHAPTER 2}

\section{LITERATURE REVIEW}

In this chapter, studies on supercritical flow instabilities within three different physical models, as mentioned in section 1.5, are presented.

\subsection{Instability Studies of Single Channel}

Zuber (1966) was a pioneer in the theoretical research on flow instability of supercritical fluids. He developed a two-region model which divided the once-through straight pipe into the "liquid like region" and "gas like region". He studied three mechanisms that may give rise to thermo-hydraulic oscillations at near-critical and supercritical pressures, and pointed out the similarities between supercritical flow instabilities and two-phase flow instabilities. Furthermore, some improvements that could be made to eliminate the onset of flow oscillations were suggested. Following Zuber's (1966) two-region model, Zhao et al. (2005) proposed a three-region model for heated channels which included the socalled "light fluid region", "heavy and light fluid mixture region", and "heavy fluid region". Stability maps were constructed with the pseudo sub-cooling number and expansion number. Based on the stability maps, the effects of the inlet orifice, inlet flow, system pressure, and inlet temperature on the single channel instability were studied. New non-dimensional parameters, namely pseudo-phase-change number and pseudo-subcooling number, were proposed by Ortega Gómez et al. (2008) to generate the stability map of a uniformly heated channel with supercritical water. Both linear and non-linear analyses were performed by utilizing these new defined parameters. Results showed that no Ledinegg or pressure drop instabilities occurred with the test cases. Ambrosini et al. 
(2008) also derived non-dimensional parameters for supercritical fluids in heated channels. Unlike Zhao et al. (2005) and Ortega Gómez et al. (2008), the new dimensionless parameters, trans-pseudo-critical number and sub-pseudo-critical number, adopted the pseudo-critical point as the only reference state which was later proved to be a success by Ambrosini $(2009,2011)$ because these new non-dimensional parameters can not only be applied to supercritical water stability analyses but also other supercritical fluids such as supercritical $\mathrm{CO}_{2}, \mathrm{R} 23$ and Ammonia. With these new dimensionless parameters, an analogy of instability analyses between water flowing in boiling channels and supercritical heated channels in a simplified model was made using the RELAP5/MOD3.3 code (Ambrosini 2007). Results concluded that the Density Wave Oscillations (DWOs) and Ledinegg instability may occur under both conditions.

Besides the analytical and numerical methods mentioned above, computational fluid dynamics (CFD) has been used as a powerful tool in the supercritical flow instability analyses. Sharabi et al. (2008) performed an instability study using FLUENT of supercritical water inside a single heated channel. Results revealed that the standard $k-\varepsilon$ model with wall functions could capture the onset of unstable behaviour. In 2009, a further instability study with a 3-D model of rod bundle geometry was carried out with the FLUENT code by Sharabi et al. (2009). Flow characteristics inside 3-D sub-channels were found to be similar to that in circular tubes. A series of investigations was conducted by Ampomah-Amoako et al. (2013) with the STAR-CCM+ CFD code, the 1D RELAP5/MOD3.3 code, and an in-house linear code, covering from the simple circular pipe models to more realistic 3-D rod bundle sub-channels. The qualitative and quantitative agreements of different codes in predicting the flow characteristics as well as 
thresholds of instabilities in single heated channel gave more confidence in using the CFD code for future stability analyses. And the agreement of 3-D CFD code with 1-D code predictions indicated that the single channel instability phenomena were mainly characterized by 1-D behavior. Both static and oscillatory instabilities in a single heated channel with supercritical water flowing upward were numerically studied by Ebrahimnia et al. (2016) with the ANSYS CFX code. They tested two turbulence models (standard $k$ $\varepsilon$ model and SST model) to predict the onset of static and oscillatory instabilities. Results indicated that instability thresholds approximated by these two turbulence models agreed well. Hence, the $k$ - $\varepsilon$ model was recommended for stability prediction based on its lower computational cost. CFD results were also compared with a 1-D non-linear code predictions. Results showed that the discrepancy between two codes predictions was small. In addition, negligible effects of turbulent Prandtl number $\left(\operatorname{Pr}_{t}\right)$ variation on instability thresholds were observed.

\subsection{Instability Studies of Parallel Channels}

Compared with the large amount of previous work on two-phase flow instability investigations within parallel channels, the literature on supercritical flow instability in parallel channels is still limited.

Chatoorgoon (2008) did an early flow instability study of two horizontal parallel channels with supercritical water. Non-dimensional parameters defining instability boundaries were analytically derived with a point heat source model, and were numerically verified with the 1-D SPORTS code. The importance of an accurate state equation for predicting supercritical flow instabilities in parallel channels was pointed out. Hou (2011) used 
linear and non-linear methods to investigate the stability performance of parallel channels of a newly designed mixed-spectrum SCWR (SCWR-M). Results showed that the fast zone of SCWR-M design had a large stability margin. In addition, stability of parallel channels was mostly determined with the hottest channel and the existence of a transitional stability region was identified. Following the same methods, Liu (2014) further tested the heat exchanging effects on flow instability in parallel channels of the mixed-spectrum SCWR (SCWR-M). Results showed that decreasing the wall thermal conductivity could stabilize the system and the system was not very sensitive to the distributions of axial power.

Xiong et al. (2012) reported results of an experimental study of flow instability in two vertical parallel channels with supercritical water. A method of defining the onset of flow instability in parallel channels with supercritical water was proposed. A total of nine points of oscillatory instability thresholds were obtained at different flow conditions, and results were normalized into non-dimensional form using Ambrosini's dimensionless parameters (Ambrosini et al. 2008). The effects of system pressure and inlet temperature on instability were studied. Over the range of conditions tested, it was found that increasing the pressure and decreasing the inlet temperature would stabilize the flow. These experiments were subsequently simulated by a 1-D nonlinear in-house code (Xiong et al., 2013) and 3-D CFX code (Xi et al., 2014). Comparisons between numerical and experimental results proved the capability of 1-D and 3-D codes to predict the onset of oscillatory instability in two parallel channels. Nevertheless, because the CFX code results were reported to agree better with Xiong's experimental data (Xiong et al., 2012) than the 1-D code results, $\mathrm{Xi}$ et al. (2014) stated that the CFX code yielded better 
predictions of the onset of flow instability than the 1-D code. In Xiong's 1-D numerical simulation work (Xiong et al., 2013), they tried three different geometrical models and finally suggested a simplified model that was identical with the model recommended in the experimental paper by Xiong et al. (2012). In their 3-D numerical simulation, Xi et al. (2014) thought it was difficult to confirm the best numerical model. Based on CFD engineers' experience, they adopted a higher order of the difference scheme and a shorter time step to obtain more accurate results. Besides, considering that the SST turbulence model was more suitable for supercritical heat transfer simulation and the standard $k-\varepsilon$ turbulence model could save computing time, the $k-\varepsilon$ model was used for their supercritical flow instability simulations.

Following this line of research, another similar experiment of supercritical water flowing upward in vertical parallel channels was carried out by Xi et al. (2014). Their experimental loop was the same as Xiong's (Xiong et al., 2012), but a larger wall thickness in the heated sections of the channels was used. In addition, Xi et al. (2014) divided each heated channels into two sections to separately control the heating power. In this way, the influence of axial power shape on the flow instability could be studied. Their experimental results indicated that the system would be more stable with a uniform axial power shape and that no out of phase flow instability was found in the experimental cases with axially increased power shape.

Dutta et al. (2015) modified a 1-D nonlinear thermal-hydraulic code (THRUST) to make it available for stability analyses of parallel channels in CANDU SCWR. Both in-phase and out-of-phase Density Wave Oscillations were studied and the results showed that the CANDU SCWR had a larger stable zone for the in-phase mode than the out-of-phase 
mode, and that for both instability modes, increasing the asymmetric level of power input would make the CANDU SCWR more unstable. A recent experimental investigation on supercritical flow instability of two vertical parallel channels with supercritical water was performed by Zhang et al. (2016). Two types of flow oscillations, namely type I (in-phase) and type II (out-of-phase), were identified during the experiment. Type I instability had long period and occurred at lower heating power when the channel exit temperature approached the pseudo-critical temperature. Type II instability had a much smaller period and occurred at relatively higher heating power with a much larger enthalpy at the exit.

\subsection{Instability Studies of Circulation Loop}

Besides the supercritical flow instability studies of single and parallel heated channels, a considerable amount of effort has been spent on the flow instability study of circulation systems with supercritical fluids, and most of these studies are conducted in the natural circulation loop.

Chatoorgoon (2001) analytically studied the flow instability of a simple rectangular open loop with supercritical water. Instability boundary was postulated to be at the peak point of the flow-power curve. Non-dimensional parameters were derived based on an idealized point heat source model, and stability map was also constructed. Using the nonlinear SPORTS code, Chatoorgoon et al. (2005a, 2005b) further numerically studied the flow stability of natural circulation loops with different fluids $\left(\mathrm{H}_{2} \mathrm{O}, \mathrm{CO}_{2}\right.$, and $\left.\mathrm{H}_{2}\right) . \mathrm{A} 95 \%$ agreement between numerical results and analytical predictions was obtained. Considering the similar flow characteristics between $\mathrm{H}_{2} \mathrm{O}$ and $\mathrm{CO}_{2}$, it was suggested to use supercritical $\mathrm{CO}_{2}$ as the working fluid for experiments as it is simpler and safer than 
supercritical water. In 2004, Lomperski et al. (2004) reported an early experimental study of supercritical $\mathrm{CO}_{2}$ in a natural circulation loop but no flow instability was found during tests. Jain et al. (2006) performed a linear stability analysis for a natural circulation loop with supercritical $\mathrm{CO}_{2}$. Results revealed that the stability threshold of natural circulation loops was a complex function of fluid properties and loop geometries, and was not strictly confined to the near-peak region of the steady state flow-power curve. A nonlinear FIASCO code was developed by Jain et al. (2008) to study flow instability of a natural circulation loop with supercritical $\mathrm{CO}_{2}$. With grid refinement and a smaller time step of $0.02 \mathrm{~s}$, the instability boundary was always found to be on the positive slope of the flow-power curve. Sharma (2010) linearly analyzed the stability of a natural circulation loop with supercritical water. The effects of the loop diameter, loop height, local loss coefficient, system pressure and the heater inlet temperature were investigated. It was found that increasing the loop diameter and the loop height would make the system more unstable whereas increasing cold loss coefficient and the system pressure would stabilize the system. Beyond a specified value of heater inlet temperature, no instability was found.

T'Joen and Rohde (2012) experimentally studied the instability of a natural circulation loop using supercritical Freon R23 as the working fluid. Coupled thermo-hydraulic neutronic instability was found with artificial neutronic feedback. Pure thermo-hydraulic flow instability was not identified. Chen (2013) experimentally investigated the flow behaviours of trans-critical and supercritical $\mathrm{CO}_{2}$ within a natural circulation closed loop. No supercritical flow instability was observed. Flow instability was only found at the sub-critical region of the test cases. Flow instability experiments of a natural circulation loop with both supercritical $\mathrm{CO}_{2}$ and $\mathrm{H}_{2} \mathrm{O}$ were carried out by Sharma $(2013,2014)$. For 
all the experimental work, either with $\mathrm{CO}_{2}$ or $\mathrm{H}_{2} \mathrm{O}$, flow instability occurred only in a very narrow range when the loop was operated near the pseudo-critical temperature.

Debrah et al. (2013) analytically extended the non-dimensional parameters used for heated channels (Ambrosini et al. 2008) to a simplified supercritical natural circulation loop. The involvement of heat structures in modeling was found to be capable of stabilizing the natural circulation loops. Archana (2015) conducted simulations of a supercritical $\mathrm{CO}_{2}$ natural circulation loop with both in-house developed 1-D and 2-D axisymmetric CFD codes. Comparisons of the obtained results indicated that the 2-D axisymmetric code had better accuracy over the 1-D code. Tilak (2015) numerically studied the dynamic response of a supercritical natural circulation system to various abrupt power surges such as step, ramp, exponential and sinusoidal excitations. Results revealed that a step rise in power input mainly destabilized the system.

\subsection{Summary of Literature Review}

From the literature review, it is noticed that investigations of supercritical flow instability mainly focused on analytical and numerical analyses, especially with 1-D linear and nonlinear codes. Related 3-D numerical simulations with CFD codes and reliable experimental data for validation are scarce. So far, only three experiments were carried out to study flow instability of supercritical water in two heated parallel channels: Xiong et al. (2012), Xi et al. (2014) and Zhang et al. (2016). 3-D CFD models have the potential to offer more precise and detailed information than 1-D codes in numerical study of supercritical flow instability within parallel channels but more work is needed in that area.

Thus far only Sharabi et al. (2008, 2009), Ampomah-Amoako et al. (2013), Xi et al. 
(2014), and Ebrahimnia et al. (2016) have analyzed the instability of supercritical flow using a CFD code. In Xi's CFD numerical simulation work (Xi et al., 2014), a rather coarse mesh (300,000 nodes for a whole parallel channel system with heating length $3 \mathrm{~m}$ and channel inner diameter $6 \mathrm{~mm}$ ) as well as a large time step of $0.1 \mathrm{~s}$ was used. Additional 3-D CFD code investigations will help to assess the Xi et al. (2014) results and to continue the assessment of CFD code prediction capabilities for supercritical flow stability.

\subsection{Objectives of Present Work}

The objectives of this study are as follows:

1. To develop, using ANSYS CFX, a 3-D CFD model of the experiment of Xiong et al. (2012) on upward flow in two heated parallel channels with supercritical water.

2. To compare the flow instability thresholds predicted by the present CFX code with the experimental data of Xiong et al. (2012).

3. To compare the flow instability thresholds predicted by the present CFX code with previous numerical results (both 1-D and 3-D) performed by other investigators for the same experiment.

4. To analyze the discrepancies between the experiment and different numerical simulations with 1-D and 3-D codes. 
5. To perform sensitivity tests on the instability threshold changes to the variations in the outlet plenum volume, the turbulent Prandtl number, the turbulence inlet conditions, the outlet $\mathrm{K}$ factor, the maximum iterations per time step and the transient scheme.

6. To assess the overall performance of the 3-D CFD code on stability analyses for this application. 


\section{CHAPTER 3}

\section{PROBLEM DESCRIPTION}

To validate the CFD simulation results, related experimental data are required. Considering the out of phase oscillatory instability in a two-parallel-channel model is investigated in this study, the experiment conducted by Xiong et al. (2012) on supercritical flow instability in two heated parallel channels with supercritical water flowing upward was selected to validate the numerical simulation results in this study. In addition, the flow conditions of this experiment are similar to the real operating conditions in SCWRs. The experimental loop as well as the flow conditions of Xiong's experiment (Xiong et al., 2012) is described in this chapter.

\subsection{Xiong's Experimental Loop (Xiong et al., 2012)}

To enrich the validation experiment for supercritical flow instability investigation, a forced supercritical water loop was constructed at the Nuclear Power Institute of China (NPIC). A schematic diagram of this experimental loop is shown in Figure 3.1. With a plunger pump, the water from the tank is driven first to be filtered. To avoid fluctuations of mass flow rate, an accumulator is placed at the exit of the plunger pump. For the convenience of controlling mass flow into the test section, a bypass was designed. Before flowing into the heating test section, water is pre-heated such that the inlet temperature of test section can be controlled to expected values. In the test section, water is heated to be supercritical. The working fluid leaving the test section mixes with that from the bypass in a mixing plenum. The mixed fluid flows through the heat exchanger to be cooled down, 
and then the cooled water feeds back to the water tank. Additional details can be found in the publication by Xiong et al. (2012).

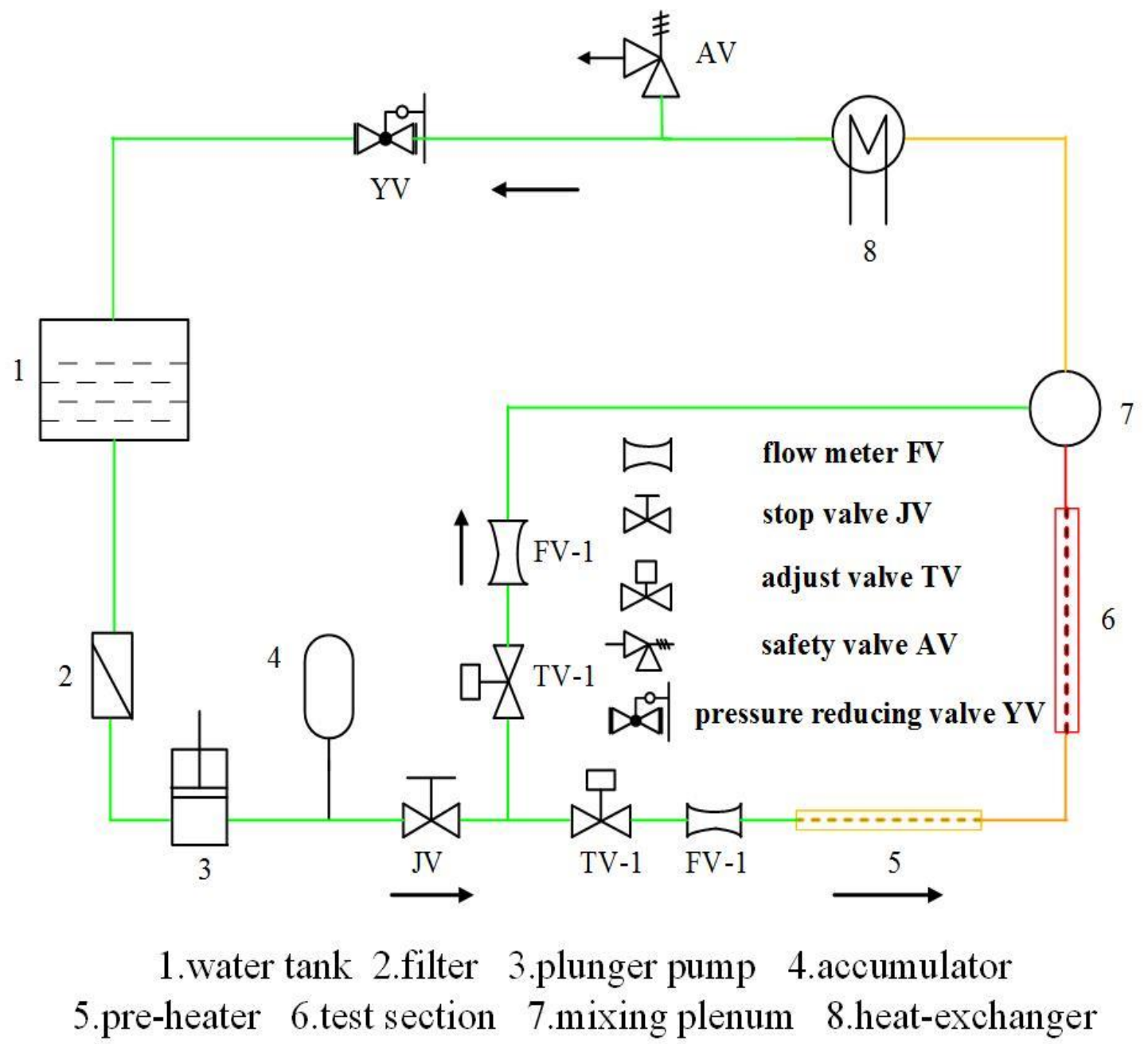

Figure 3.1: Schematic diagram of the Xiong et al. (2012) experimental loop

The test section of the Xiong et al. (2012) experimental loop is a two-parallel-channel system consisting of a lower plenum, entrance sections, heated sections, riser sections and an upper plenum, as shown in Figure 3.2. In the experiment, INCONEL Alloy pipes, with inner diameter $6 \mathrm{~mm}$ and heated length $3000 \mathrm{~mm}$, were used for the two heated 
sections. The applied heat flux was almost axisymmetric. Orifices were installed at the outlet of the heated sections. Venturi flow meters were used to measure the flow rate.

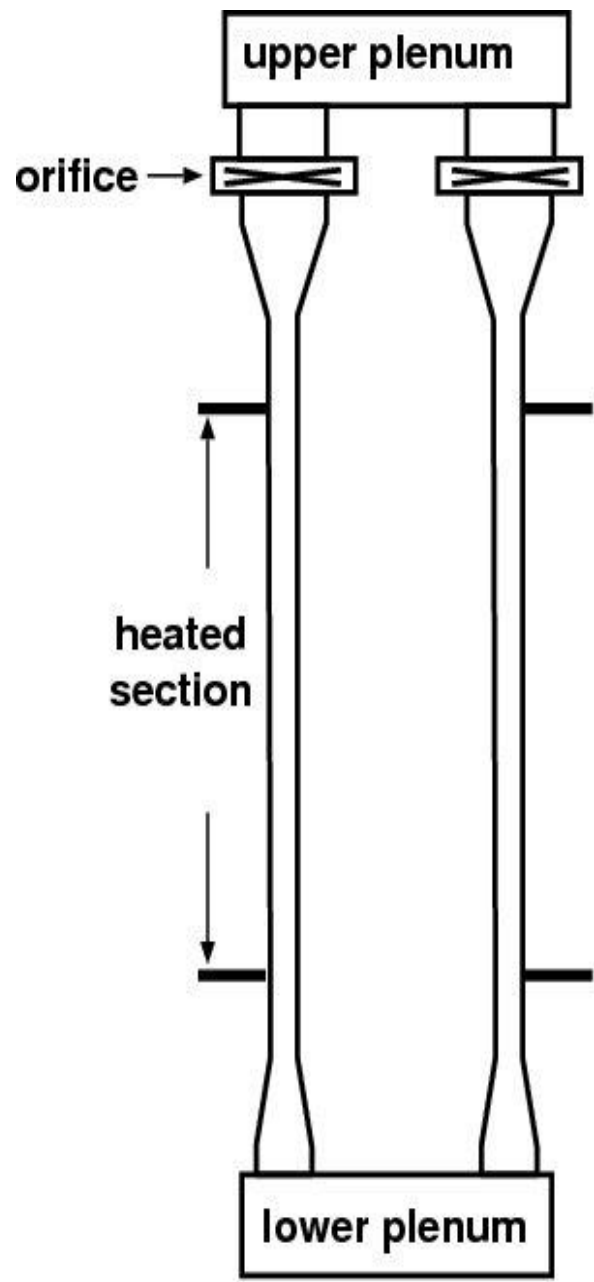

(a) Front View

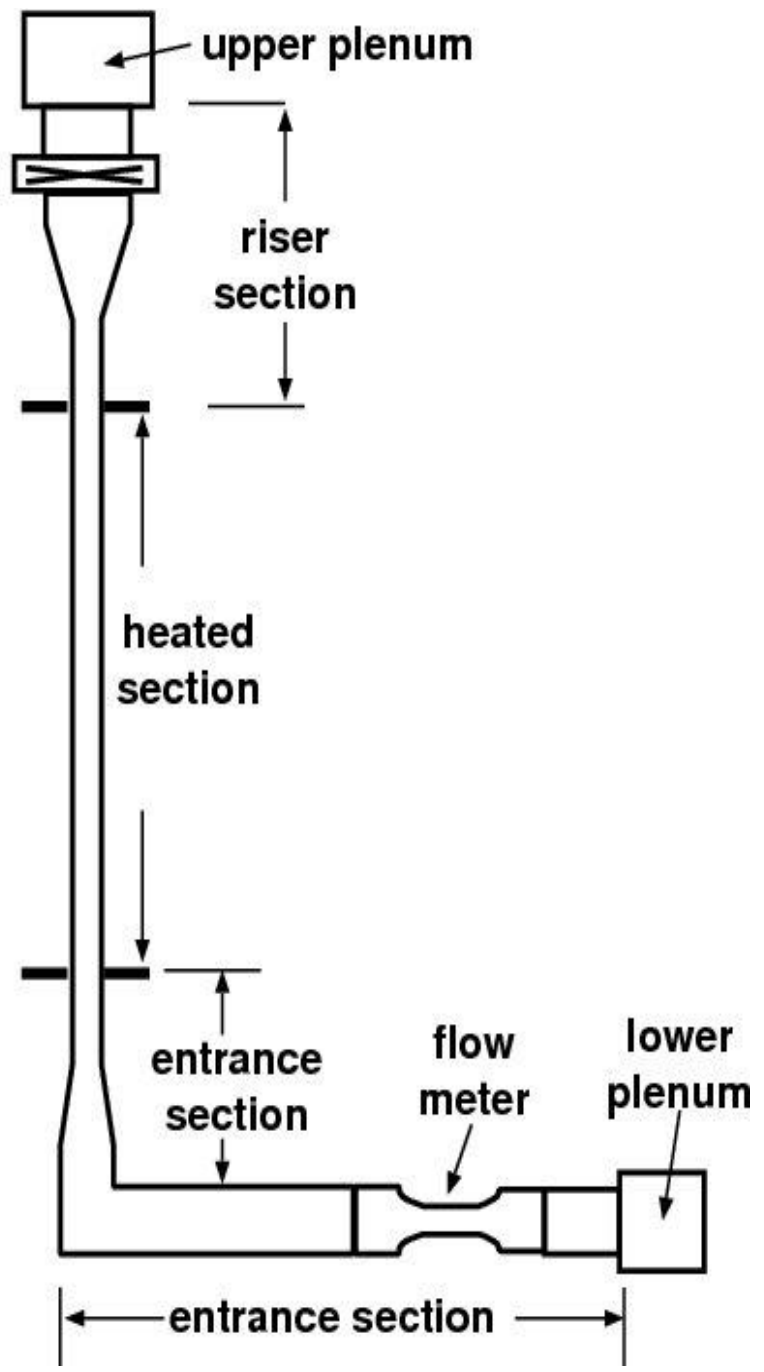

(b) Side View

Figure 3.2: Schematic diagram of the test section in Xiong's experiment (Xiong et al., 2012) 


\subsection{Flow Conditions for the Xiong's Experiment (Xiong et al., 2012)}

Flow instability experiments with supercritical water flowing upward in two heated parallel channels were carried out by Xiong et al. (2012) at different flow conditions. Nine typical parallel-channel-instability cases were performed at pressures from 23 to 25 $\mathrm{MPa}$ and inlet temperatures from 180 to $240{ }^{\circ} \mathrm{C}$, and are summarized in Table 3.1.

Table 3.1: Different flow conditions run using the Xiong et al. (2012) experimental loop, as obtained from Xi et al. (2014)

\begin{tabular}{|c|c|c|c|c|}
\hline Case & $\begin{array}{c}\text { System Pressure } \\
(\mathrm{MPa})\end{array}$ & $\begin{array}{c}\text { Inlet Temperature } \\
(\mathrm{K})\end{array}$ & $\begin{array}{c}\text { Inlet Mass Flow Rate } \\
(\mathrm{kg} / \mathrm{s})\end{array}$ & $\begin{array}{c}\text { Threshold Power } \\
(\mathrm{KW})\end{array}$ \\
\hline 1 & 23 & 453 & 0.0342 & 67.9 \\
\hline 2 & 23 & 473 & 0.0333 & 66.0 \\
\hline 3 & 23 & 493 & 0.0333 & 65.6 \\
\hline 4 & 24 & 473 & 0.0333 & 67.0 \\
\hline 5 & 24 & 493 & 0.0333 & 66.0 \\
\hline 6 & 24 & 513 & 0.0331 & 64.6 \\
\hline 7 & 25 & 473 & 0.0328 & 69.3 \\
\hline 8 & 25 & 493 & 0.0333 & 68.9 \\
\hline 9 & 25 & 513 & 0.0339 & 67.9 \\
\hline
\end{tabular}

The above experiments were run by fixing the inlet mass flow rate and changing the heating power until the instability was observed. Therefore, the inlet mass flow rates in Table 3.1 are the instability threshold mass flow rates for the power indicated for each case. 


\section{CHAPTER 4}

\section{NUMERICAL MODELING}

\subsection{Geometrical Model}

In the experimental test section of Xiong et al. (2012), there are several throttles, bend tubes and diameter-varied pipes from the lower plenum to the entrance of heated section (called the entrance section) and from the exit of heated section to the upper plenum (called the riser section). As a result, this geometrical configuration of the Xiong et al. (2012) experimental test section is complicated for numerical simulations. A simplified version of the Xiong et al. (2012) experimental test section was proposed by Xiong et al. (2012). This simplified model modifies the entrance and riser sections by making the pipes with different inner diameters in these sections have uniform inner diameter, which is equal to the inner diameter of the pipe in the heated section. Local pressure drops are assumed to be concentrated on special orifices. The feasibility of this simplified model to simulate the Xiong et al. (2012) experiment was also verified with a 1-D in-house code by Xiong et al. (2013). Therefore, this simplified equivalent geometry was also modeled in this study. Considering that the whole physical geometry is symmetrical, to save computational time only one half of the simplified geometry is simulated in this study by applying a symmetry boundary condition.

Figure 4.1 illustrates the simplified numerical model of the Xiong et al. (2012) experimental test section used in this study with specific dimensions. To match the Xiong et al. (2012) experiment, the inner diameter and heating length of each heated channel are $6 \mathrm{~mm}$ and $3000 \mathrm{~mm}$, respectively. Plena sizes at the inlet and outlet are: $430 \mathrm{~mm}$ in 
length, $23 \mathrm{~mm}$ in height and $10 \mathrm{~mm}$ in width. The inlet and outlet flow areas are a portion of the bottom surface of the lower plenum and the top surface of the upper plenum, respectively. In addition, both the inlet and outlet areas are square with $10 \mathrm{~mm}$ length on each side. All of these mentioned dimensions are for half of the simplified model proposed by Xiong et al. (2012).

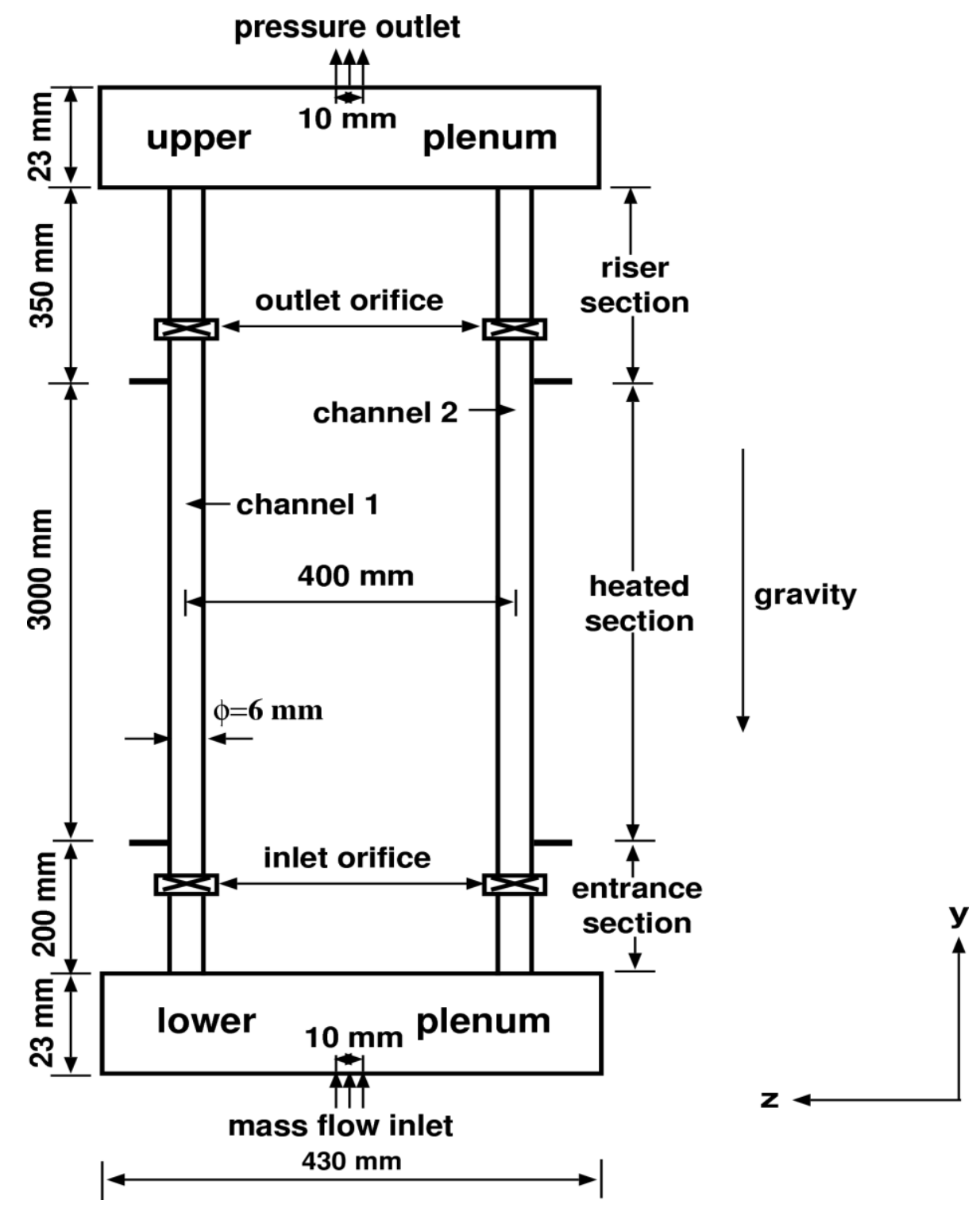

Figure 4.1: Schematic diagram of the numerical model used in simulation 
A portion of the geometry used in the CFX model is shown in Figure 4.2 to illustrate the actual scale of the channels and the lower plenum.

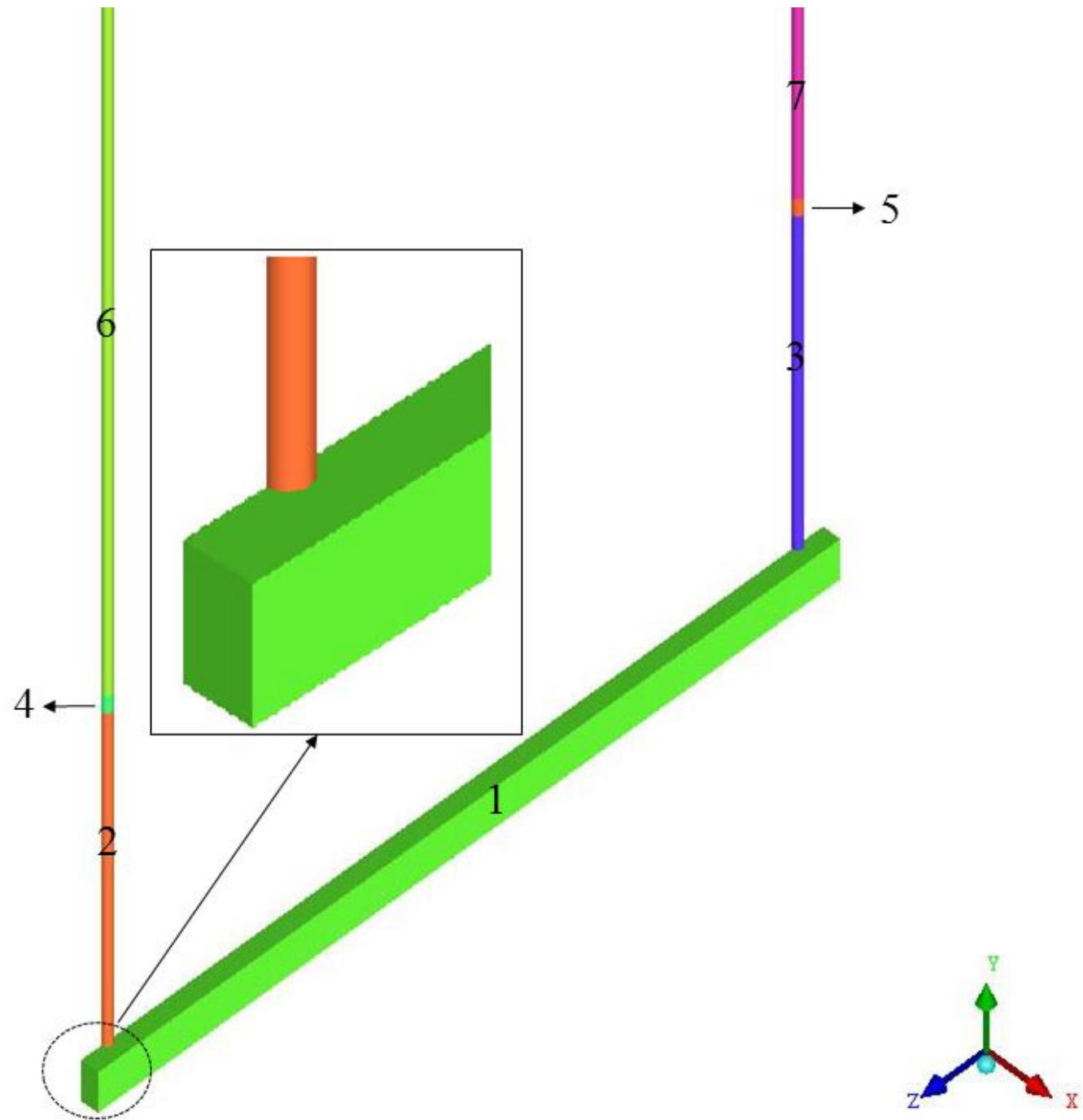

Figure 4.2: Part view of the numerical model used in simulation from CFX with partial enlargement

In Figure 4.2, 1 is the lower plenum, 2 and 3 are the entrance sections of the channels, 4 and 5 are the sections where the local pressure drops at inlet orifices are modeled, and 6 and 7 are the heated sections of the channels. These two parallel channels extend upward 
until they meet at the upper plenum. The enlarged image inset in Figure 4.2 shows how only one half of the simplified model is simulated.

There are both inlet and outlet orifices for two parallel channels where local pressure drops are thought be concentrated on. However, due to manufacturing and installation differences of the channels, these two channels have different local pressure drops at the inlet and outlet orifices, respectively. That is, the two parallel channels have asymmetric inlet and outlet pressure drop coefficients (K factors), which were previously reported by Xiong et al. (2012):

$\mathrm{K}_{\mathrm{in}, 1}=5.40 \quad \mathrm{~K}_{\mathrm{in}, 2}=5.50 \quad \mathrm{~K}_{\text {out }, 1}=4.93 \quad \mathrm{~K}_{\text {out }, 2}=6.46$

To calculate these $\mathrm{K}$ factors, the total pressure drops of the entrance section (from the lower plenum to the entrance of heated section) and the riser section (from the exit of heated section to the upper plenum) were measured for each channel. The measured total pressure drop, $\Delta \mathrm{P}$, consisted of friction pressure drop, $\Delta P_{f}$, local pressure drop, $\Delta P_{l}$, and gravitational pressure drop, $\Delta P_{g}$ :

$\Delta \mathrm{P}=\Delta P_{f}+\Delta P_{l}+\Delta P_{g}$

For friction pressure drop, it is calculated by:

$\Delta P_{f}=\sum f_{r} \frac{l}{D} \frac{G^{2}}{2 \rho}$

where $l$ is the length of the section under consideration, $D$ is the hydraulic diameter of the cross section and $G$ is the mass flux. $f_{r}$ is the friction factor that is calculated using Haaland's (1983) formula: 
$f_{r}=\left[-1.8 \log \left(\left(\frac{\delta}{3.7 D}\right)^{1.11}+\frac{6.9}{R e}\right)\right]^{-2}$

where $\delta$ is the surface roughness. $R e$ is the Reynolds number.

The local pressure drop is related to the $\mathrm{K}$ factor as follows:

$\Delta P_{l}=\sum K \frac{G^{2}}{2 \rho}$

where $K$ is the local pressure drop coefficient.

For the gravitational pressure drop, it is determined by the height of the entrance or riser section under consideration, and is not influenced by bend tubes or throttles:

$\Delta P_{g}=\rho g \mathrm{H}$

where $\mathrm{H}$ is the height of the section under consideration.

Finally, K factor can be determined by:

$K=\frac{\Delta P-\Delta P_{f}-\Delta P_{g}}{\frac{G^{2}}{2 \rho}}$

These same K factors were used in this study.

\subsection{Assumptions}

The following assumptions are made with regards to the governing equations of mass, momentum, and energy conservations.

- The flow is symmetric with respect to a $y-z$ plane through the center of the two channels. 
- The flow is turbulent based on the calculated Reynolds number that will be presented later.

- The water is Newtonian.

- All wall boundary conditions are no-slip and smooth.

- A uniform wall heat flux is applied in the heated section of the channels.

- Radiation heat transfer is negligible because of the relatively low temperature difference expected between the channel and plenum walls.

- Heat transfer loss to the surroundings is negligible as the wall is thought to be well insulated.

- Reynolds stresses can be approximated by the eddy-viscosity assumption.

\subsection{Governing Equations}

The governing equations consist of transport equations for conservation of mass, momentum, energy and turbulence quantities.

The governing equations in Cartesian coordinates are:

- Continuity Equation:

$\frac{\partial(\rho)}{\partial t}+\frac{\partial\left(\rho U_{j}\right)}{\partial x_{j}}=0$

- Momentum Conservation Equation: 


$$
\begin{aligned}
\left(\frac{\partial\left(\rho U_{i}\right)}{\partial t}\right)+( & \left.\frac{\partial\left(\rho U_{j} U_{i}\right)}{\partial x_{j}}\right) \\
& =-\frac{\partial P^{\prime}}{\partial x_{i}}+\frac{\partial}{\partial x_{j}}\left(\left(\mu+\mu_{t}\right)\left[\frac{\partial U_{i}}{\partial x_{j}}+\frac{\partial U_{j}}{\partial x_{i}}\right]\right)+S_{M, b u o y}+S_{M, \text { frict }}
\end{aligned}
$$

where $P^{\prime}$ is the modified pressure and $\mu_{t}$ is the eddy viscosity.

$S_{M, b u o y}$ is a source term added to the momentum equations as follows for buoyancy calculation:

$S_{M, \text { buoy }}=\left(\rho-\rho_{\text {ref }}\right) g_{i}$

where reference density, $\rho_{r e f}$, is defined as the average density over the entire fluid domain. In this study, a value of $500 \mathrm{~kg} / \mathrm{m}^{3}$ for $\rho_{\text {ref }}$ was used. For the y axis, aligned with the upward flow direction, the acceleration due to gravity, $g_{y}$, is $-9.81 \mathrm{~m} / \mathrm{s}^{2}$. In the other two directions, both $g_{x}$ and $g_{z}$ are $0 \mathrm{~m} / \mathrm{s}^{2}$.

The Full Buoyancy model implemented in CFX was used in this study because of the spatial variation of the water density due to pressure and temperature change. When buoyancy is enabled in CFX, the pressure in the momentum equation excludes the hydrostatic gradient due to $\rho_{\text {ref }}$. Then, the pressure term appears in the momentum equation becomes the modified pressure, $P^{\prime}$, which is defined by using the static pressure $P$ and turbulence kinetic energy $k$ :

$P^{\prime}=P+\frac{2}{3} \rho k$

This modified pressure is also related to the absolute pressure as follows:

$$
P_{a b s}=P^{\prime}+P_{r e f}+\rho_{r e f} g\left(\vec{r}-\vec{r}_{r e f}\right)
$$


where $P_{r e f}$ is the reference pressure over the entire fluid domain. All relative pressures in CFX are relative to this pressure. $\overrightarrow{r_{r e f}}$ is the buoyancy reference location, specified at the centroid of one of the pressure-specified boundaries.

In Equation (4.11), the last term of right hand side is hydrostatic pressure, that is:

$P_{\text {hyd }}=\rho_{\text {ref }} g\left(\vec{r}-\overrightarrow{r_{r e f}}\right)$

The sum of the modified pressure and the hydrostatic pressure is the static pressure:

$P=P^{\prime}+P_{h y d}$

Substituting Equations (4.12) and (4.13) into (4.11) leads to:

$P_{a b s}=P+P_{r e f}$

$S_{M, f r i c t}$ is a general momentum source used to model the local friction pressure drop caused by a $\mathrm{K}$ factor. There are two options to apply momentum sources in CFX: Loss model and General Momentum Source. The differences between these two models were discussed by Ebrahimnia (2014). Based on those results, the general momentum source is preferred and enabled in this study to agree with the $\mathrm{K}$ factor modeling used in 1-D codes.

The general momentum source is able to specify the momentum sources in a specified direction, directly in terms of a momentum value per unit volume. To apply the general momentum source, fluid subdomains with a short length of $10 \mathrm{~mm}$ and adiabatic walls were inserted into the main fluid domains in this study. By neglecting the effect of velocity variation, shear stress and gravity in the subdomain, the momentum equation for steady-state condition becomes: 
$-\frac{\partial P}{\partial x_{i}}+S_{M, f r i c t, i}=0$

Therefore, desired pressure gradient can be obtained by specifying the general momentum source in a specific direction. In the flow direction (y direction), the general momentum source is specified by:

$S_{M, \text { frict }, y}=-\frac{K}{\Delta y} \times \frac{G}{2} \times V$

where $K$ is the local pressure drop coefficient, $\Delta y$ is the length of the subdomain, and $G$ is the mass flux which is equal to:

$G=\frac{\dot{m}}{A}$

where $\dot{m}$ is the mass flow rate and $\mathrm{A}$ is the cross section area. In Equation (4.16), $V$ is the area-averaged value of the $y$-direction velocity.

When the source term is a function of velocity, to obtain good convergence the Momentum Source Coefficient (k) is specified in CFX for linearizing the source term with the following relation:

$-\frac{\partial P}{\partial x_{i}}=\mathrm{k} U_{i}$

Combing Equation (4.18) with Equations (4.15) and (4.16), k can be calculated with the following equation:

$\mathrm{k}=\frac{K}{\Delta y} \times \frac{G}{2}$ 
Since for this study, the general momentum source is meant to bring in pressure drop, the "Redistribute in Rhie Chow" and "Include Coefficient in Rhie Chow" options in CFX should be enabled to avoid possible pressure oscillations near the subdomain boundary.

- Energy Conservation Equation:

Compared to the thermal energy equation, the total energy equation is preferred in this study. For a compressible flow, the total energy equation can achieve a more accurate solution by including the mechanical energy.

The total energy conservation equation is as follows:

$$
\begin{aligned}
\left(\frac{\partial\left(\rho h_{t o t}\right)}{\partial t}\right)+ & \left(\frac{\partial\left(\rho U_{j} h_{t o t}\right)}{\partial x_{j}}\right) \\
& =\frac{\partial}{\partial x_{j}}\left(\left(\lambda+\frac{\mu_{t}}{P r_{t}}\right) \frac{\partial h}{\partial x_{j}}+\frac{\partial}{\partial x_{j}}\left(U_{j}\left[\tau_{i j}-\rho \overline{u_{\imath} u_{j}}\right]\right)+U_{j} \cdot S_{M}\right.
\end{aligned}
$$

where $h_{\text {tot }}$ is the total enthalpy and is related to the static enthalpy, mechanical energy, and turbulence kinetic energy as follows:

$h_{\text {tot }}=h+\frac{1}{2} U_{i} U_{i}+k$

where $h$ is the static enthalpy. The turbulence kinetic energy, $k$, is modeled by:

$k=\frac{1}{2} \overline{u_{\imath} u_{\imath}}$

where $u_{i}$ is the velocity fluctuation.

In Equation (4.20), $\frac{\partial}{\partial x_{j}}\left(U_{j}\left[\tau_{i j}-\rho \overline{u_{\imath} u_{j}}\right]\right)$ represents the work due to viscous stresses and is named as the viscous work term. It models the internal heating by viscosity in the fluid, and is negligible in most flows. However, because of compressibility of this flow, it is 
included in the total energy equation in this study. The term $U_{j} \cdot S_{M}$ represents the work due to external momentum sources and is currently neglected.

In the present study, both steady-state and transient analyses of the governing equations were performed.

\subsection{Turbulence Closure}

In general, turbulent flow could be said to exhibit average characteristics, with an additional time-varying, fluctuating component. Therefore, the original unsteady NavierStokes equations can be modified by the application of averaged and fluctuating quantities to produce the Reynolds Averaged Navier-Stokes (RANS) equations. Because Large Eddy Simulation (LES) and Direct Numerical Simulation (DNS) are too computationally expensive to model this problem, a RANS-based model is selected in this work.

However, the Reynolds averaging for RANS model introduces additional unknown terms including products of the fluctuating quantities, which are known as 'turbulent' or 'Reynolds' stresses. On one hand, Reynolds stresses are difficult to determine directly and need to be modeled by additional equations with known quantities. On the other hand, there are only four equations (the momentum equations in three directions and the continuity equation) to solve ten unknown quantities (the velocity variations in $\mathrm{x}, \mathrm{y}$ and $\mathrm{z}$ three directions, the pressure variation, and the six Reynolds stresses) in isothermal turbulent flow problems. Hence, turbulence modeling for six unknown Reynolds stresses is required to close the equation system. 


\subsubsection{Standard k- $\varepsilon$ Turbulence Model}

The standard $k-\varepsilon$ turbulence model by Launder and Sharma (1974) is one of the most commonly used turbulence models, and it includes two extra transport equations to represent the turbulence quantities of the flow. These two additional equations are the turbulence kinetic energy, $k$, and the turbulent dissipation rate, $\varepsilon$.

The standard $k-\varepsilon$ model with a scalable wall-function was used to calculate $\mu_{t}$ with the following relation:

$\mu_{t}=C_{\mu} \rho \frac{k^{2}}{\varepsilon}$

where $C_{\mu}$ is a closure constant and equal to 0.09 . The turbulence kinetic energy, $k$, and the turbulence dissipation rate, $\varepsilon$, are obtained by solving the following two transport equations:

$\frac{\partial(\rho k)}{\partial t}+\frac{\partial\left(\rho U_{j} k\right)}{\partial x_{j}}=\frac{\partial}{\partial x_{j}}\left(\left(\mu+\frac{\mu_{t}}{\sigma_{k}}\right) \frac{\partial k}{\partial x_{j}}\right)+P_{k}-\rho \varepsilon+P_{k b}$

$\frac{\partial(\rho \varepsilon)}{\partial t}+\frac{\partial\left(\rho U_{j} \varepsilon\right)}{\partial x_{j}}=\frac{\partial}{\partial x_{j}}\left(\left(\mu+\frac{\mu_{t}}{\sigma_{\varepsilon}}\right) \frac{\partial \varepsilon}{\partial x_{j}}\right)+\frac{\varepsilon}{k}\left(C_{\varepsilon 1} P_{k}-C_{\varepsilon 2} \rho \varepsilon+C_{\varepsilon 1} P_{\varepsilon b}\right)$

where closure constants $\sigma_{\mathrm{k}}=1.0, \sigma_{\varepsilon}=1.3, C_{\varepsilon 1}=1.44$ and $C_{\varepsilon 2}=1.92$. The turbulence production term, $P_{k}$, is modeled using:

$P_{k}=\mu_{t}\left(\frac{\partial U_{i}}{\partial x_{j}}+\frac{\partial U_{j}}{\partial x_{j}}\right) \frac{\partial U_{i}}{\partial x_{j}}-\frac{2}{3} \frac{\partial U_{k}}{\partial x_{k}}\left(3 \mu_{t} \frac{\partial U_{k}}{\partial x_{k}}+\rho k\right)$

$\frac{\partial \mathrm{U}_{\mathrm{k}}}{\partial \mathrm{x}_{\mathrm{k}}}$ is large only in regions where velocity divergence is high for compressible flow, such as shocks. Therefore, the second term on the right hand side of Equation (4.26) does not contribute significantly to the production for current flow conditions. 
$P_{k b}$ and $P_{\varepsilon b}$ in Equations (4.24) and (4.25) are turbulence production and dissipation due to buoyancy forces, respectively. They are included in the $k$ and $\varepsilon$ equation when the Buoyancy Turbulence option in CFX is set to 'Production and Dissipation' (ANSYS CFX-Solver Theory Guide, 2013).

When the Full Buoyancy model is being used, the buoyancy production term, $P_{k b}$, is modeled as:

$P_{k b}=-\frac{\mu_{t}}{\rho \sigma_{\rho}} g_{i} \frac{\partial \rho}{\partial x_{i}}$

where $\sigma_{\rho}$ is the Turbulent Schmidt number and is equal to 1 for the Full Buoyancy model.

The buoyancy dissipation term, $P_{\varepsilon b}$, is assumed to be proportional to $P_{k b}$ and must be positive, which is modeled as:

$P_{\varepsilon b}=C_{3} \cdot \max \left(0, P_{k b}\right)$

where $C_{3}$, the Dissipation Coefficient, is equal to 1 .

\subsubsection{Scalable Wall Functions}

The near-wall region can be subdivided into viscous sub-layer and logarithmic layer. For the viscous sublayer, the molecular viscosity is dominant in momentum and heat or mass transfer, whereas turbulence plays a major role in logarithmic layer. Wall functions, a set of semi-empirical formulas and functions presumed to lie in log-layer, can be employed to link near-wall conditions in the viscosity affected sublayer region to the dependent variables at the near-wall cells.

The logarithmic relation for the near-wall velocity is given by: 
$u^{+}=\frac{U_{t}}{u_{\tau}}=\frac{1}{\mathrm{~K}} \ln \left(y^{+}\right)+C$

where $u^{+}$is the near-wall velocity, $u_{\tau}$ is the friction velocity, $U_{t}$ is the known velocity tangent to the wall at a distance of $\Delta y$ from the wall, $k$ is the von-Karman constant being typically 0.41 , and $C$ is a log-layer constant depending on the wall roughness ( $C=5.2$ for a smooth wall). $\mathrm{y}^{+}$, the dimensionless distance from the wall, and friction velocity, $u_{\tau}$, are modeled as:

$y^{+}=\frac{\rho \Delta y u_{\tau}}{\mu}$

$u_{\tau}=\left(\frac{\tau_{\omega}}{\rho}\right)^{\frac{1}{2}}$

where $\tau_{\omega}$ is the wall shear stress.

To solve the singular problem of Equation (4.29) when $U_{t}$ goes to zero, an alternative velocity scale, $u^{*}$, is used instead of $u_{\tau}$ in the logarithmic region:

$u^{*}=C_{\mu}^{1 / 4} k^{1 / 2}$

Then $u_{\tau}$ can be obtained using:

$u_{\tau}=\frac{U_{t}}{\frac{1}{k} \ln \left(y^{*}\right)+C}$

The absolute value of wall shear stress $\tau_{\omega}$ is obtained from:

$\tau_{\omega}=\rho u^{*} u_{\tau}$

where

$y^{*}=\left(\rho u^{*} \Delta y\right) / \mu$ 
However, this-wall function approach has the drawback that refining the mesh does not necessarily result in a unique solution of increasing accuracy (Grotjans and Menter, 1998). The use of scalable wall function formulation in ANSYS CFX for $\varepsilon$-equation based turbulence models can overcome this problem. It can be applied on arbitrarily fine meshes and produces consistent results for grids of varying $\mathrm{y}^{+}$, independent of the Reynolds number of the application.

Scalable wall functions are bounded with standard k- $\varepsilon$ turbulence model in CFX, the basic idea behind the scalable wall function approach is to limit the value of $y^{*}$ used in the logarithmic formulation by a value of $y^{*}=\max \left(y^{*}, 11.06\right)$, where 11.06 is the value of $y^{*}$ at the intersection between the logarithmic and the linear wall profile. This method avoids the use of log-layer equations in a region where they were not appropriate.

The non-dimensional distance from the wall, $\mathrm{y}^{+}$, has to be within a certain range for a specific turbulence model with proper wall function. When using the $k-\varepsilon$ turbulence model with a scalable wall function, $y+$ should be less than 300 .

\subsection{Boundary and Initial Conditions}

Boundary conditions at the inlet, outlet, wall, symmetry and domain interface as well as the initial conditions of fluid domains and subdomains are introduced in this section. The determination of some parameters such as the inlet turbulence intensity and the turbulent Prandtl number is based on the sensitivity study results that will be presented later.

Inlet:

- Specified mass flow rate 
- Specified inlet temperature

- Turbulence: Medium Intensity ( $I=5 \%)$

- Flow direction: normal to boundary condition

Outlet:

- Relative Static Pressure: 0 [Pa]

Wall:

- No-Slip wall with uniform heat flux in the heated section of the two parallel channels

- No-Slip adiabatic wall conditions in the other parts of the parallel-channel system

Symmetry:

- Applied on the y-z plane that splits geometry in half

Domain Interface:

- Conservation of mass, momentum, turbulence, and heat transfer between two domains

\section{Fluid Domains:}

- Material: Supercritical Water

- Reference Pressure: 23-25 MPa, depends on the specific experimental case

- Buoyancy model: $g_{x}=0, g_{y}=-9.81 \mathrm{~m} / \mathrm{s}^{2}, g_{z}=0, \rho_{\text {ref }}=500 \mathrm{~kg} / \mathrm{m}^{3}$

- Heat Transfer: Total Energy

- Turbulence model: standard $k-\varepsilon$ with scalable wall function 
- Turbulent Prandtl Number $\left(\operatorname{Pr}_{t}\right): 0.95$

- Buoyancy Turbulence: Production and Dissipation

Fluid Subdomains:

- General Momentum Source: $S_{M, \text { frict }, x}=0, S_{M, \text { frict }, y}=-\frac{1}{2} \frac{K}{0.01} \frac{\dot{m}}{A} V, S_{M, \text { frict }, z}=0$

- Momentum source coefficient: $\mathrm{k}=\frac{1}{2} \frac{K}{0.01} \frac{\dot{m}}{A}$

\subsection{Water Properties}

In CFX, water properties are calculated based on thermodynamic properties of water and steam from the IAPWS-IF97 database, formulated by Wagner et al. (2000). This database provides an accurate equation of state for water and steam properties as well as an increase in computational speed. The IAPWS database adopts formulations for five distinct thermodynamic regions (shown in Figure 4.3) for water and steam, namely:

- subcooled water (Region 1)

- $\quad$ supercritical water/steam (Region 2)

- $\quad$ superheated steam (Region 3)

- saturation data (Line 4)

- high temperature steam (Region 5)

Region 5 has not been implemented in ANSYS CFX yet. 


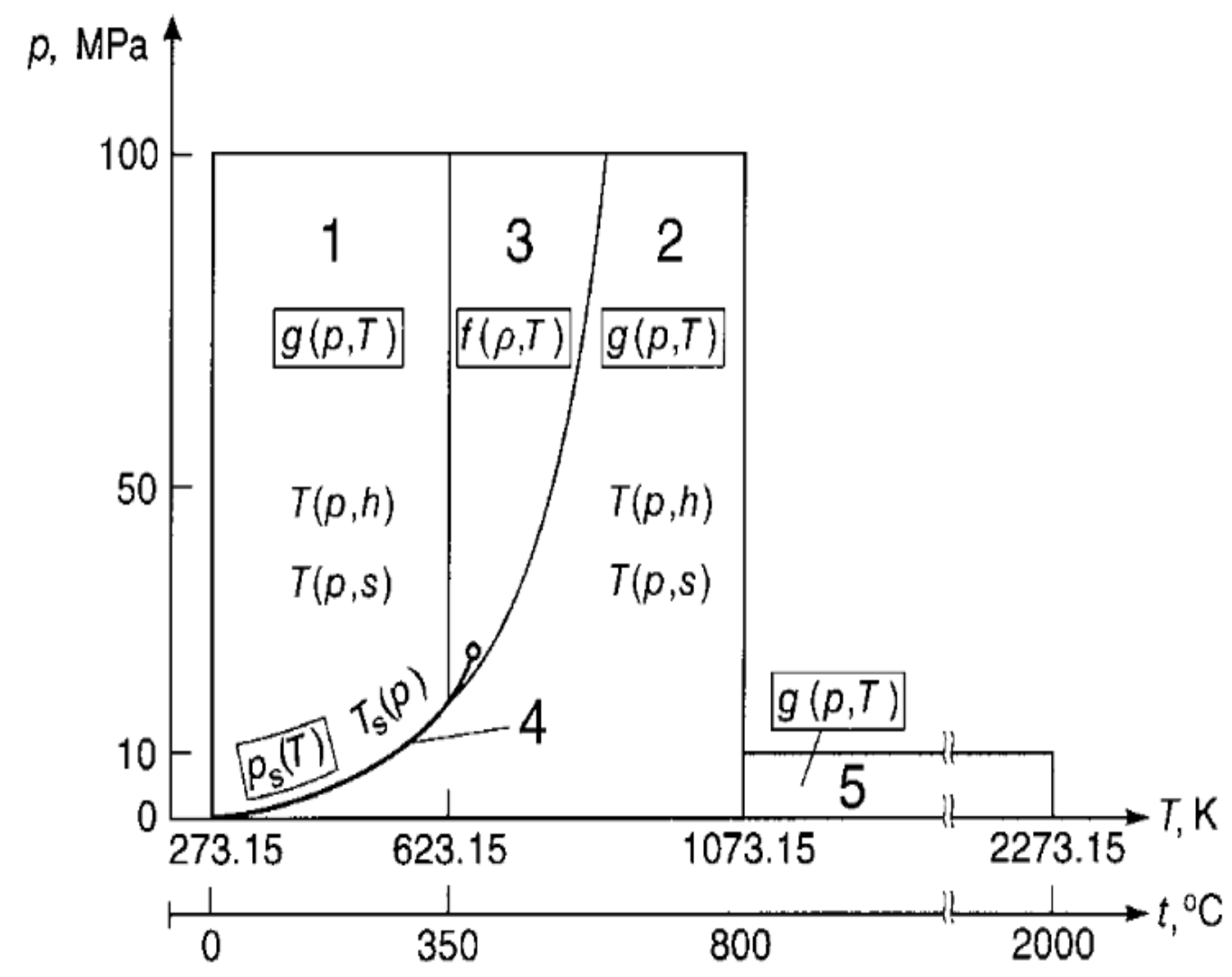

Figure 4.3: Regions and Equations of IAPWS-IF97 (ANSYS CFX-Solver Theory Guide, 2013)

There is a limited range of validity for the whole sets of equations in IAPWS-IF97, so temperature and pressure should be kept within this range. The range of validity for this property package as implemented in CFX is as follows:

$0{ }^{\circ} \mathrm{C}<\mathrm{T} \leq 800{ }^{\circ} \mathrm{C} \quad$ for $\quad 10 \mathrm{MPa} \leq \mathrm{P} \leq 100 \mathrm{MPa}$

and

$800{ }^{\circ} \mathrm{C}<\mathrm{T}<2000{ }^{\circ} \mathrm{C} \quad$ for $\quad \mathrm{P}<10 \mathrm{MPa}$

In CFX, to generate a lookup table of all the necessary physical properties of the fluid for the entire range of temperatures and pressures that will be encounter in each run, the 
minimum and maximum temperature and pressure have to be set as well as the maximum number of integration points. The minimum and maximum value of temperature and pressure set in CFX depend on the simulated experiment, and the range set should cover the variation range of experimental temperature and pressure. In this study, to improve accuracy in physical properties calculation, the minimum and maximum value of temperature and pressure were set to be equal to those of the experiments, respectively. Furthermore, a maximum of 1000 points was applied for all cases in this study.

\subsection{Grid Generation}

The mesh, consisting of hexahedral elements and dividing solution domain into discrete volumes, was created by using ANSYS ICEM CFD v14.5 software in this study.

Because small gradients of the flow and physical properties are expected at the inlet and outlet plena, a relatively coarse mesh was used there. In the two heated parallel channels, however, a fine mesh was used to resolve the sharp change of water physical properties.

Figure 4.4 shows the half $\mathrm{O}$-grid mesh of a coarse grid used in the pipe cross section. A non-uniform nodal distribution was used in the radial direction to achieve refinement near the wall. In other directions of the channels, nodes are distributed uniformly.

Figures 4.5 and 4.6 show how the coarse mesh connects the plenum to the channel from different views. 

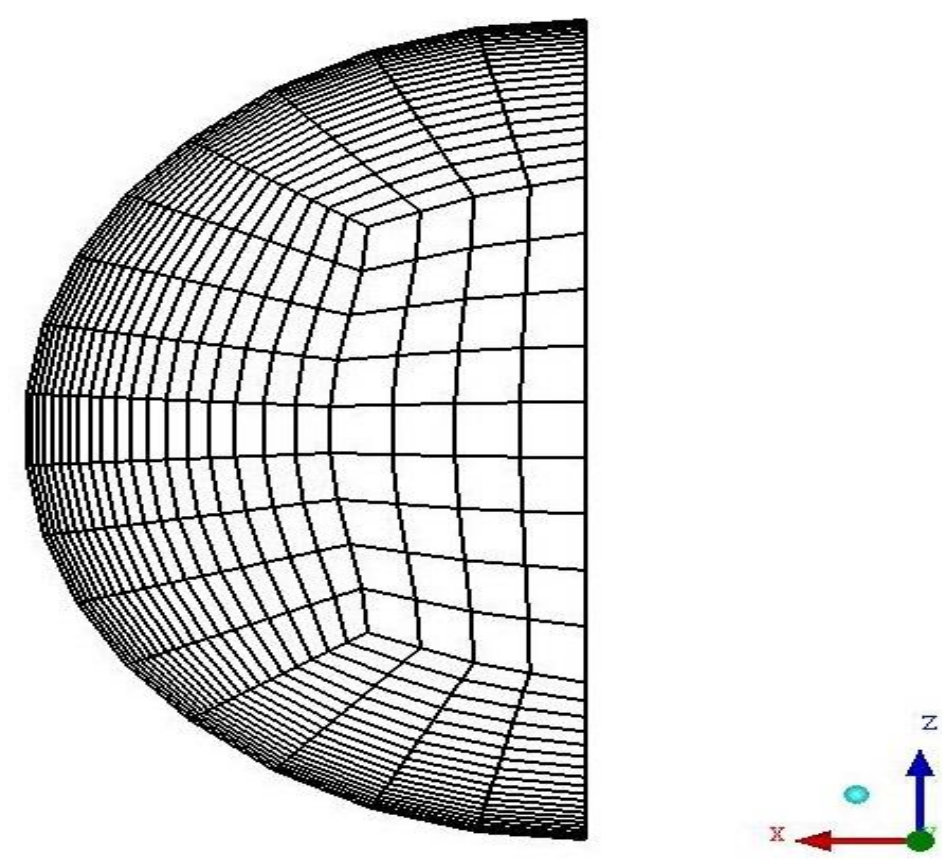

Figure 4.4: A cross-sectional view of the half O-grid mesh used in the channel

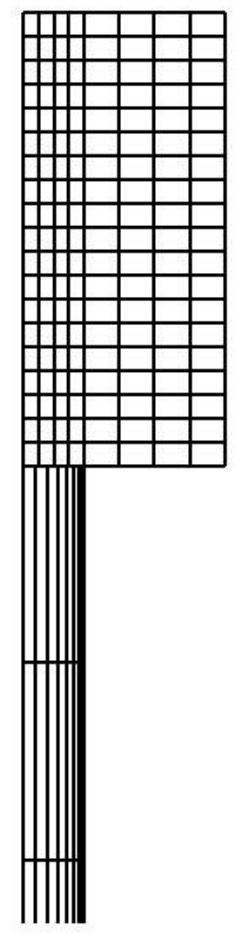

(a) Side View
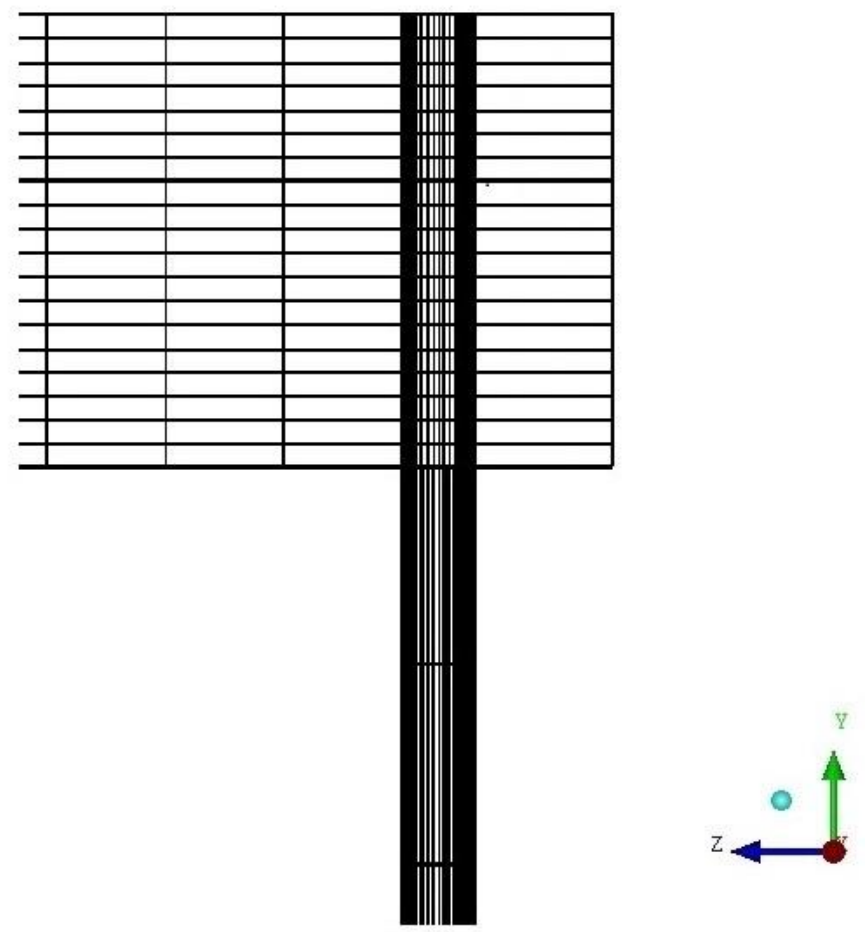

(b) Front View

Figure 4.5: Detailed views of the channel in the plenum region 

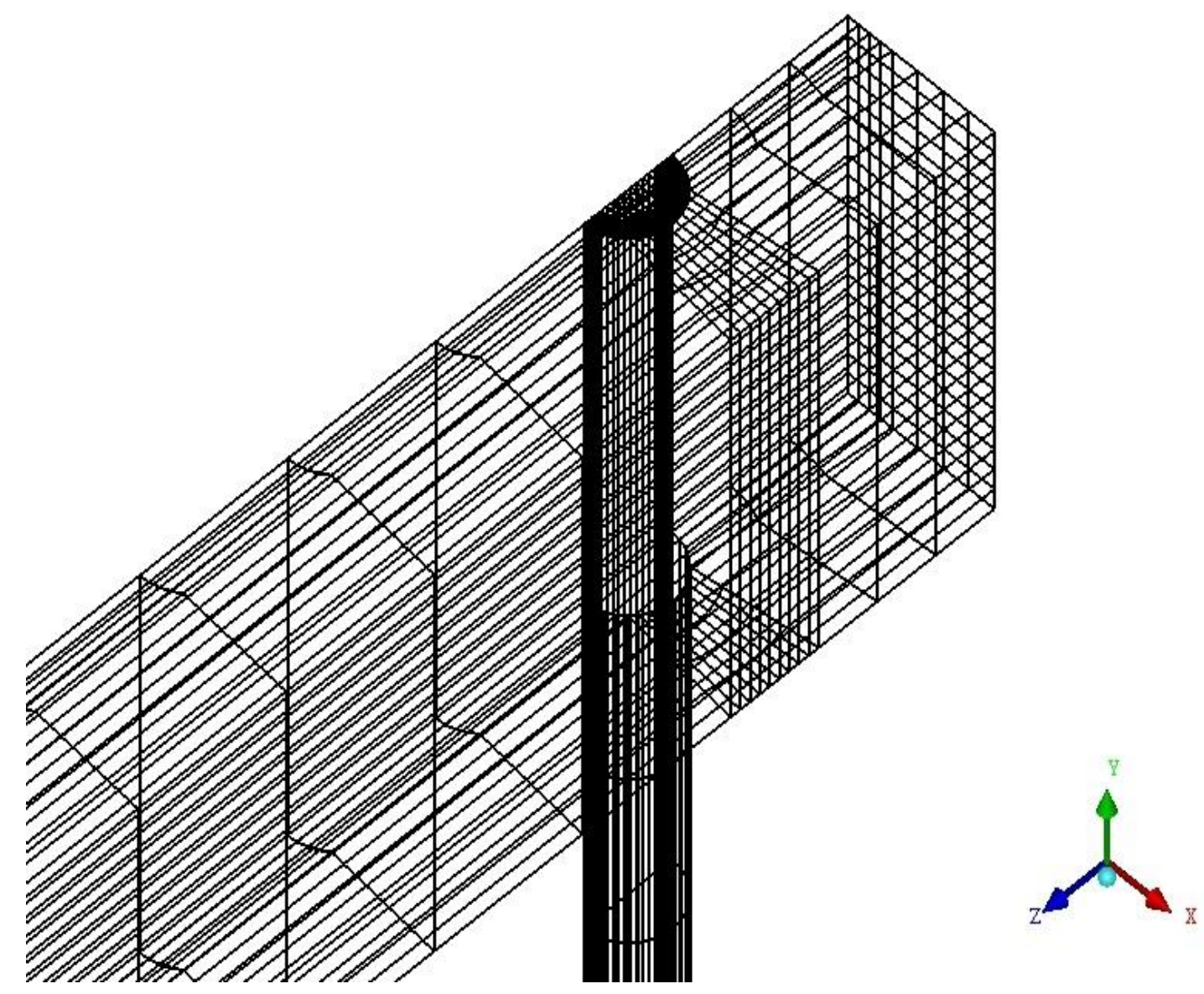

Figure 4.6: Isometric view of the mesh that connects the plenum to the channel

To generate mentioned meshes in ICEM CFD, the following steps were taken:

1. Points were created using $\mathrm{x}, \mathrm{y}$, and $\mathrm{z}$ coordinates. It should be noted that units adopted in ICEM CFD is the millimeter. The geometry is scaled to meters in the final step.

2. Curves were created by connecting all the points to define the edges of the geometry.

3. Surfaces were created using 3 or 4 curves and defined as parts with names corresponding to boundary conditions that would be imposed at that surface. 
4. An initial block was created using 3-D bounding box that enclosed all the points, curves, and surfaces.

5. The initial block was split at certain locations and unneeded blocks were deleted to fit the geometrical model. Additional splits were needed to enable the definition of subdomains.

6. For meshes with multiple domains, each domain block was defined as a separate part with an appropriate name.

7. Vertices and edges of the blocks were respectively associated to the appropriate points and curves of the geometry.

8. Appropriate faces and blocks were selected to generate the half O-grid.

9. Projected all the vertices that were associated to respective points, curves or surfaces, and check if the association was correct.

10. The number of nodes distributed in certain directions was specified using edge parameters, and they were copied to parallel edges.

11. A pre-mesh was enabled, which was then converted to an unstructured mesh.

12. The unstructured mesh was then converted to a .cf $x 5$ mesh file that was recognized by ANSYS CFX, and 0.001 was entered as the $\mathrm{x}, \mathrm{y}$, and $\mathrm{z}$ scaling factors to achieve proper units of measurement. 


\subsection{Domain Definitions}

The .cfx5 mesh file was imported into CFX-Pre, and then eight fluid domains were defined: inlet fluid domain, channel 1 Kin fluid domain, channel 2 Kin fluid domain, channel 1 heated fluid domain, channel 2 heated fluid domain, channel 1 Kout fluid domain, channel 2 Kout fluid domain and outlet fluid domain, as shown in Figure 4.7. To model local pressure drops by $\mathrm{K}$ factors, fluid subdomains were inserted into channel 1 Kin fluid domain, channel 2 Kin fluid domain, channel 1 Kout fluid domain and channel 2 Kout fluid domain.

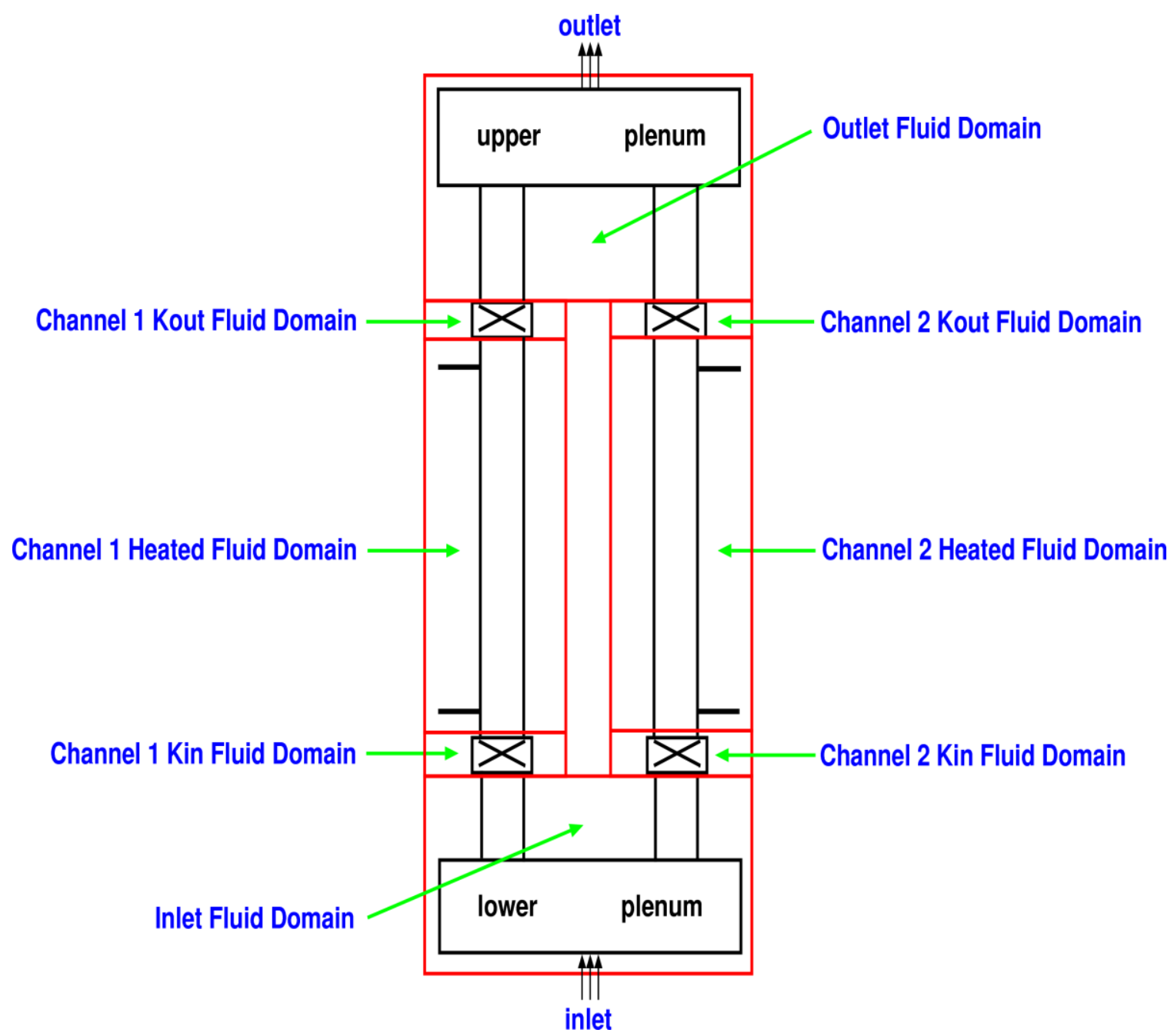

Figure 4.7: Fluid domains of the numerical model used in this study 


\subsection{Numerical Solution Method}

To obtain solution fields for all desired variables of flows, the governing equations of mass, momentum, energy, and turbulence are discretized to obtain an equivalent algebraic equation set.

ANSYS CFX uses an element-based finite volume method with which the spatial domain is discretized into finite control volumes. Relevant quantities such as mass, momentum, and energy are conserved on those control volumes. In addition, ANSYS CFX employs a co-located grid layout, where solution fields and other fluid properties are stored at control volume centers defined as mesh nodes in CFX. This kind of grid design is convenient for using the same control volumes to solve all transport equations. However, co-located method can also cause decoupled pressure field problem, as mentioned by Patankar (1980). To avoid this decoupling, an alternative discretization for mass flows, put forward by Rhie and Chow (1983), is applied so that the pressure field is instead coupled with the velocity field.

A typical two-dimensional mesh as a simplification of actual 3-D mesh in CFX is shown in Figure 4.8 below. A control volume (the shaded area) is constructed around each mesh node using the median dual as boundaries. Solid points represent mesh nodes and hollow points are integration points.

The governing equations are integrated over each control volume. Then, volume integrals are discretized within each element sector, and accumulated to the control volume to which the sector belongs. Gauss' Divergence Theorem is applied to convert volume integrals of divergence and gradient operators to surface integrals which are then 
discretized at the integration points located at the center of the surfaces that separate element sectors.

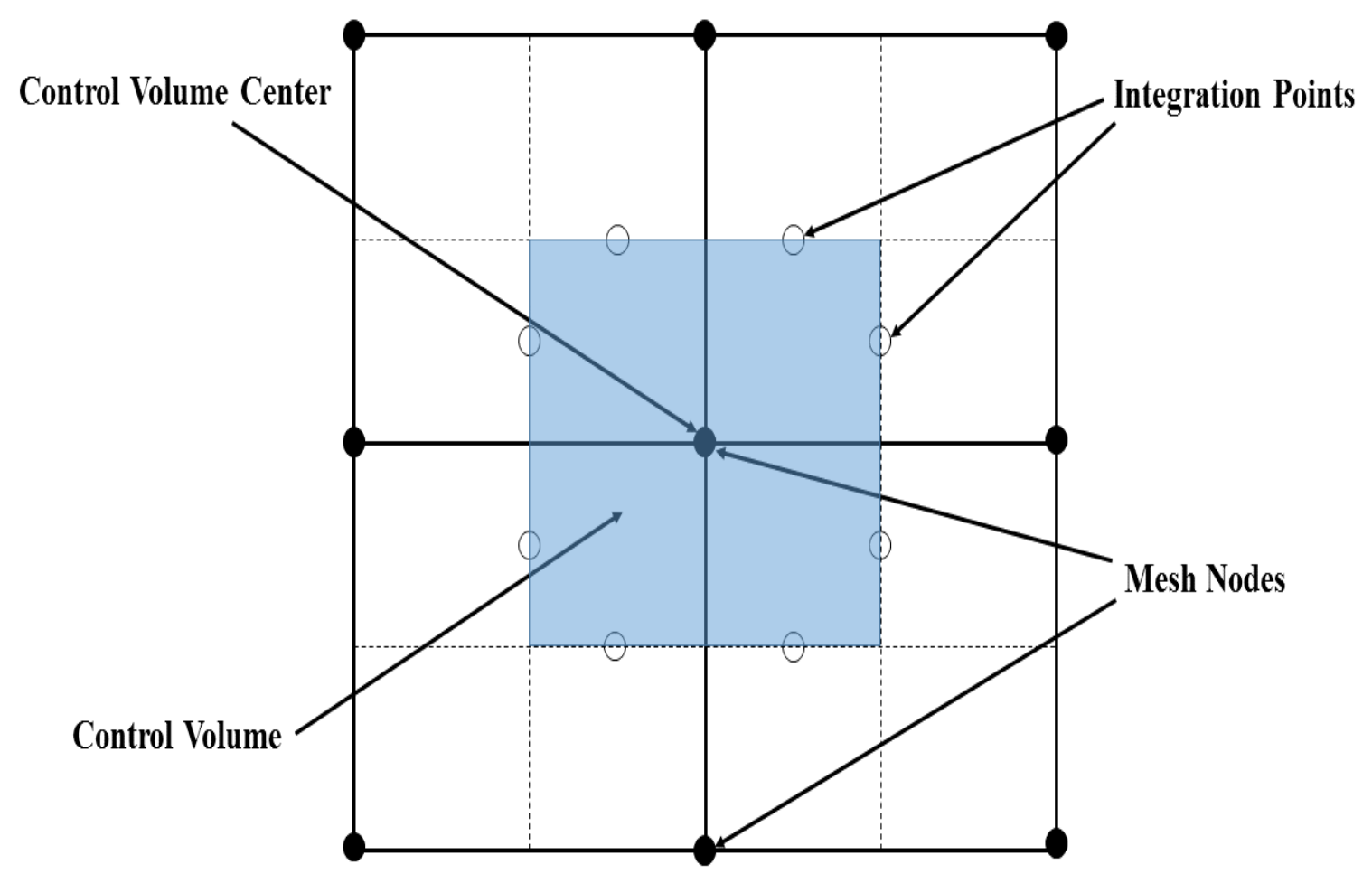

Figure 4.8: 2D simplification of a typical control volume in CFX

Control volume face quantities that are needed in the discretization process are evaluated at the integration points. For diffusion terms, finite-element shape functions are adopted to perform these approximations in ANSYS CFX. The following formula explains how the solution variable, $\varphi$, is approximated from the nodal value, $\varphi_{i}$, and the shape function, $N_{i}$ :

$\varphi=\sum_{i=1}^{N_{\text {node }}} N_{i} \varphi_{i}$ 
where $N_{i}$ is the shape function for node $i, \varphi_{i}$ is the value of $\varphi$ at node $i$, and $N_{\text {node }}$ is the total number of nodes in considered element. If the $N_{i}$ value of all nodes is summed up, following shape function property is obtained:

$\sum_{i=1}^{N_{\text {node }}} N_{i}=1$

The Gauss' divergence theorem is used to evaluate the gradient of a solution variable as follows:

$\nabla \varphi=\frac{1}{V} \sum_{i p}(\varphi \Delta \vec{n})_{i p}$

where $\Delta \vec{n}$ is the outward surface vector at integration point ip. The solution variable $\varphi$ can be evaluated at integration points using Equation (4.36).

Spatial derivatives of all diffusion terms are evaluated using shape functions:

$\left.\frac{\partial \varphi}{\partial x_{i}}\right|_{i p}=\left.\sum_{n} \frac{\partial N_{n}}{\partial x_{i}}\right|_{i p} \varphi_{n}$

where $\varphi_{n}$ is the value of $\varphi$ at node $n$. The above summation is over all the shape functions of the mesh element. The Cartesian derivatives of each shape function are calculated using the Jacobian transformation matrix as follows:

$\left[\begin{array}{l}\frac{\partial N}{\partial x} \\ \frac{\partial N}{\partial y} \\ \frac{\partial N}{\partial z}\end{array}\right]=\left[\begin{array}{lll}\frac{\partial x}{\partial s} & \frac{\partial y}{\partial s} & \frac{\partial z}{\partial s} \\ \frac{\partial x}{\partial t} & \frac{\partial y}{\partial t} & \frac{\partial z}{\partial t} \\ \frac{\partial x}{\partial u} & \frac{\partial y}{\partial u} & \frac{\partial z}{\partial u}\end{array}\right]^{-1}\left[\begin{array}{l}\frac{\partial N}{\partial s} \\ \frac{\partial N}{\partial t} \\ \frac{\partial N}{\partial u}\end{array}\right]$ 
For the advection terms, the integration point values of the filed solution variable $\varphi$ need to be approximated from the nodal values of $\varphi$. The general form of advection schemes implemented in ANSYS CFX is:

$\varphi_{i p}=\varphi_{u p}+\beta \nabla \varphi \cdot \Delta \vec{r}$

where $\varphi_{u p}$ is the value of solution variable $\varphi$ at the upwind node, $\vec{r}$ is the vector from the upwind node to the current integration point $i p$, and the values of $\beta$ and $\nabla \varphi$ depend on the advection scheme being used.

Two main advection schemes are used: the first order Upwind Difference Scheme (UDS) and the High Resolution Scheme.

The first order Upwind Difference Scheme is obtained by setting $\beta$ to zero. This is a very robust scheme and is ideal for turbulence quantities. Diffusive discretization errors introduced by this scheme are likely to smear steep spatial gradients in the solution though.

The High Resolution Scheme evaluates the advective flux using $\beta$ and $\nabla \varphi$ values from the upwind node. The value of $\beta$ at each node is obtained using the special nonlinear method of Barth and Jesperson [1989]. This approach calculates a $\varphi_{\min }$ and $\varphi_{\max }$ at each node first, using the values of adjacent nodes and the value of the node itself. Then, Equation (4.41) is used to solve $\beta$ for each integration point around the node so that the solution variable $\varphi$ is not less than $\varphi_{\min }$ or more than $\varphi_{\max }$. The minimum $\beta$ value of all integration points surrounding the node is imposed as the nodal value of $\beta$. And, it is noteworthy that the value of $\beta$ can never exceed 1 . 
For the pressure term, the integration point value of pressure, $P_{i p}$, is evaluated using the shape function:

$P_{i p}=\sum_{n} N_{n}\left(s_{i p}, t_{i p}, u_{i p}\right) P_{n}$

where the pressure at nodes, $P_{n}$, and the value of shape functions $N_{n}$ at the integration point $\left(s_{i p}, t_{i p}, u_{i p}\right)$ should be known.

For the transient term, the general discrete approximation for the $\mathrm{n}^{\text {th }}$ time step is:

$\frac{\partial}{\partial t} \int_{V} \rho \varphi d V \approx V \frac{(\rho \varphi)^{n+\frac{1}{2}}-(\rho \varphi)^{n-\frac{1}{2}}}{\Delta t}$

where superscripts $\left(n+\frac{1}{2}\right)$ and $\left(n-\frac{1}{2}\right)$ are used to differentiate solution values at the end and start of the time step, accordingly.

In CFX, there are mainly two options for transient scheme: the First Order Backward Euler scheme and the Second Order Backward Euler scheme, using different approach to approximate the start and the end of time step values.

In the First Order Backward Euler scheme, solution values at the old time level are used to approximate the start of time step values, and the end of time step values are approximated using the current time level solution values. So the discretization in Equation (4.37) becomes:

$\frac{\partial}{\partial t} \int_{V} \rho \varphi d V=V\left(\frac{\rho \varphi-\rho^{o} \varphi^{o}}{\Delta t}\right)$

The Second Order Backward Euler scheme, however, calculates the start and end of time step values as follows: 


$$
\begin{aligned}
& (\rho \varphi)^{n-\frac{1}{2}}=(\rho \varphi)^{o}+\frac{1}{2}\left((\rho \varphi)^{o}-(\rho \varphi)^{o o}\right) \\
& (\rho \varphi)^{n+\frac{1}{2}}=(\rho \varphi)+\frac{1}{2}\left((\rho \varphi)-(\rho \varphi)^{o}\right)
\end{aligned}
$$

Substituting above two approximations into Equation (4.43) results in:

$\frac{\partial}{\partial t} \int_{V} \rho \varphi d V \approx V \frac{1}{\Delta t}\left(\frac{3}{2}(\rho \varphi)-2(\rho \varphi)^{o}+\frac{1}{2}(\rho \varphi)^{o o}\right)$

Both of these two transient schemes are robust, implicit, conservative in time, and do not have a time step size limitation. But the First Order Transient scheme is bounded, whereas the second order one is not. The First Order Transient scheme is only first-order accurate in time and behaves similar to the First Order Upwind Difference Scheme by introducing discretization errors that tend to diffuse steep temporal gradients. Although the Second Order Transient scheme is second-order accurate in time, it may induce nonphysical solution oscillations.

By applying the finite control volume method to all elements in the solution domain, the original governing equations are discretized into a linear set of equations, also named as discrete conservation equations, have the following general form:

$\sum_{n b_{i}} a_{i}^{n b} \varphi_{i}^{n b}=b_{i}$

where $a_{i}$ are the coefficients of a nodal equation, $\varphi_{i}$ is the solution, and $b_{i}$ is the right hand side. The superscript $n b$ signifies "neighbor". The summation on the left hand side also includes the central coefficient multiplying the solution at the $i$ th node. The complete set of these equations over all control volumes constitutes the whole linearized equation system. 
The linearized equation system is solved by ANSYS CFX using a coupled solver which solves the hydrodynamic equations (for $u, v, w, p$ ) as a single system. This solution approach uses a fully implicit discretization of the equations at any given time step. When solving fields in the CFX-Solver, the outer (time step) iteration is controlled by the physical time scale for steady-state analyses and time step for transient analyses. The physical time scale works like a relaxation parameter that guides the approximate solutions to a steady-state solution. Therefore, the iteration numbers required to achieve steady state convergence is reduced, superior to a segregated solver. Furthermore, only one inner (linearization) iteration is performed per outer iteration in steady-state analyses, whereas multiple inner iterations are performed per time step in transient analyses.

During the solution of the linearized system of discrete equations, imbalance of equations defined as raw residual in CFX is calculated per iteration. The raw residuals are then normalized to monitor solutions and be used as a convergence criterion. In general, the normalized residual is given by:

$\left[\tilde{r}_{\varphi}\right]=\frac{\left[r_{\varphi}\right]}{a_{p} \Delta \varphi}$

where $\tilde{r}_{\varphi}$ and $r_{\varphi}$ are the normalized residual and raw residual for solution variable $\varphi, a_{P}$ represents coefficient of the control volume, and $\Delta \varphi$ is the range of solution variable in the domain.

Domain imbalances are also calculated per iteration in CFX by summing the solution variables at the boundary of each domain first, and then normalizing the sum by the largest contributor of that solution variable to generate an imbalance percentage. The imbalance in percentage for each domain is computed as follows: 
Imbalance $=\frac{100}{\operatorname{Max}\left(\left|\sum_{i=1}^{N} \varphi_{i, j}\right|\right)} \sum_{j=1}^{N_{\text {boundaries }}} \sum_{i=1}^{N} \varphi_{i, j}$

where $\varphi$ is the solution variable, $N$ is the total number of sampled locations on a boundary, and $N_{\text {boundaries }}$ is the total number of boundaries in each domain.

For the present study, double precision was used for the computations throughout. When the maximum normalized residual of each discretized equations was less than $1 \times 10^{-6}$ and domain imbalances for the continuity, momentum, energy, and turbulence equations were controlled within $0.01 \%$, then the steady-state calculation was considered to be converged. For transient analyses, the First Order Backward Euler scheme was applied and the solver relaxation parameter was set to be 1.0 rather than the default value of 0.9 . Furthermore, a maximum of 30 iterations were performed per time step. The High Resolution Advection scheme was used for both steady state and transient analyses. 


\section{CHAPTER 5}

\section{RESULTS AND DISCUSSION}

Because the objective of this study is to investigate oscillatory instability of supercritical flow in heated parallel channels numerically, the definition of oscillatory instability and the way to determine the instability boundary are introduced first. Next, the results of the predictions of the Xiong et al. (2012) experiments are presented and compared with other results. Finally, the results of sensitivity analyses are presented.

\subsection{Determining the Instability Threshold}

The instability threshold mass flow rate is determined by a transient analysis in which the time variation of the inlet and outlet mass flow rates in the heated channels are monitored. The initial condition for the transient analyses is a steady-state analysis. Therefore, for every run with different inlet mass flow rate, the steady-state solution must first be performed and obtained.

The inlet and outlet channel mass flow rates are monitored to determine if oscillations grow in amplitudes with time. If so, the flow is said to be unstable and this kind of instability is defined as an oscillatory instability. If the oscillation amplitudes become constant with time, the flow is said to be at the instability threshold, or neutrally stable. It should be noted that transient analyses have to sustain long enough (at least $25 \mathrm{~s}$ is required in this study) to clearly identify a flow instability.

For a given case, the approach to determine the instability threshold begins with a relatively high mass flow rate for which the flow is stable. Then the heating power of two 
parallel channels is held constant and the mass flow rate is reduced in decrements until sustained or diverging oscillations are observed. In this study, a decrement of $0.0002 \mathrm{~kg} / \mathrm{s}$ was used in search for the instability boundary. Within this decrement, if the higher mass flow rate caused a stable flow while the lower mass flow rate caused an unstable flow, then the average of these two mass flow rates was chosen as the threshold mass flow rate or instability boundary.

\subsection{Spatial Resolution Independence Study}

By varying the number of nodes distributed in the channel cross section and in the axial

direction of channels, three meshes with different number of nodes and different spatial grid sizes were generated using ICEM CFD. These three meshes listed in Table 5.1 were used to study spatial grid refinement effects on the instability boundary for three cases. For all three cases, a time step size of $0.02 \mathrm{~s}$ was used.

Table 5.1: Different meshes used for spatial independence study

\begin{tabular}{|c|c|}
\hline Mesh & Number of Nodes (half geometry) \\
\hline 1 & 152,216 \\
\hline 2 & 440,576 \\
\hline 3 & $1,032,080$ \\
\hline
\end{tabular}

With these three meshes, oscillatory instability boundaries were determined for Case 1 , Case 3 and Case 7 in Table 3.1. Table 5.2 summarizes the results and lists the discrepancy between the results of meshes 1 and 2 compared to mesh 3 . The maximum discrepancy takes place between mesh 1 and mesh 3 in Case 7. Nevertheless, even the largest difference is only $1.15 \%(<2 \%)$, all of the other discrepancies are within $1 \%$. Furthermore, considering the mass flow rate decrement used in this study is a small 
enough value, $0.0002 \mathrm{~kg} / \mathrm{s}$, threshold mass flow rates predicted by the three different meshes are essentially very close to each other. These results indicate that spatial grid refinement does not have a significant effect on the instability boundary. As a compromise between accuracy and computational effort, mesh 2 was selected for the ensuing analyses.

Table 5.2: The threshold mass flow rate $(\mathrm{kg} / \mathrm{s})$ predicted with different meshes (mass flow rates are for the full geometry and discrepancies are relative to the mesh 3 results)

\begin{tabular}{|c|c|c|c|c|c|}
\hline Case & mesh 1 & discrepancy & mesh 2 & discrepancy & mesh 3 \\
\hline 1 & 0.0341 & $-0.29 \%$ & 0.0341 & $-0.29 \%$ & 0.0342 \\
\hline 3 & 0.0365 & $0.83 \%$ & 0.0360 & $-0.55 \%$ & 0.0362 \\
\hline 7 & 0.0351 & $1.15 \%$ & 0.0349 & $0.58 \%$ & 0.0347 \\
\hline
\end{tabular}

\subsection{Temporal Resolution Independence Study}

To investigate time step size effects on flow instability, four different time steps were tested: $0.01 \mathrm{~s}, 0.02 \mathrm{~s}, 0.05 \mathrm{~s}$ and $0.1 \mathrm{~s}$. Mesh 2 was used throughout this study.

Oscillatory instability boundaries were determined for the same three experimental cases that were used for the spatial resolution independence study. Threshold mass flow rates predicted with the four different time steps are listed in Table 5.3. The discrepancy values in Table 5.3 for each time step size are relative to the threshold mass flow rate obtained with the smallest time step, $0.01 \mathrm{~s}$. 
Table 5.3: The threshold mass flow rate $(\mathrm{kg} / \mathrm{s})$ predicted with different time steps (mass

flow rates are for the full geometry and discrepancies are relative to the $0.01 \mathrm{~s}$ results)

\begin{tabular}{|c|c|c|c|c|c|c|c|}
\hline Case & $0.1 \mathrm{~s}$ & discrepancy & $0.05 \mathrm{~s}$ & discrepancy & $0.02 \mathrm{~s}$ & discrepancy & $0.01 \mathrm{~s}$ \\
\hline 1 & 0.0321 & $-5.87 \%$ & 0.0335 & $-1.76 \%$ & 0.0341 & $0.00 \%$ & 0.0341 \\
\hline 3 & 0.0345 & $-4.43 \%$ & 0.0345 & $-4.43 \%$ & 0.036 & $-0.28 \%$ & 0.0361 \\
\hline 7 & 0.0335 & $-4.56 \%$ & 0.0347 & $-1.14 \%$ & 0.0349 & $-0.57 \%$ & 0.0351 \\
\hline
\end{tabular}

The results in Table 5.3 show that, for the same case, with the increase in the time step size, the predicted threshold mass flow rate, in general, decreases, leading to a growing discrepancy. This means the flow system is predicted to be more stable with a larger time step, in agreement with the 1-D code findings by Xiong et al. (2013). This trend also indicates that the predicted oscillatory instability boundary is sensitive to the time step size used. But, on the other hand, if we observe the discrepancy between $0.01 \mathrm{~s}$ and $0.02 \mathrm{~s}$ boundaries, all of discrepancies are less than 1\%, implying that temporal convergence is reached between $0.01 \mathrm{~s}$ and $0.02 \mathrm{~s}$.

To further illustrate the above observations, a plot of the time variation of the inlet mass flow rate in channel 1 for Case 1 and for all four time step sizes is presented in Figure 5.1.

From Figure 5.1, the effect of time-step size on the transient mass flow rate can be discerned. With increasing the time step size from $0.01 \mathrm{~s}$, the sine-wave oscillation shape becomes more rugged, or less smooth, and the oscillation amplitude decreases. Responses at $0.01 \mathrm{~s}$ and $0.02 \mathrm{~s}$ collapse onto each other and agree reasonably well though. The $0.05 \mathrm{~s}$ and $0.1 \mathrm{~s}$ responses show that temporal convergence has not been achieved. 


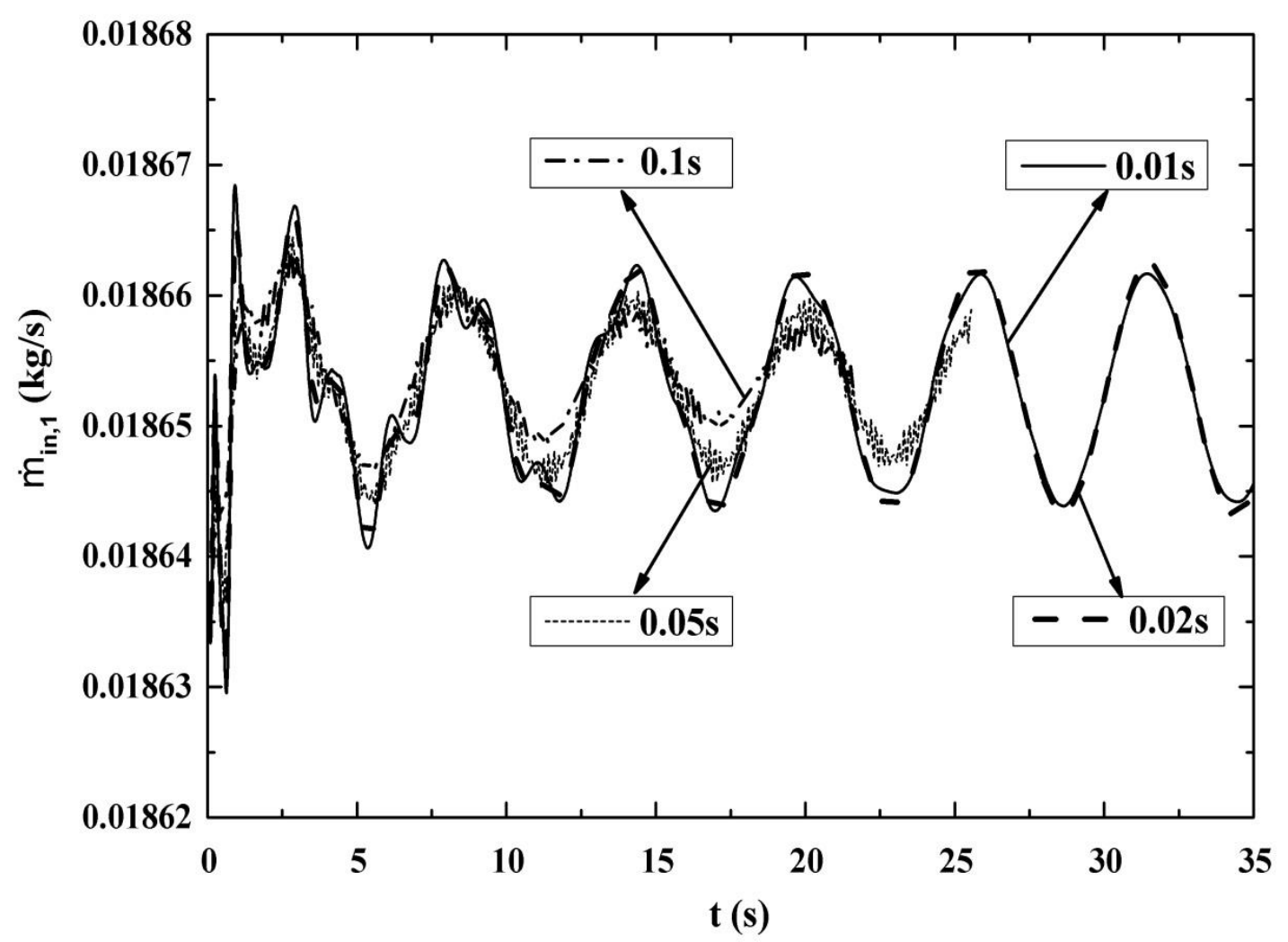

Figure 5.1: Time responses of inlet mass flow rate in channel 1 at different time steps and a total mass flow rate of $0.0340 \mathrm{~kg} / \mathrm{s}$ for Case 1

To sum up these findings, $0.05 \mathrm{~s}$ and $0.1 \mathrm{~s}$ are too large a time-step for accurate stability analyses, and $0.02 \mathrm{~s}$ can be said to be the 'optimum' time step, for it offers the same accuracy as $0.01 \mathrm{~s}$ but at a lower computational cost.

\subsection{Present CFX Predictions of Threshold Mass Flow Rates}

After determining the mesh and time step size, the nine experimental cases given in Table 3.1 were numerically investigated. Their instability boundaries for the full geometry were obtained using ANSYS CFX. 
In the graphs of mass flow rate in this section, the normalized channel inlet mass flow rate, $\dot{m}_{i n}{ }^{*}$, is calculated by dividing the transient channel inlet mass flow rate by the initial transient channel inlet mass flow rate at $\mathrm{t}=0 \mathrm{~s}$.

Figure 5.2 illustrates, under Case 1 flow conditions, the monitored transient responses of normalized inlet mass flow rate in channel 1 at two different total mass flow rates: 0.0340 $\mathrm{kg} / \mathrm{s}$ and $0.0342 \mathrm{~kg} / \mathrm{s}$.

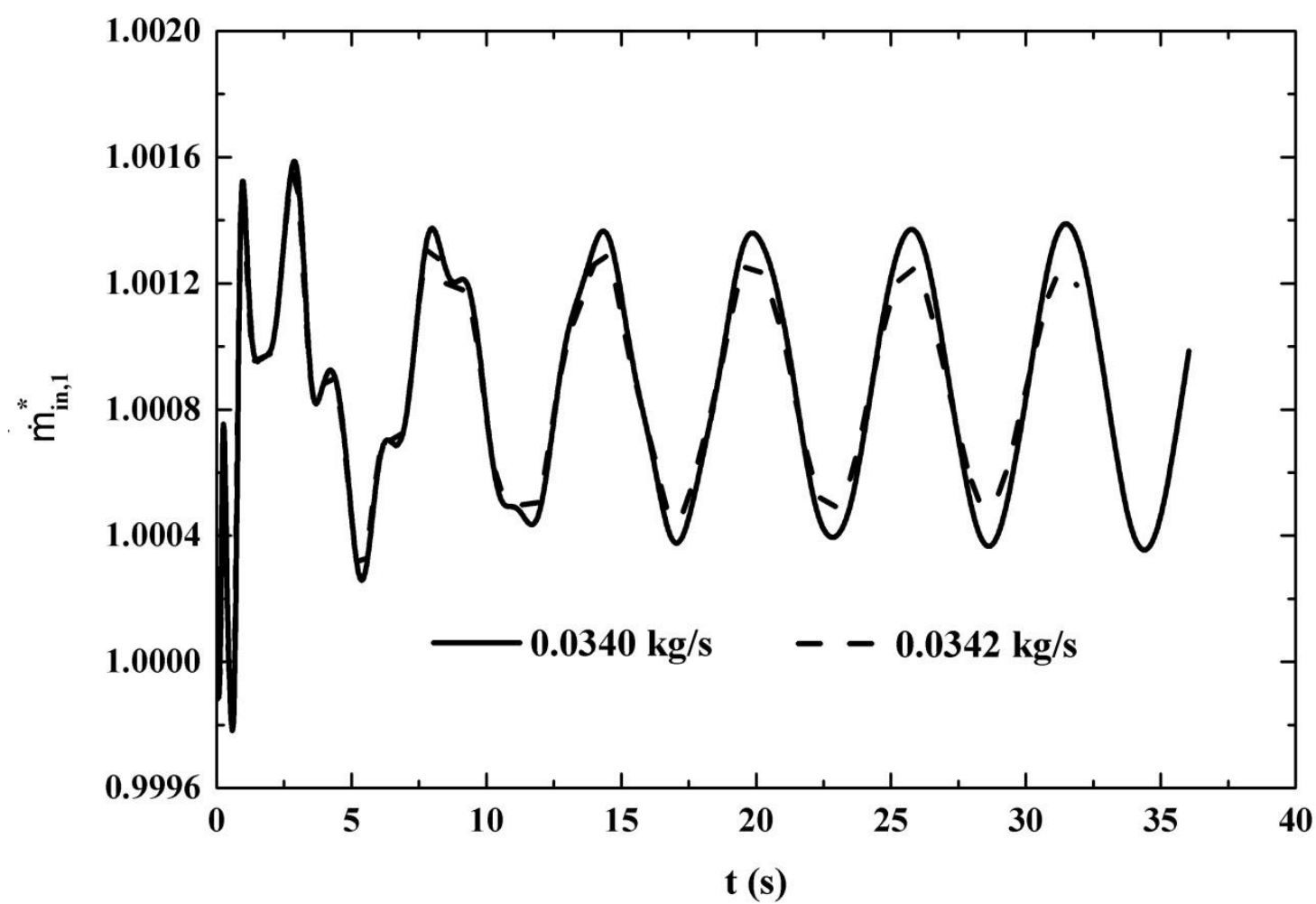

Figure 5.2: Time responses of the normalized channel 1 inlet mass flow rate at two different total mass flow rates for Case 1

For a total mass flow rate of $0.0340 \mathrm{~kg} / \mathrm{s}$, the oscillation amplitudes grow slowly with time; on the other hand, the amplitude of the oscillations decreases with time for a total mass flow rate of $0.0342 \mathrm{~kg} / \mathrm{s}$. Therefore, the flow is unstable at a total mass flow rate of 
$0.0340 \mathrm{~kg} / \mathrm{s}$, and is stable at a total mass flow rate of $0.0342 \mathrm{~kg} / \mathrm{s}$. The average value, $0.0341 \mathrm{~kg} / \mathrm{s}$, is taken as the Case 1 stability boundary mass flow rate. Because a very small decrement in mass flow rate $(0.0002 \mathrm{~kg} / \mathrm{s})$ was applied to search for the instability boundary, the two mass flow rates in Figure 5.2 are very close to the threshold mass flow rate whose oscillation amplitudes become constant with time. As a result, the growing and reduction in the oscillation amplitudes for the two mass flow rates in Figure 5.2 are not significant.

For a parallel channel system, if one channel oscillates first, it will initiate oscillations in the other channel, in order to conserve the total mass flow rate. Thenceforth, both channels oscillate. Because the inlet boundary condition for the parallel channel system of this study is constant total mass flow rate, channel 1 and channel 2 oscillate $180^{\circ}$ out of phase to conserve the total mass flow rate, as demonstrated in Figure 5.3.

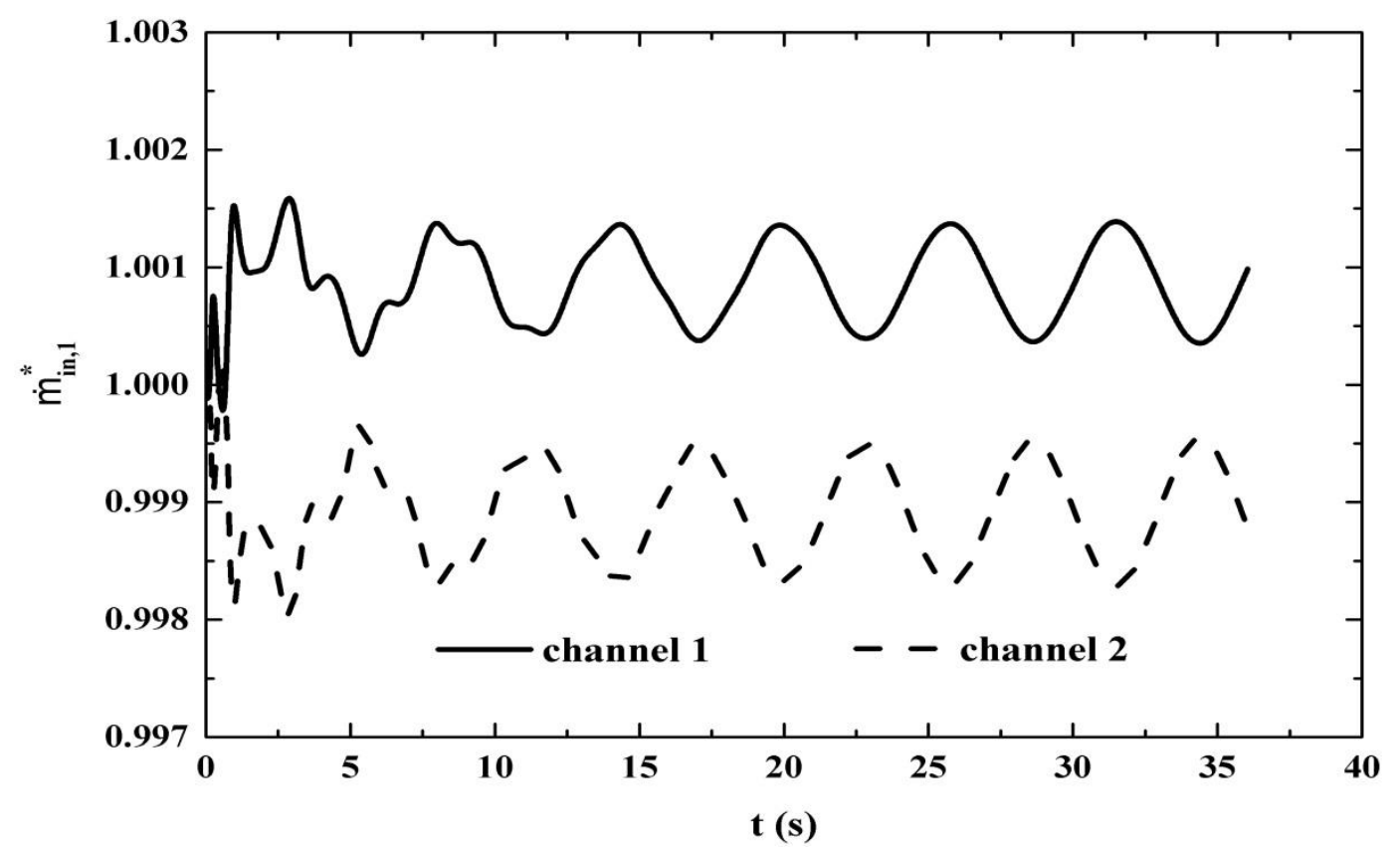

Figure 5.3: Time responses of the normalized inlet mass flow rate in two parallel channels at a same total mass flow rate of $0.0340 \mathrm{~kg} / \mathrm{s}$ for Case 1 
Figure 5.3 shows that the mass flow rate in channel 2 is relatively lower than that of channel 1; this difference is because channel 2 has a larger outlet pressure drop coefficient ( $\mathrm{K}$ factor).

Table 5.4 summarizes the threshold mass flow rates of nine experimental cases predicted by CFX, and the constant experimental heating power is applied for each case to obtain these instability boundaries.

Table 5.4: Threshold mass flow rates of nine experimental cases predicted by CFX

\begin{tabular}{|c|c|}
\hline Case & $\dot{m}_{\text {thold,CFX }}(\mathrm{kg} / \mathrm{s})$ \\
\hline 1 & 0.0341 \\
\hline 2 & 0.0347 \\
\hline 3 & 0.0360 \\
\hline 4 & 0.0343 \\
\hline 5 & 0.0353 \\
\hline 6 & 0.0367 \\
\hline 7 & 0.0349 \\
\hline 8 & 0.0365 \\
\hline 9 & 0.0381 \\
\hline
\end{tabular}

To verify that the flow in the channels is turbulent, the Reynolds number at the inlet and outlet of both channels was calculated with the following equation:

$R e=\frac{4 \dot{m}}{\pi D \mu}$

where $\dot{m}$ is the mass flow rate, $D$ is the hydraulic diameter and equal to the tube diameter for a pipe, and $\mu$ is the dynamic viscosity.

Model results were available for instances of total inlet mass flow rate with a decrement or increment of $0.0002 \mathrm{~kg} / \mathrm{s}$ for each experimental case studied. For the purpose of the Reynolds 
number calculations, the total inlet mass flow rate selected was the value at the instability threshold or the next lowest value available. Then, the separate channel mass flow rates were extracted; those values are summarized in Table 5.5. The calculated channel Reynolds numbers are also summarized in Table 5.5.

Table 5.5: The Reynolds number at the inlet and outlet of both channels for nine experimental cases

\begin{tabular}{|c|c|c|c|c|c|c|c|}
\hline Case & $\dot{m}(\mathrm{~kg} / \mathrm{s})$ & $\dot{m}_{1}(\mathrm{~kg} / \mathrm{s})$ & $\dot{m}_{2}(\mathrm{~kg} / \mathrm{s})$ & $R e_{\text {in }, 1}$ & $R e_{\text {out }, 1}$ & $R e_{\text {in }, 2}$ & $R e_{\text {out }, 2}$ \\
\hline 1 & 0.0340 & 0.0186 & 0.0154 & 25432 & 142180 & 20934 & 115017 \\
\hline 2 & 0.0346 & 0.0189 & 0.0157 & 28705 & 144417 & 23880 & 118412 \\
\hline 3 & 0.0360 & 0.0196 & 0.0164 & 32856 & 150383 & 27434 & 123714 \\
\hline 4 & 0.0342 & 0.0186 & 0.0156 & 28276 & 140699 & 23615 & 114166 \\
\hline 5 & 0.0353 & 0.0192 & 0.0161 & 32063 & 145025 & 26945 & 118724 \\
\hline 6 & 0.0366 & 0.0198 & 0.0168 & 36130 & 149654 & 30699 & 124831 \\
\hline 7 & 0.0348 & 0.0190 & 0.0158 & 28723 & 140874 & 23990 & 113594 \\
\hline 8 & 0.0364 & 0.0198 & 0.0166 & 33011 & 147023 & 27723 & 119945 \\
\hline 9 & 0.0381 & 0.0206 & 0.0175 & 37524 & 152993 & 31900 & 127634 \\
\hline
\end{tabular}

All of the Reynolds numbers in Table 5.5 are much greater than 2300, which is the critical Reynolds number corresponding to the onset of turbulence in a pipe. Therefore, the flow in this problem is regarded as turbulent flow. The maldistribution of total inlet mass flow rate to the two channels is evident in Table 5.5. Channel 1 always has a higher mass flow rate than channel 2; this was already seen in Figure 5.3. It is also observed that, for both channels, the outlet Reynolds number is always much larger than the inlet Reynolds number due to the change in the dynamic viscosity with temperature.

\subsection{1-D SPORTS Predictions of Threshold Mass Flow Rate}

The oscillatory instability boundaries of the nine experimental cases were also predicted with the 1-D non-linear SPORTS code (Chatoorgoon, 1986); these results were provided 
by Dr. V. Chatoorgoon (Chatoorgoon, 2016). Just as what was used in the 1-D in-house code of Xiong et al. (2013), the 1-D SPORTS code uses the Haaland (1983) empirical friction-factor correlation (Equation 4.3) to compute the friction pressure drop. This is different from the 3-D CFD code, which uses wall functions.

The instability boundaries of the nine experimental cases predicted by the 1-D non-linear SPORTS code are listed in Table 5.6. The experimental power was also used to obtain the flow rates at the instability boundary.

Table 5.6: Threshold mass flow rates of nine experimental cases predicted by the 1-D non-linear SPORTS code

\begin{tabular}{|c|c|}
\hline Case & $\dot{m}_{\text {thold,1D }}(\mathrm{kg} / \mathrm{s})$ \\
\hline 1 & 0.0338 \\
\hline 2 & 0.0342 \\
\hline 3 & 0.0354 \\
\hline 4 & 0.0342 \\
\hline 5 & 0.0349 \\
\hline 6 & 0.0356 \\
\hline 7 & 0.0346 \\
\hline 8 & 0.0358 \\
\hline 9 & 0.0367 \\
\hline
\end{tabular}

\subsection{Comparisons between Numerical Simulations and the Experiment}

For Xiong's flow instability experiment of two heated parallel channels with supercritical water flowing upward, Xiong et al. (2013) presented a 1-D numerical simulation and Xi et al. (2014) presented a 3-D numerical simulation. In those studies, the total mass flow rate was held constant and the total channel heating power was varied until the threshold power was found. In this study, on the other hand, the heating power was kept constant at 
the experimental value and the total mass flow rate was varied until the threshold mass flow rate was determined. It was found that both approaches give exactly the same answer if the results are transformed into the non-dimensional parameter of Ambrosini and Sharabi (2008), $N_{T P C}$, which is calculated as follows:

$N_{T P C}=\frac{Q}{\dot{m}} \frac{\beta_{P C}}{C_{P, P C}}$

where $Q$ is the total heating power, $\dot{m}$ is the total mass flow rate, $\beta_{P C}$ and $C_{P, P C}$ are the isobaric thermal expansion and specific heat at constant pressure at the pseudo-critical point, respectively.

Table 5.7 presents the comparisons of $N_{T P C}$ values between the calculated results and Xiong's experimental results. The values in parenthesis are the deviations relative to the corresponding experimental results. Root mean square (RMS) error of each numerical simulation is also calculated.

Table 5.7: $N_{T P C}$ comparisons between numerical simulations and experimental results

\begin{tabular}{|c|c|c|c|c|c|}
\hline Case & $\exp$ & 1D-Xiong & CFX-Xi & 1D-SPORTS & $\begin{array}{c}\text { CFX-present } \\
\text { study }\end{array}$ \\
\hline 1 & 3.5476 & $3.4326(-3.24 \%)$ & $3.6468(2.80 \%)$ & $3.5895(1.18 \%)$ & $3.5580(0.29 \%)$ \\
\hline 2 & 3.5415 & $3.3108(-6.52 \%)$ & $3.6434(2.88 \%)$ & $3.4483(-2.63 \%)$ & $3.3986(-4.03 \%)$ \\
\hline 3 & 3.5200 & $3.1659(-10.06 \%)$ & $3.4878(-0.91 \%)$ & $3.3112(-5.93 \%)$ & $3.2560(-7.50 \%)$ \\
\hline 4 & 3.4992 & $3.2746(-6.42 \%)$ & $3.3947(-2.99 \%)$ & $3.4071(-2.63 \%)$ & $3.3971(-2.92 \%)$ \\
\hline 5 & 3.4469 & $3.1492(-8.64 \%)$ & $3.2798(-4.85 \%)$ & $3.2889(-4.58 \%)$ & $3.2516(-5.67 \%)$ \\
\hline 6 & 3.3942 & $3.0001(-11.61 \%)$ & $3.1472(-7.28 \%)$ & $3.1558(-7.02 \%)$ & $3.0612(-9.81 \%)$ \\
\hline 7 & 3.5379 & $3.2010(-9.52 \%)$ & $3.3490(-5.34 \%)$ & $3.3539(-5.20 \%)$ & $3.3250(-6.02 \%)$ \\
\hline 8 & 3.4647 & $3.0775(-11.18 \%)$ & $3.1982(-7.69 \%)$ & $3.2227(-6.98 \%)$ & $3.1609(-8.77 \%)$ \\
\hline 9 & 3.3540 & $2.9539(-11.93 \%)$ & $3.0428(-9.28 \%)$ & $3.0981(-7.63 \%)$ & $2.9842(-11.02 \%)$ \\
\hline RMS & & $9.21 \%$ & $5.54 \%$ & $5.32 \%$ & $7.02 \%$ \\
\hline
\end{tabular}


Six main conclusions are drawn from Table 5.7. Firstly, compared with the experiment, the RMS error of present CFX numerical study over nine experimental cases is $7.02 \%$, while normally the experimental uncertainty itself is expected to be at least $\pm 10 \%$. Hence, the numerical results of this study, predicted by the ANSYS CFX 15.0 and 16.2 codes, are considered to be within the experimental uncertainty and agree well with Xiong's experimental results.

Secondly, if we rank numerical simulation results listed in Table 5.7 by the overall RMS error, the 1-D non-linear SPORTS code has the lowest RMS error, followed by the 3-D CFX simulations conducted by Xi et al. (2014), the 3-D CFX results of present study, and then the 1-D in-house code studies by Xiong et al. (2013).

Thirdly, in terms of each experimental case, the 1-D code results of Xiong et al. (2013) deviate most from the experiment. This deviation is believed to be caused by the pressure boundary condition they imposed at the inlet and outlet of the channels. They imposed equal static pressure at the channel inlet and outlet, whereas the SPORTS code imposed equal stagnation pressure at the channel inlet and outlet. The latter is believed to be more accurate.

Fourthly, certain differences can be noticed between the present CFX results and those of Xi et al. (2014). Four possible reasons are proposed:

\section{- Different time step}

The 3-D CFX-Xi results were obtained using a time step of $0.1 \mathrm{~s}$, whereas a time step of $0.02 \mathrm{~s}$ was applied in the present study. As the temporal resolution independence study in the section 5.3 revealed, the CFX code showed a high sensitivity to the time 
step size used, and 0.1s was deemed too large a time step for accurate instability analyses. Furthermore, the large time step $0.1 \mathrm{~s}$ would predict a more stable system, leading to a larger $N_{T P C}$ value at the instability boundary. Comparing the $N_{T P C}$ value between CFX-Xi and CFX-present study in Table 5.7, eight out of nine cases, the CFX-Xi results have a relatively larger $N_{T P C}$ value. Therefore, although the CFX-Xi results appear to be closer to the experiment, it seems likely that their numerical results are not properly temporally converged.

\section{- Different mesh}

The mesh adopted in the CFX-Xi study was 300,000 nodes for the whole geometry, whereas the final mesh chosen in this study was 440,576 nodes for half of the geometry, which is equivalent to 881,152 nodes for the whole geometry. Although insignificant grid size refinement effects on the instability boundary were observed in the spatial resolution independence study (section 5.2), this difference in mesh refinement may have caused some differences in the results.

\section{- Different convergence criteria}

Both CFX simulations solve the governing equations based on the conservation of them. When Xi et al. (2014) carried out the numerical simulation, they thought that the calculation was converged when the residual of each discretized equations was less than $1 \times 10^{-4}$. Whereas, in the present study, converged results were considered to be obtained when the maximum residual reached $1 \times 10^{-6}$. This difference in convergence criteria may be a possible source of discrepancies on the instability results, but this factor was not explored in this work. 
- Different simplified geometrical model

The geometrical model used in present numerical simulation was already depicted in Figure 4.1. The geometrical model used by Xi et al. (2014) is slightly different, as shown in Figure 5.4. They replaced the entrance and riser sections with inlet and outlet diffusers, respectively. This different way to simplify the geometrical model may have caused certain differences in the results.

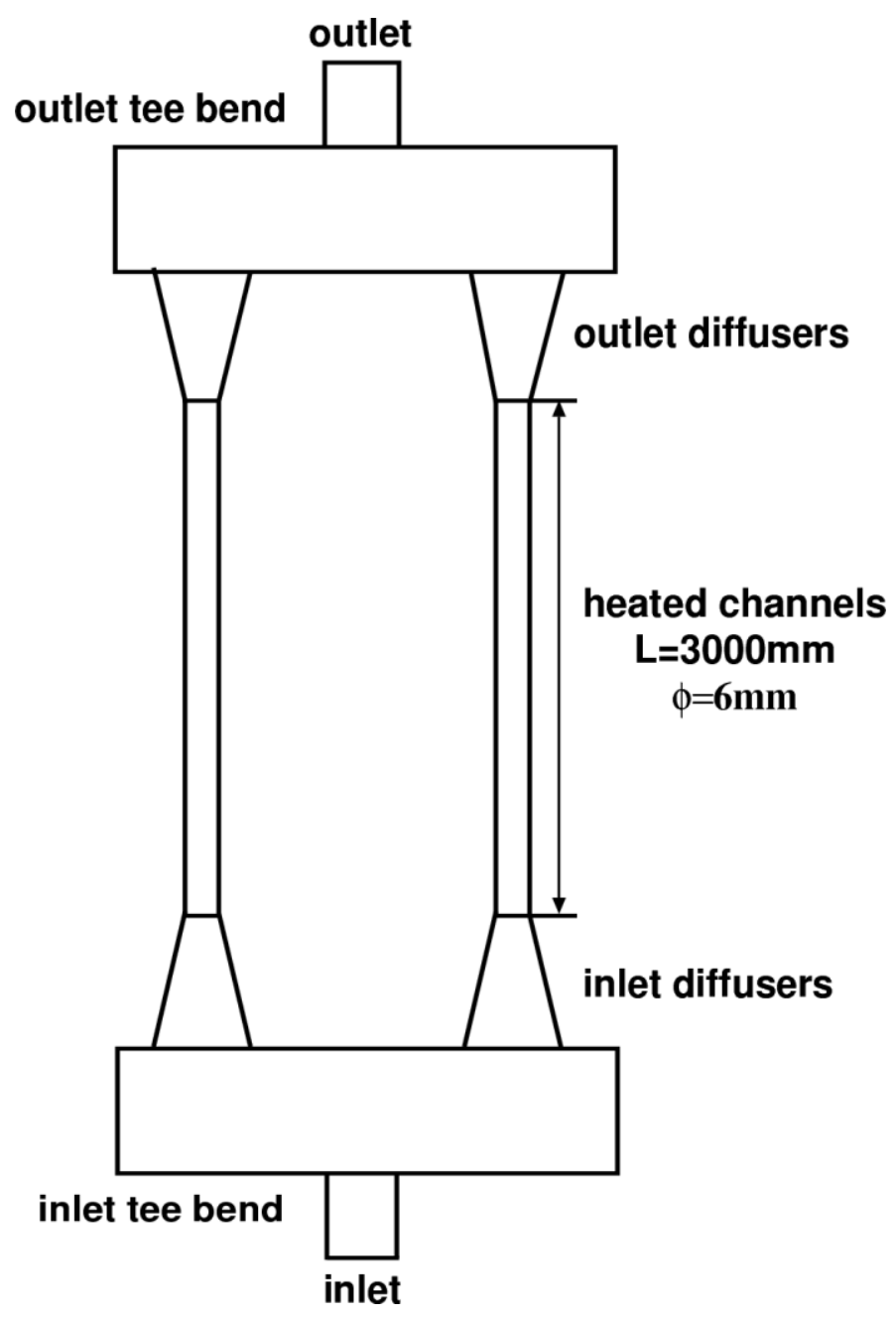

Figure 5.4: Geometrical model used in Xi's simulation

Fifthly, the discrepancies between the 1-D SPORTS predictions and the 3-D CFX predictions in the present study are thought to be due to two reasons. The first reason is a 
difference in the outlet boundary condition; at the inlet, both codes specified the inlet total mass flow rate. The 1-D SPORTS code specified the outlet total pressure to ensure that the two parallel channels have equal total pressure drop. The 3-D CFX code specified the outlet static pressure to be constant because it is currently not possible to specify outlet total pressure in CFX. This difference in the outlet pressure boundary condition is thought to be the key reason for the differences between 1-D SPORTS results and present 3-D CFX results. This theory is also supported by the differences between the 1-D SPORTS results and the 1-D results of Xiong et al. (2013), which were related to the same difference in the outlet pressure boundary condition, as previously mentioned. If the outlet total pressure could be specified in CFX, it is thought that the differences between 1-D SPORTS predictions and present 3-D CFX results would be reduced and that perhaps the 3-D CFX code might predict the experimental results better than 1-D code; this needs to be investigated. The second reason is the different way of calculating the frictional pressure drop, as mentioned in section 5.5.

Lastly, regarding the comparison of 1-D and 3-D CFX results, the present study leads to a different conclusion than the one stated by Xi et al. (2014). They stated that their 3-D CFX predictions of the actual experiments were better than the 1-D predictions. This statement is disputable because, as already stated in the third and fourth conclusions, the 1-D results of Xiong et al. (2013) were in error due to using equal static pressure at the channels entrance and exit, as opposed to equal stagnation pressure, and the CFX results of Xi et al. (2014) were not properly temporally converged. The present study found that the 1-D SPORTS predictions had a smaller RMS error than the CFX-present results. Therefore, it appears that the 1-D results are better than the 3-D CFX results. This cannot 
be known for sure until 3-D CFX results can be obtained using a total outlet pressure boundary condition specification.

\subsection{Sensitivity Studies}

In this section, the effect on the instability boundary prediction of changing a key problem geometric quantity (outlet plenum volume), key problem parameters (turbulent Prandtl number, inlet turbulence intensity with eddy viscosity ratio and outlet $\mathrm{K}$ factor) and solution parameters (maximum iterations per time step and transient scheme) are examined to test the CFX code sensitivity, and also to verify the reliability of the predicted results in this study. Unless otherwise stated, these runs in this section used a turbulent Prandtl number of 0.95 , an inlet turbulence intensity of 5\% with the eddy viscosity ratio of 10, 30 maximum iterations per time step, the First Order Backward Euler scheme, mesh 2 and a time step size of $0.02 \mathrm{~s}$.

\subsubsection{Effect of Changing the Outlet Plenum Volume}

In the physical model, there are inlet and outlet plena. The fluid flowing into the inlet plenum is uniform. And, due to the adiabatic wall boundary conditions in the inlet plenum, fluid physical properties are constant throughout. On the other hand, the fluid flowing into the outlet plenum is supercritical water after being heated and the water properties may experience sharp changes. As a result, the volume size of the outlet plenum may influence the expansion or spread of the flow coming out from the channels. Therefore, the size of the outlet plenum may influence the stability prediction more than the size of the inlet plenum. Usually plenum sizes are designed large enough so that plenum effects on the instability analyses are negligible. In this study, the length, height 
and width of both plena were taken as $430 \mathrm{~mm}, 23 \mathrm{~mm}$ and $10 \mathrm{~mm}$, respectively. To establish if this outlet plenum size was sufficiently large, another outlet plenum with a volume ten times larger than the present outlet plenum was tested.

For the dimensions of the larger outlet plenum, its length and width are same as those of the original outlet plenum, respectively. Whereas, its height is ten times greater than that of the original outlet plenum.

Table 5.8 presents the instability boundaries predicted by the CFX code for Cases 1 and 3 with the two different outlet plenum volumes. The small outlet plenum and large outlet plenum in this table refer to the original outlet plenum used in this study and the larger outlet plenum mentioned above, respectively. The relative discrepancies in this table are calculated by comparing the larger outlet plenum results to the small outlet plenum results.

Table 5.8: Comparisons of threshold mass flow rates obtained with two different outlet plena volumes for Case 1 and Case 3

\begin{tabular}{|c|c|c|}
\hline outlet plenum size & $\dot{m}_{\text {thold,CFX }}$ for Case 1 (kg/s) & $\dot{m}_{\text {thold,CFX }}$ for Case 3 (kg/s) \\
\hline small outlet plenum & 0.0341 & 0.0360 \\
\hline large outlet plenum & 0.0342 & 0.0363 \\
\hline discrepancy & $0.29 \%$ & $0.83 \%$ \\
\hline
\end{tabular}


Table 5.8 reveals that, although the large outlet plenum predicts a relatively higher threshold mass flow rate (a more unstable system) for both cases, the discrepancy caused by enlarging the outlet plenum volume by 10 times is slight $(<1 \%)$. Therefore, in this outlet plenum volume test, insignificant effects on flow instability boundaries are observed.

To explore the possible reasons of the above results, the velocity field in the outlet plenum and the area-averaged total pressure drop from the steady-state results for each channel were examined at a total mass flow rate of $0.0340 \mathrm{~kg} / \mathrm{s}$ for Case 1.

Figure 5.5 illustrates the velocity field contours on the symmetry plane in the two outlet plena. In Figure 5.5, the velocity fields out of both channels are partially magnified to show them clearly. It can be noticed from the above figure that, the flow issuing from the channel behaves like a jet. For the small outlet plenum, the velocity impacts the top surface of the outlet plenum directly, as shown in Figure 5.5 (a). For the large outlet plenum, the velocity impact problem is avoided for the velocity spreads and reduces significantly before touching the top surface of the outlet plenum, as shown in Figure 5.5 (b). 


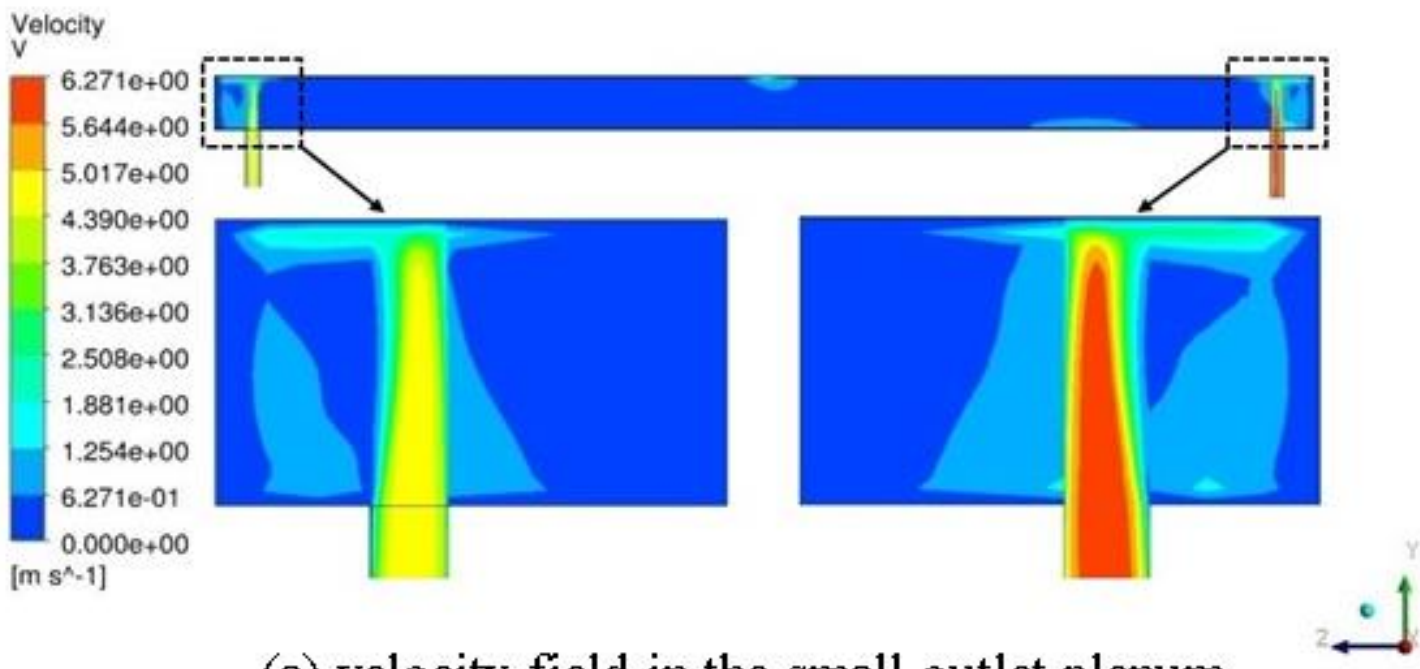

(a) velocity field in the small outlet plenum

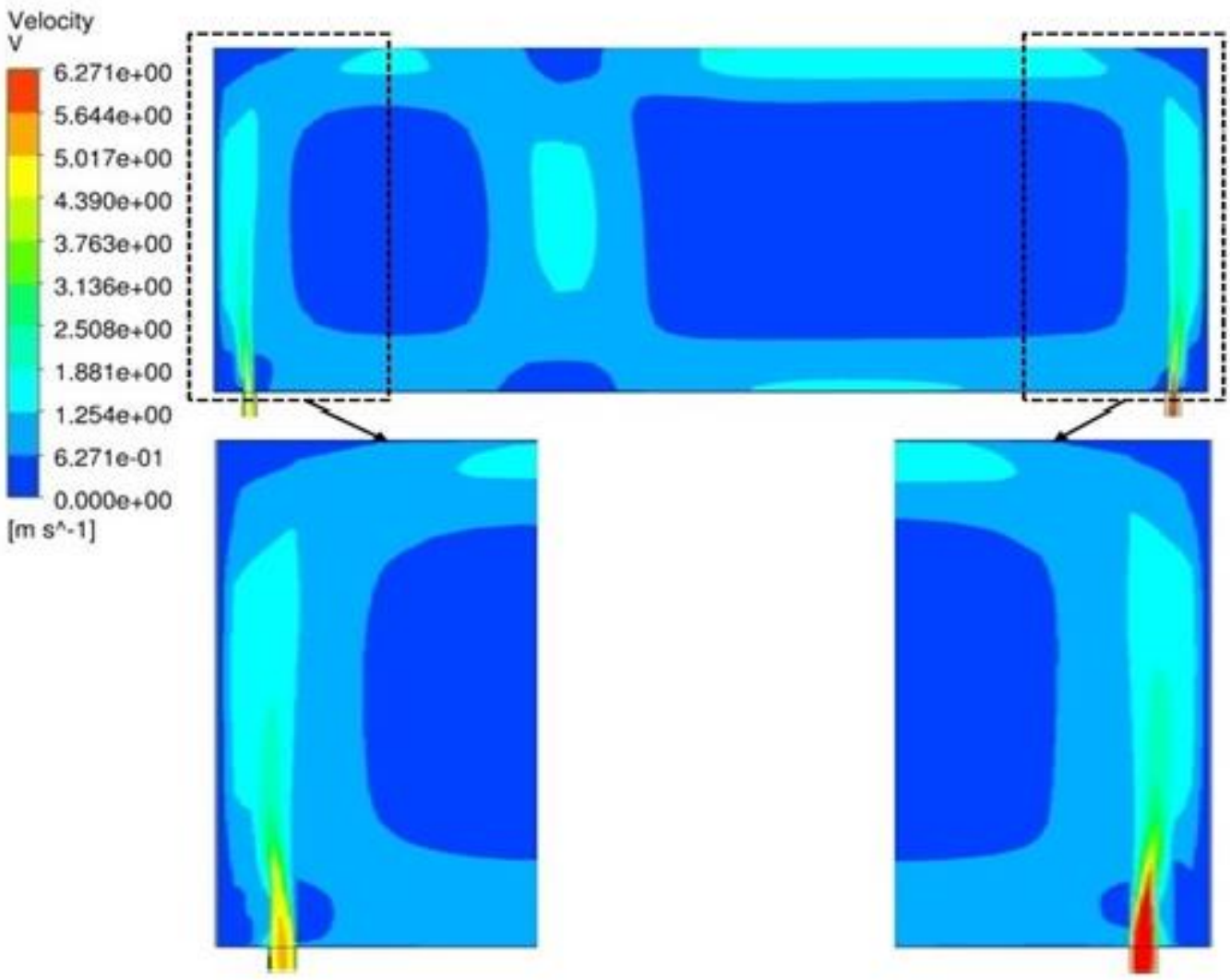

(b) velocity field in the large outlet plenum

Figure 5.5: Comparisons of velocity field obtained with two outlet plena at a same total mass flow rate of $0.0340 \mathrm{~kg} / \mathrm{s}$ for Case 1 (outlets of two channels were magnified) 
Nevertheless, despite of the velocity field difference between these two outlet plena, the difference of total pressure drop in each channel was found to be negligible, as summarized in Table 5.9. The oscillatory instability is mainly influenced by the change of total pressure drop in the channels; therefore, the instability thresholds of the cases studied will vary slightly because of the slight change of the channel total pressure drop caused by the variation of outlet plenum volumes. This is in agreement with the conclusion drawn from Table 5.8.

Table 5.9: Comparisons of total pressure drops in two channels obtained with two outlet plena at a same total mass flow rate of $0.0340 \mathrm{~kg} / \mathrm{s}$ for Case 1

\begin{tabular}{|c|c|c|}
\hline & $\Delta \mathrm{P}_{\text {tot, } 1}(\mathrm{~Pa})$ & $\Delta \mathrm{P}_{\text {tot, }}(\mathrm{Pa})$ \\
\hline small outlet plenum & 15429.6 & 15290.6 \\
\hline large outlet plenum & 15381.7 & 15246.4 \\
\hline difference & $-0.31 \%$ & $-0.29 \%$ \\
\hline
\end{tabular}

\subsubsection{Effect of Changing the Turbulent Prandtl Number}

The turbulent Prandtl number $\left(\operatorname{Pr}_{t}\right)$, the ratio of the momentum eddy diffusivity to the heat transfer eddy diffusivity, has a significant influence on the heat transfer of turbulent boundary layer flows. For equivalent turbulent mixing effects on momentum and heat transfer, $P r_{t}$ will have a value of unity. However, $P r_{t}$ generally ranges from 0.7 to 0.9 (or with an average value of 0.85 ) in most actual experiments. The CFX code implements a default value of 0.9 for $\operatorname{Pr}_{t}$. Ebrahimnia (2014) found that a $\operatorname{Pr}_{t}$ value of 0.95 was most 
appropriate for upward supercritical water flow in a pipe, so that value was used in this study to obtain the stability boundary mass flow rates given in Table 5.7.

In this section, to establish the sensitivity of the predictions of the instability threshold for this problem to the changes in the turbulent Prandtl number, two additional values of $P r_{t}$ (1.05 and 0.85) were used for Case 3 and a total mass flow rate of $0.0360 \mathrm{~kg} / \mathrm{s}$.

Because the turbulent Prandtl number affects heat transfer characteristics of turbulent flows, the wall temperature of channels will vary with the change of $\operatorname{Pr}_{t}$. Figure 5.6 is an example of the averaged axial wall temperature variations with the change of $P r_{t}$ for channel 1. Wall heat flux is applied from $y / L=0.06$ to 0.9 . The pseudocritical temperature for case 3 at $23 \mathrm{MPa}$ is $650.65 \mathrm{~K}$. The wall temperature reaches the pseudocritical temperature at about $\mathrm{y} / \mathrm{L}=0.3$, whereas the bulk fluid temperature reaches the pseudocritical temperature at about $\mathrm{y} / \mathrm{L}=0.4$ where the wall temperature is about $670 \mathrm{~K}$. When the bulk temperature approaches the pseudocritical temperature at $y / L=0.4$, the sharp increase in specific heat and decrease in the viscosity can cause an improvement in the heat transfer coefficient and, hence, enhance the heat transfer and reduce the wall temperature. However, as the wall heat flux input increases, the near-wall fluid temperature will go beyond the pseudocritical temperature. As a result, the near-wall region is mainly occupied by low-density fluid and the high-specific-heat region moves away from the wall, leading to the impairment of heat transfer coefficients. With the further increase of wall heat flux, the heat transfer deterioration occurs and the wall temperature goes up. These phenomena can be seen in Figure 5.6. 


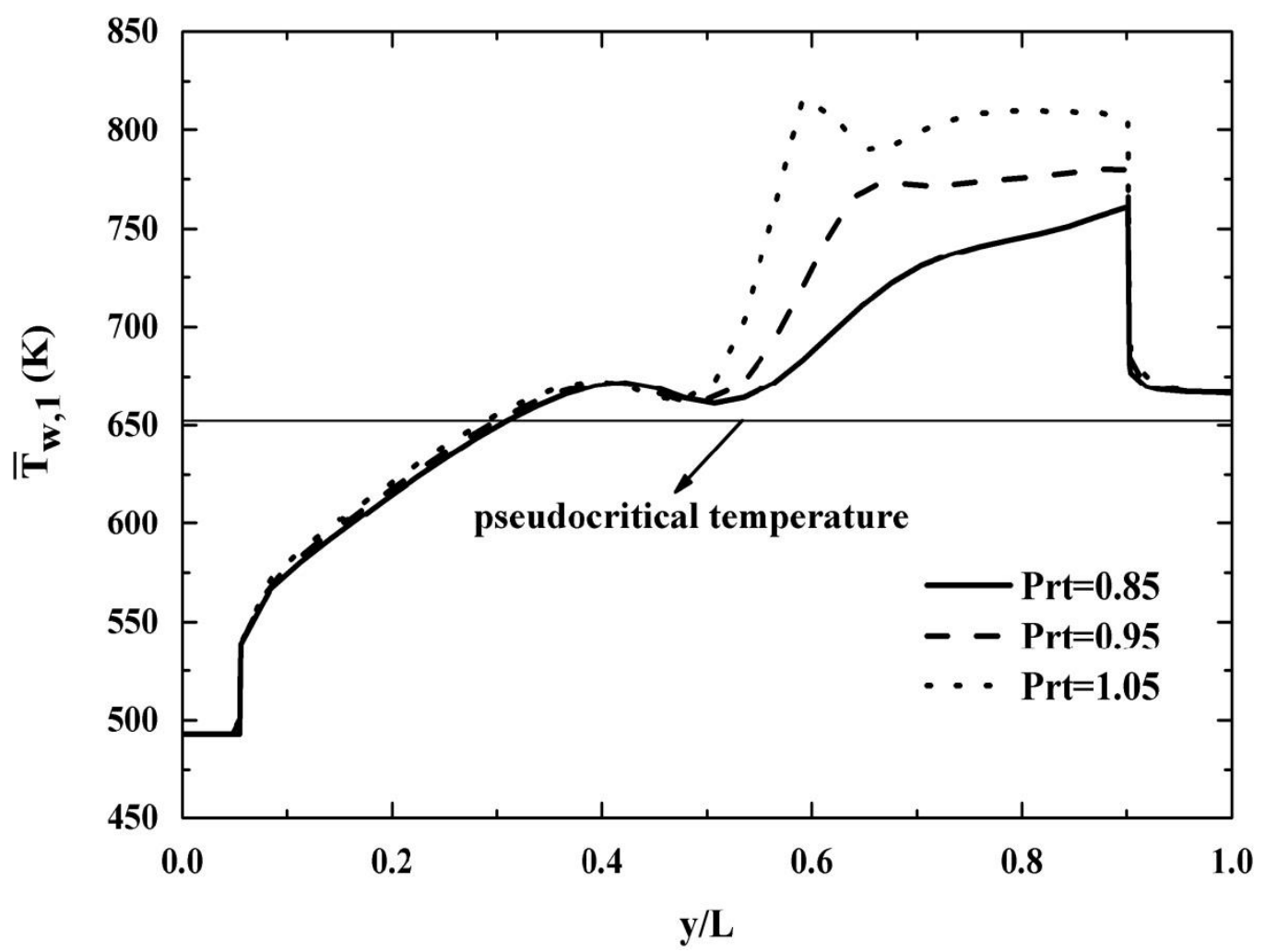

Figure 5.6: Channel 1 average wall temperature variations with different Prt values for Case 3 at a total mass flow rate of $0.0360 \mathrm{~kg} / \mathrm{s}$

In addition, as shown in Figure 5.6, increasing $P r_{t}$ raises the wall temperature. The reason is that, at the wall, energy is transported to the fluid only by the conduction. Therefore, we can write:

$q_{w}^{\prime \prime}=-\left.\lambda_{t} \frac{\partial T}{\partial n}\right|_{w a l l}$

where $q_{w}^{\prime \prime}$ is the wall heat flux, $\lambda_{t}$ is the turbulent thermal conductivity and $\left.\frac{\partial T}{\partial n}\right|_{\text {wall }}$ is the wall temperature gradient.

Using the definition of $P r_{t}$,

$\lambda_{t}=\frac{\mu_{t} C_{P}}{P r_{t}}$ 
where $\mu_{t}$ is the eddy viscosity and $C_{P}$ is the specific heat capacity at constant pressure.

and the wall temperature gradient can be written as:

$\left.\frac{\partial T}{\partial n}\right|_{w a l l}=-\frac{q_{w}^{\prime \prime} P r_{t}}{\mu_{t} C_{P}}$

For fixed $q_{w}^{\prime \prime}, \mu_{t}$ and $C_{P}$, increasing $P r_{t}$ will increase $\left.\frac{\partial T}{\partial n}\right|_{w a l l}$, which will increase the wall temperature relative to the fluid temperature adjacent to the wall. This increase in wall temperature is interpreted as a deterioration of the effective heat transfer from the wall to the fluid.

The wall temperature differences among different $P r_{t}$ values are small before $\mathrm{y} / \mathrm{L}=0.5$, and are significant in the heat transfer deterioration region with a maximum difference of 100 K. Furthermore, a larger $\operatorname{Pr}_{t}$ has a higher peak wall temperature, hence, the increase in $\mathrm{Pr}_{t}$ increases the magnitude of heat transfer deterioration.

Despite of the wall temperature variations, it was noted before that the change of total pressure drops in the channels play a more important role on stability analyses. Table 5.9 compares the area-averaged total pressure drop from the steady-state in each channel among three different $P r_{t}$ values, which were obtained at a total mass flow rate of 0.0360 $\mathrm{kg} / \mathrm{s}$ and under Case 3 flow conditions. In this table, differences are relative to the results at $\operatorname{Pr}_{t}=0.95$.

Table 5.10 indicates that the total pressure drops in both channels decrease with the increase in the Prt values. The differences in pressure drop caused by the variation of Prt, however, are not significant, as they are all less than $2 \%$. Therefore, the onset of Case 3 instability should also not be influenced by the variation of Prt within the tested range. 
Table 5.10: Comparison of total pressure drops in two channels with different Prt values for Case 3 (total mass flow rate: $0.0360 \mathrm{~kg} / \mathrm{s}$ )

\begin{tabular}{|c|c|c|c|c|c|c|}
\hline & $P r_{t}=1.05$ & difference & $P r_{t}=0.95$ & difference & $P r_{t}=0.85$ & difference \\
\hline$\Delta \mathrm{P}_{\mathrm{tot}, 1}(\mathrm{~Pa})$ & 16073.4 & $-0.96 \%$ & 16228.5 & - & 16523.0 & $1.81 \%$ \\
\hline$\Delta \mathrm{P}_{\mathrm{tot}, 2}(\mathrm{~Pa})$ & 16035.8 & $-1.26 \%$ & 16240.2 & - & 16539.2 & $1.84 \%$ \\
\hline
\end{tabular}

The threshold mass flow rate of Case 3 with different $\operatorname{Pr}_{t}$ values are also located and compared, see Table 5.11 below.

Table 5.11: Comparisons of Case 3 instability boundaries obtained with three different Prt values

\begin{tabular}{|c|c|c|}
\hline$P r_{t}$ number & $\dot{m}_{\text {thold,CFX }}$ for Case $3(\mathrm{~kg} / \mathrm{s})$ & deviation \\
\hline 1.05 & 0.0361 & $0.28 \%$ \\
\hline 0.95 & 0.0360 & - \\
\hline 0.85 & 0.0362 & $0.56 \%$ \\
\hline
\end{tabular}

Consistent with the total pressure drop deduction from Table 5.10, the variation of $\operatorname{Pr}_{t}$ has only a small effect on the flow instability boundary within the range tested in this section. Both deviations are much less than $1 \%$. Thus, the $\operatorname{Pr}_{t}$ value of 0.95 applied throughout this study is assumed to be reasonable.

\subsubsection{Effect of Changing the Turbulence Inlet Conditions}

When setting boundary conditions for a CFD simulation, it is necessary to estimate the turbulence inlet conditions. In CFX, there are different options available to specify the 
inlet turbulence characteristics. In this study, the method used was specifying inlet turbulence intensity $(I)$ and the eddy viscosity ratio $\left(\frac{\mu_{t}}{\mu}\right)$.

The turbulence intensity, $I$, is defined as the ratio between the root-mean-square of turbulent velocity fluctuations, $u^{\prime}$, and the mean flow velocity, $U$. The intensity of turbulence affects the kinetic energy strength of the turbulence. Because the actual turbulence intensity of Xiong's experiment (Xiong et al., 2012) is unknown, an estimate of medium intensity with $I=5 \%$ and $\frac{\mu_{t}}{\mu}=10$ was used throughout this study. However, to examine the appropriateness of this medium intensity in predicting the instability thresholds, predictions with two other turbulence inlet conditions $\left(I=2.5 \%\right.$ with $\frac{\mu_{t}}{\mu}=5$ and $I=10 \%$ with $\left.\frac{\mu_{t}}{\mu}=100\right)$ were obtained and compared.

Because the change of channel total pressure drop mainly affects the onset of flow instability, the variation of area-averaged total pressure drop across the two channels was examined for the steady-state results of Case 3 at a total mass flow rate of $0.0360 \mathrm{~kg} / \mathrm{s}$ and under three different turbulence inlet conditions. These results are summarized in Table 5.12.

In Table 5.12, the differences are calculated by comparing with the results obtained at $I=$ $5 \%$ and $\frac{\mu_{t}}{\mu}=10$. It can be noted from this table that the total pressure drop at different turbulence intensities for each channel is hard to distinguish from each other. Therefore, within the tested range, the turbulence intensity variation effects on flow instability are negligible. 
Table 5.12: Comparisons of total pressure drops in two channels with different turbulence intensities for Case 3 (total mass flow rate: $0.0360 \mathrm{~kg} / \mathrm{s}$ )

\begin{tabular}{|c|c|c|c|c|c|c|}
\hline & $\begin{array}{c}I=10 \% \\
\frac{\mu_{t}}{\mu}=100\end{array}$ & $\begin{array}{c}\text { difference } \\
(\%)\end{array}$ & $\begin{array}{c}I=5 \% \\
\frac{\mu_{t}}{\mu}=10\end{array}$ & $\begin{array}{c}\text { difference } \\
(\%)\end{array}$ & $\begin{array}{c}I=2.5 \% \\
\frac{\mu_{t}}{\mu}=5\end{array}$ & $\begin{array}{c}\text { difference } \\
(\%)\end{array}$ \\
\hline$\Delta \mathrm{P}_{\text {tot, } 1}(\mathrm{~Pa})$ & 16228.4 & $-6 \times 10^{-4}$ & 16228.5 & - & 16228.2 & $-2 \times 10^{-3}$ \\
\hline$\Delta \mathrm{P}_{\text {tot }, 2}(\mathrm{~Pa})$ & 16241.3 & $7 \times 10^{-3}$ & 16240.2 & - & 16239.0 & $-7 \times 10^{-3}$ \\
\hline
\end{tabular}

To further verify the above conclusion from Table 5.12, the threshold mass flow rates of Case 3 by varying the turbulence intensity and eddy viscosity ratio are obtained and listed in Table 5.13. All of the discrepancies in this table are compared with the results for $I=5 \%$ and $\frac{\mu_{t}}{\mu}=10$. The variation of turbulence inlet conditions does not influence Case 3 instability threshold significantly, for only deviations of $0.28 \%$ were observed when $I$ was changed from $5 \%$ to $2.5 \%$ and $5 \%$ to $10 \%$. Hence, the medium intensity with $I=5 \%$ and $\frac{\mu_{t}}{\mu}=10$ is reasonable for predicting the onset of flow instability in this study.

Table 5.13: Comparison of Case 3 instability boundaries obtained with different turbulence inlet conditions

\begin{tabular}{|c|c|c|}
\hline turbulence inlet conditions & $\dot{m}_{\text {thold,CFX }}$ for Case 3 (kg/s) & discrepancy \\
\hline$I=2.5 \% \& \frac{\mu_{t}}{\mu}=5$ & 0.0361 & $0.28 \%$ \\
\hline$I=5 \% \& \frac{\mu_{t}}{\mu}=10$ & 0.0360 & - \\
\hline$I=10 \% \& \frac{\mu_{t}}{\mu}=100$ & 0.0361 & $0.28 \%$ \\
\hline
\end{tabular}




\subsubsection{Effect of Changing the Outlet K Factor}

Both inlet and outlet pressure drop coefficients ( $\mathrm{K}$ factors) influence the onset of supercritical flow instability. An increase in the inlet $\mathrm{K}$ factor causes an increase in the pressure drop on the cold fluid side (high density region), making the system more stable such that the instability happens at a lower mass flow rate than before at a given power. An increase in the outlet $\mathrm{K}$ factor, however, makes the system more unstable.

The fluid flowing through the channel inlet orifice is single-phase liquid because the wall heat flux has not been applied. The fluid flowing through the channel outlet orifice, on the other hand, is supercritical water after being heated. Therefore, when $\mathrm{K}$ factors are calculated from pressure drop measurements (as described in section 4.1), it is thought that there is a higher degree of uncertainty in determining the outlet $\mathrm{K}$ factor than in determining the inlet $\mathrm{K}$ factor. To examine the $\mathrm{K}$ factor sensitivity on the instability thresholds, the outlet $\mathrm{K}$ factors of both channels were selected because of the expected higher degree of uncertainty associated with them. When carrying out this sensitivity study, only one parameter was varied at a time. For example, for the $\mathrm{K}_{\mathrm{out}, 1}$ (outlet $\mathrm{K}$ factor of channel 1) sensitivity test, except for $K_{\text {out, },}$, other pressure drop coefficients including $\mathrm{K}_{\mathrm{in}, 1}, \mathrm{~K}_{\mathrm{in}, 2}$ and $\mathrm{K}_{\mathrm{out}, 2}$ were fixed. And, to observe the variation trend of the instability thresholds by changing the $\mathrm{K}_{\text {out }}$, a variation of $5 \%$ to the experimental $\mathrm{K}_{\text {out }}$ value was applied for this outlet $\mathrm{K}$ factor sensitivity test.

Tables 5.14 and 5.15 present the instability boundaries for Case 3 obtained by separately varying the outlet $\mathrm{K}$ factor in each of the two channels. As revealed by Table 5.14, increasing or decreasing $\mathrm{K}_{\mathrm{out}, 1}$ by $5 \%$ causes very little change in the instability boundary. 
The differences are less than one mass flow rate decrement or increment $(0.0002 \mathrm{~kg} / \mathrm{s})$; this is within the numerical uncertainty. Because the value of $\mathrm{K}_{\text {out,2 }}(6.46)$ is larger than $\mathrm{K}_{\mathrm{out}, 1}$ value (4.93), the $5 \%$ variation of $\mathrm{K}_{\mathrm{out}, 2}$ is also accordingly larger than that of $\mathrm{K}_{\mathrm{out}, 1}$. The deviation in the instability boundary caused by the change of $\mathrm{K}_{\mathrm{out}, 2}$ is greater than that for the change in $\mathrm{K}_{\mathrm{out}, 1}$. Table 5.15 shows that those deviations are $1.39 \%$ and $-0.83 \%$ for the increase and decrease of $\mathrm{K}_{\mathrm{out}, 2}$, respectively. All changes in Tables 5.14 and 5.15 are within $2 \%$. Hence, varying the outlet $\mathrm{K}$ factor by $5 \%$ does not have a dramatic effect on the instability boundary in this case.

Table 5.14: Comparisons of Case 3 instability boundaries obtained with different outlet $\mathrm{K}$ factors in channel 1

\begin{tabular}{|c|c|c|}
\hline $\mathrm{K}_{\text {out }, 1}$ & $\dot{m}_{\text {thold }, C F X}$ for Case $3(\mathrm{~kg} / \mathrm{s})$ & discrepancy \\
\hline 4.684 (5\% smaller) & 0.0361 & $0.28 \%$ \\
\hline 4.930 (experiment) & 0.0360 & - \\
\hline 5.177 (5\% larger) & 0.0361 & $0.28 \%$ \\
\hline
\end{tabular}

Table 5.15: Comparisons of Case 3 instability boundaries obtained with different outlet $\mathrm{K}$ factors in channel 2

\begin{tabular}{|c|c|c|}
\hline $\mathrm{K}_{\text {out }, 2}$ & $\dot{m}_{\text {thold,CFX }}$ for Case 3 $(\mathrm{kg} / \mathrm{s})$ & discrepancy \\
\hline 6.137 (5\% smaller) & 0.0357 & $-0.83 \%$ \\
\hline 6.460 (experiment) & 0.0360 & - \\
\hline 6.783 (5\% larger) & 0.0365 & $1.39 \%$ \\
\hline
\end{tabular}

\subsubsection{Effect of Changing the Maximum Iterations per Time Step}

For transient analyses, the CFX-Solver performs a number of solutions of the linearized set of equations at each time step. These solutions are usually referred to as coefficient 
iterations and can be controlled using either a specified maximum number or a predefined residual target level. In this study, the maximum number of iterations per time step was specified. The CFX code implements a default value of maximum 10 iterations at each time step.

In this section, to investigate the effect of the maximum number of iterations per time step on the flow instability analyses, four maximum iterations per time step (10, 20, 30, and 40) were tested under Case 3 flow conditions. Transient computations at each time step will terminate after the maximum number of iterations; however, the maximum value is not always reached if the residual tolerance is achieved first.

At the same total mass flow rate, transient responses of normalized channel 1 inlet mass flow rate were plotted together for comparison, as illustrated in Figure 5.7. Figure 5.7 demonstrates that the maximum number of iterations per time step for transient simulations has a noticeable influence on the transient responses of mass flow rate. At the same total mass flow rate $0.0360 \mathrm{~kg} / \mathrm{s}$ for Case 3 , the maximum 10 iterations per time step results predicts a converging channel 1 inlet mass flow rate: a stable case. The oscillation amplitude of channel 1 inlet mass flow rate diverges (an unstable case), however, when the maximum 20 iterations per time step is used. For the maximum 30 and 40 iterations per time step runs, the transient responses of the channel 1 inlet mass flow rate agree well; both are nearly constant in amplitude with time. Therefore, when the maximum number of coefficient iterations reaches 30 , converged results are achieved. To improve accuracy of results as well as save computational costs, maximum 30 coefficient iterations per time step were performed throughout this study. 


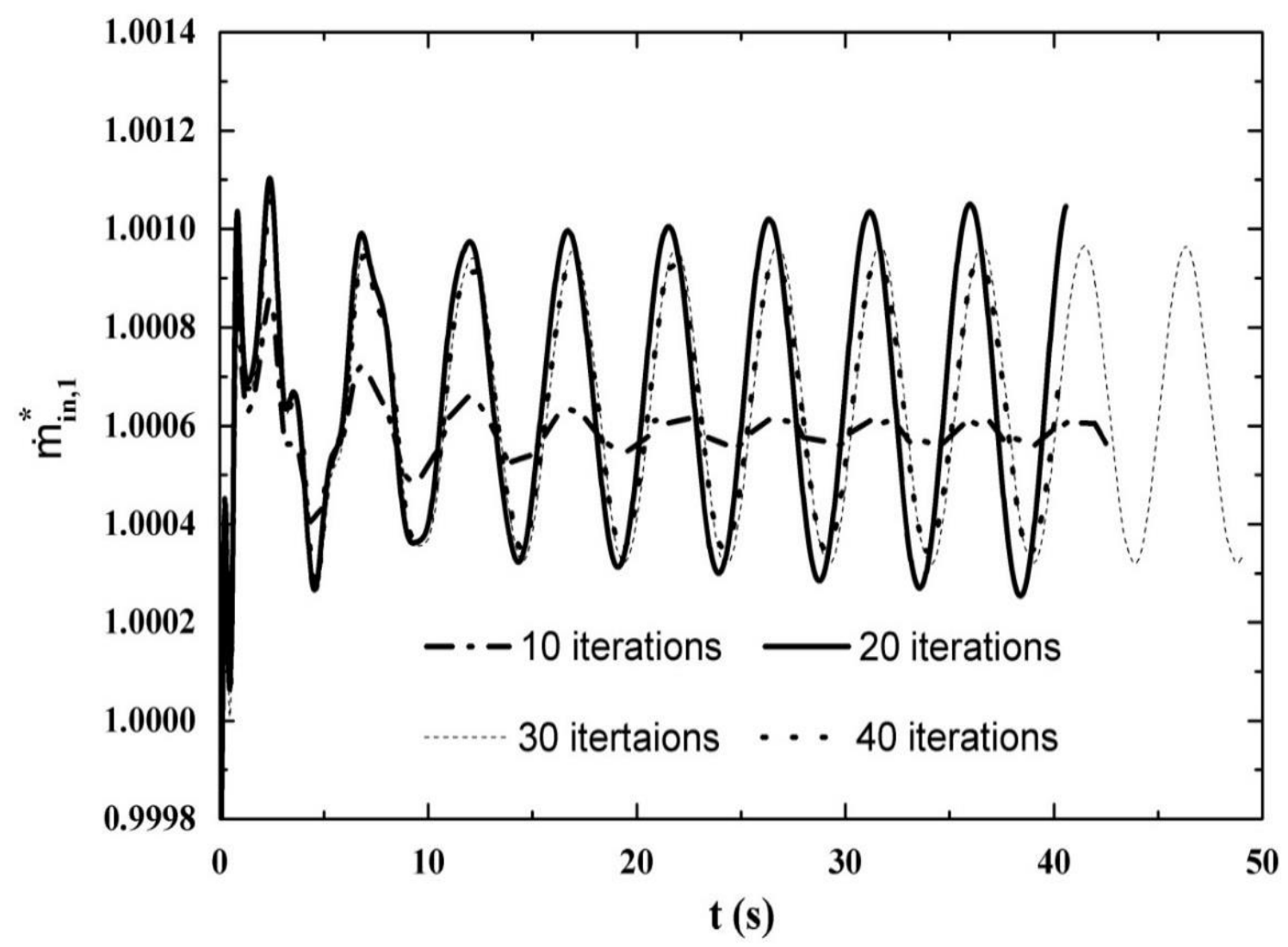

Figure 5.7: Comparisons of the normalized channel 1 inlet mass flow rate transient responses at different maximum numbers of iterations per time step for Case 3 and at a total mass flow rate of $0.0360 \mathrm{~kg} / \mathrm{s}$

\subsubsection{Effect of Changing the Transient Scheme}

As mentioned in Section 4.9 of Chapter 4, two options can be used to set the transient scheme in CFX when performing a transient analysis: the "First Order Backward Euler" scheme and the "Second Order Backward Euler" scheme. Both schemes were used to investigate the effect of the change on the instability threshold prediction.

Figure 5.8 illustrates, under Case 1 flow conditions, the transient responses of normalized inlet mass flow rate in channel 1 obtained with two different transient schemes. 


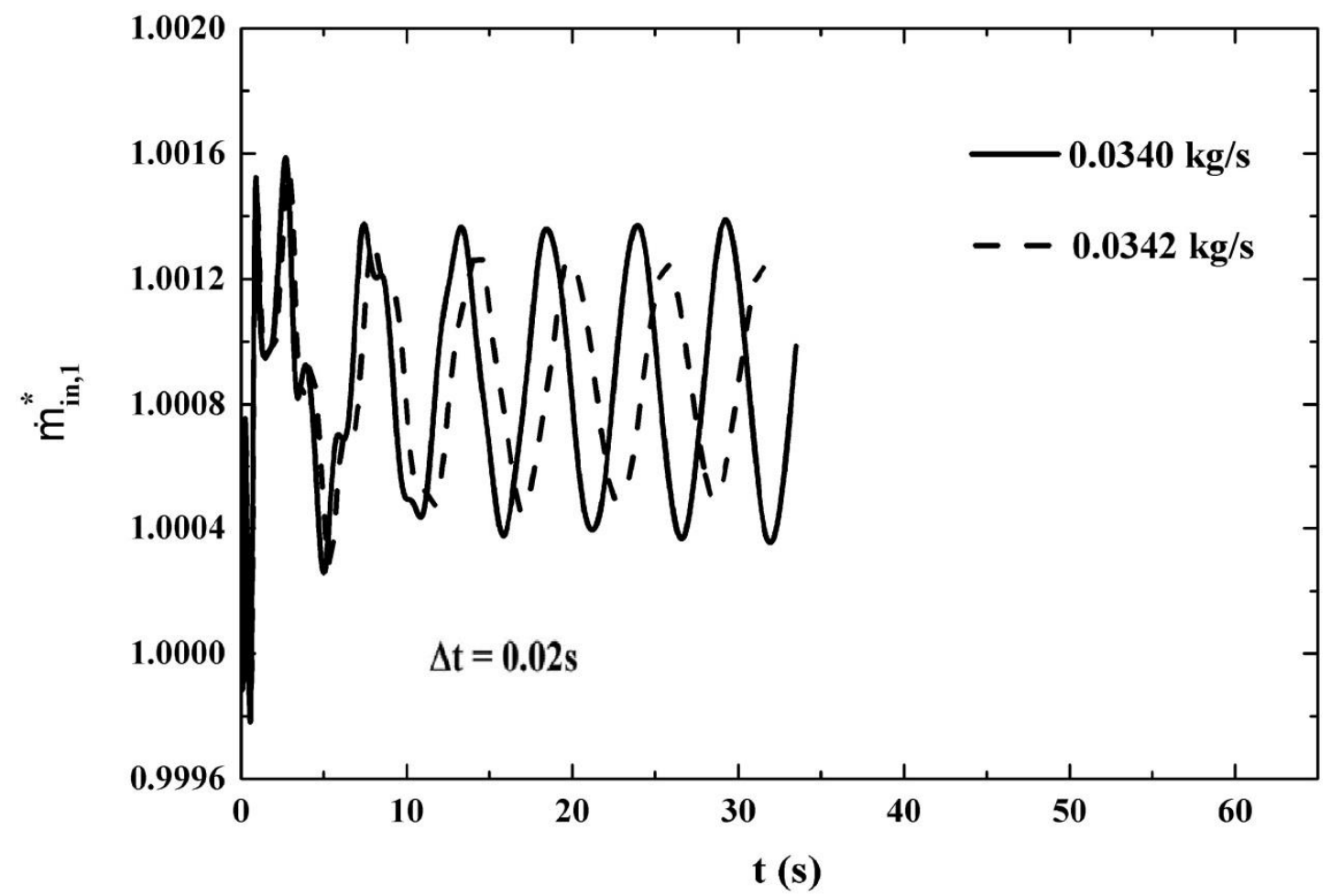

(a) first order

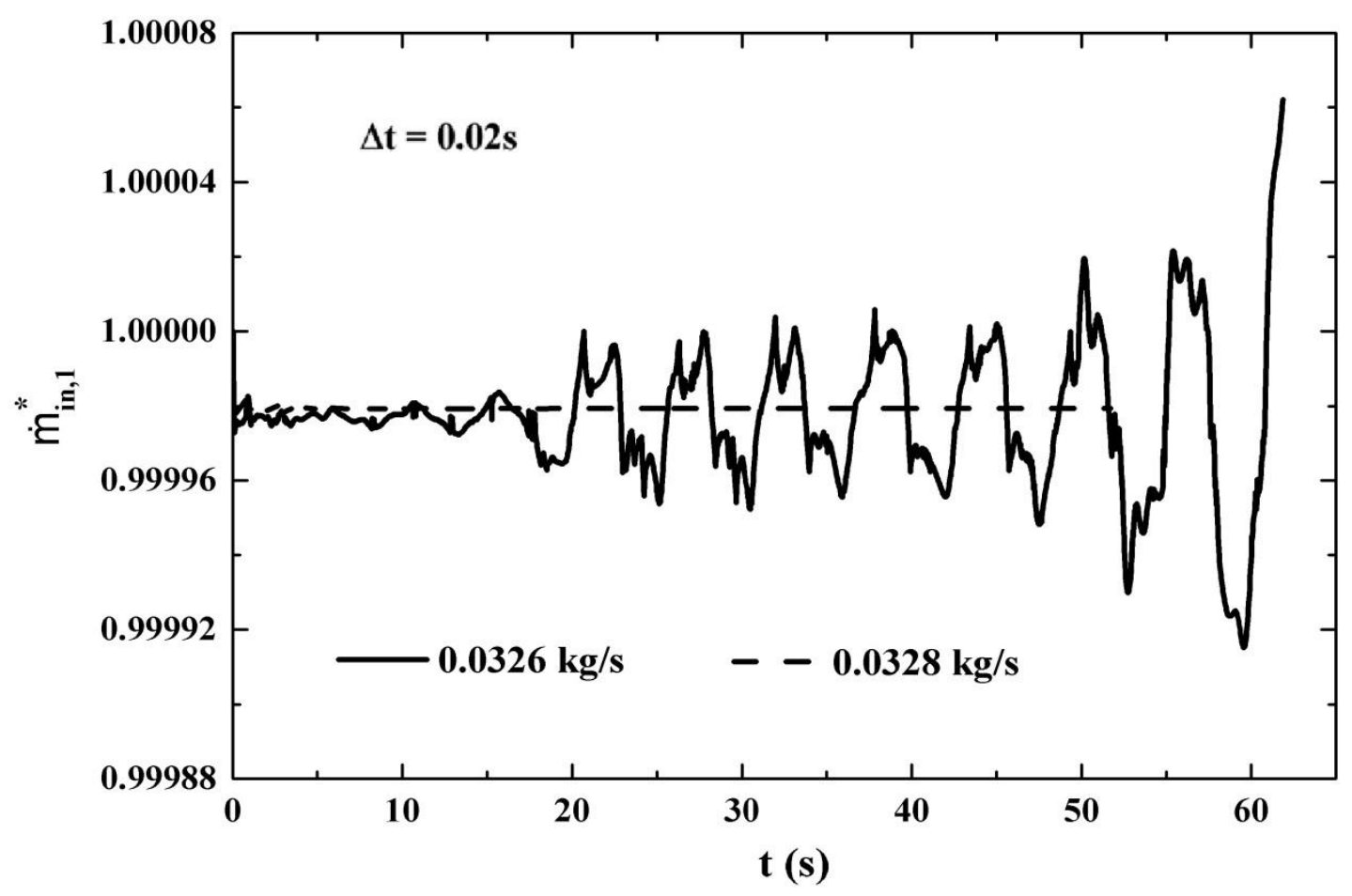

(b) second order

Figure 5.8: Case 1 instability boundary predicted by different transient schemes 
If the First Order Transient scheme is applied to search for the threshold mass flow rate, it is found that the flow is unstable at a total mass flow rate of $0.0340 \mathrm{~kg} / \mathrm{s}$ but stable at a total mass flow rate of $0.0342 \mathrm{~kg} / \mathrm{s}$, as shown in Figure 5.8 (a). Therefore, $0.0341 \mathrm{~kg} / \mathrm{s}$ is the Case 1 instability threshold found by the First Order Transient scheme. However, if the Second Order Transient scheme is used, the flow is unstable at a total mass flow rate of $0.0326 \mathrm{~kg} / \mathrm{s}$ and stable at a total mass flow rate of $0.0328 \mathrm{~kg} / \mathrm{s}$, as shown in Figure 5.8 (b). As a result, the threshold mass flow rate predicted is reduced to $0.0327 \mathrm{~kg} / \mathrm{s}$ when the Second Order Transient scheme is adopted.

Therefore, the different transient schemes predict different instability thresholds under the same flow conditions, and the Second Order Transient scheme predicts a relatively lower boundary mass flow rate than the First Order Transient Scheme.

We can also observe from Figure 5.8 that the transient response of the Second Order Transient scheme has many more noise-type fluctuations compared to that of the First Order Transient scheme, so there seems to be more numerical noise for the second order transient scheme. In addition, it takes much longer time for the Second Order Transient scheme to predict an identifiable oscillation pattern than the First Order Transient scheme.

Considering the different transient behaviours between the two transient schemes, it was thought that the Second Order Transient scheme could be run after running the First Order Transient scheme for a period of time to decrease numerical noise and also to save time to predict identifiable oscillations. Follow this idea, the inverse way which starts the First Order Transient scheme after running the Second Order Transient scheme for a 
period of time was also tested to observe the effects. Based on these ideas, two restart tests were designed:

- Test 1: First, start a transient run from a steady-state result using the Second Order Transient scheme for at least 25s, then stop the run and restart it using the First Order Transient scheme.

- Test 2: First, start a transient run from a steady-state result using the First Order Transient scheme for at least 25s, then stop the run and restart it using the Second Order Transient scheme.

Figure 5.9 illustrates an example of these two restart tests results. Figure 5.9 (a) presents the Test 1 results at a total inlet mass flow rate of $0.0328 \mathrm{~kg} / \mathrm{s}$. Because the Second Order Transient scheme predicts $0.0327 \mathrm{~kg} / \mathrm{s}$ as the threshold mass flow rate, the flow should be stable at $0.0328 \mathrm{~kg} / \mathrm{s}$, and this is seen in the figure. For the First Order Transient scheme, the instability boundary predicted is $0.0340 \mathrm{~kg} / \mathrm{s}$, so the flow should be unstable at a total mass flow rate of $0.0328 \mathrm{~kg} / \mathrm{s}$ which is lower than the instability threshold. The results in Figure 5.9 (a) show that the First Order Transient scheme predicts an unstable flow after the restart.

Figure 5.9 (b) shows the Test 2 results at a total inlet mass flow rate of $0.0340 \mathrm{~kg} / \mathrm{s}$. For the First Order Transient scheme, the flow is unstable at $0.0340 \mathrm{~kg} / \mathrm{s}$ which is lower than the boundary $0.0341 \mathrm{~kg} / \mathrm{s}$. For the Second Order Transient scheme, the flow should be stable at $0.0340 \mathrm{~kg} / \mathrm{s}$, which is higher than the boundary $0.0327 \mathrm{~kg} / \mathrm{s}$. The restart with the second order, however, predicts an unstable flow. This prediction of unstable flow at a mass flow rate well above the previously predicted stability boundary for the Second 
Order Transient scheme indicates that the Second Order Transient scheme does not produce consistent results.

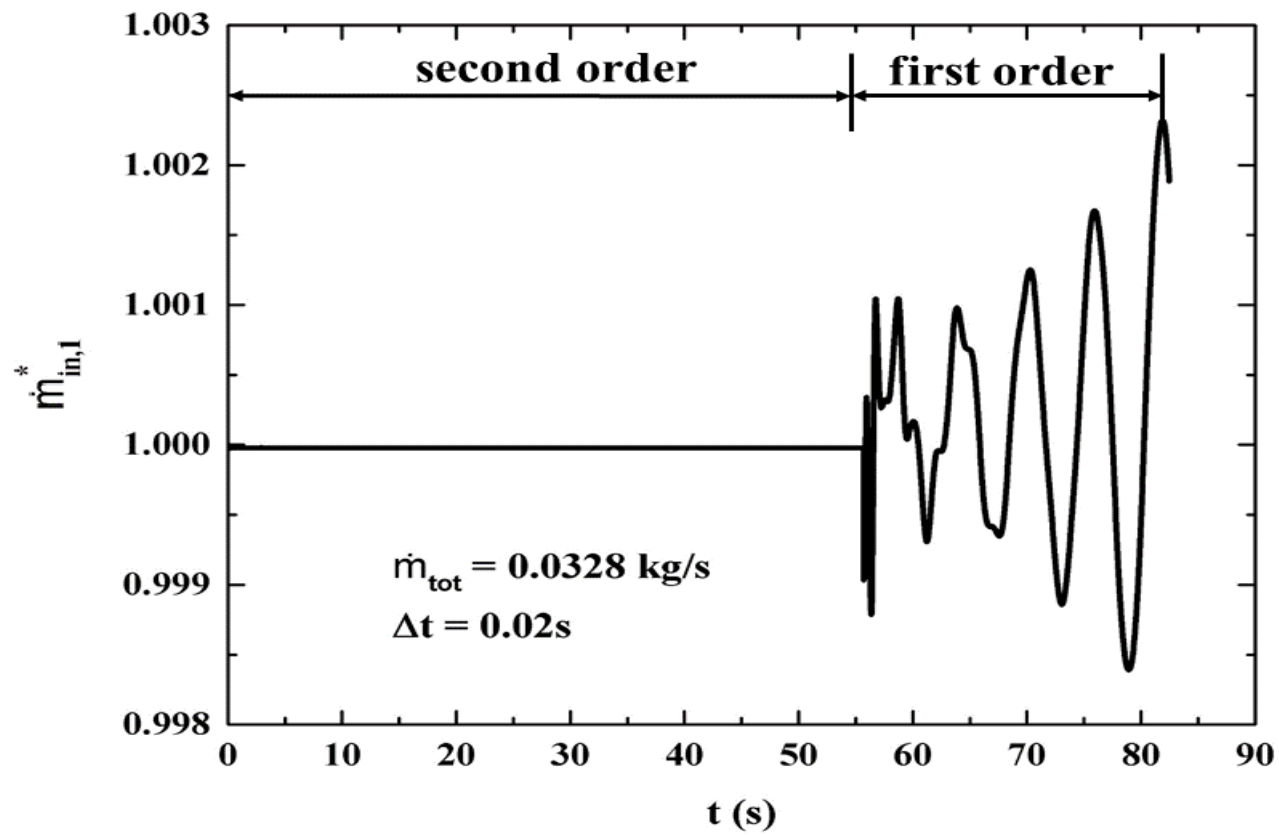

(a) Test 1 at a total inlet mass flow rate of $0.0328 \mathrm{~kg} / \mathrm{s}$

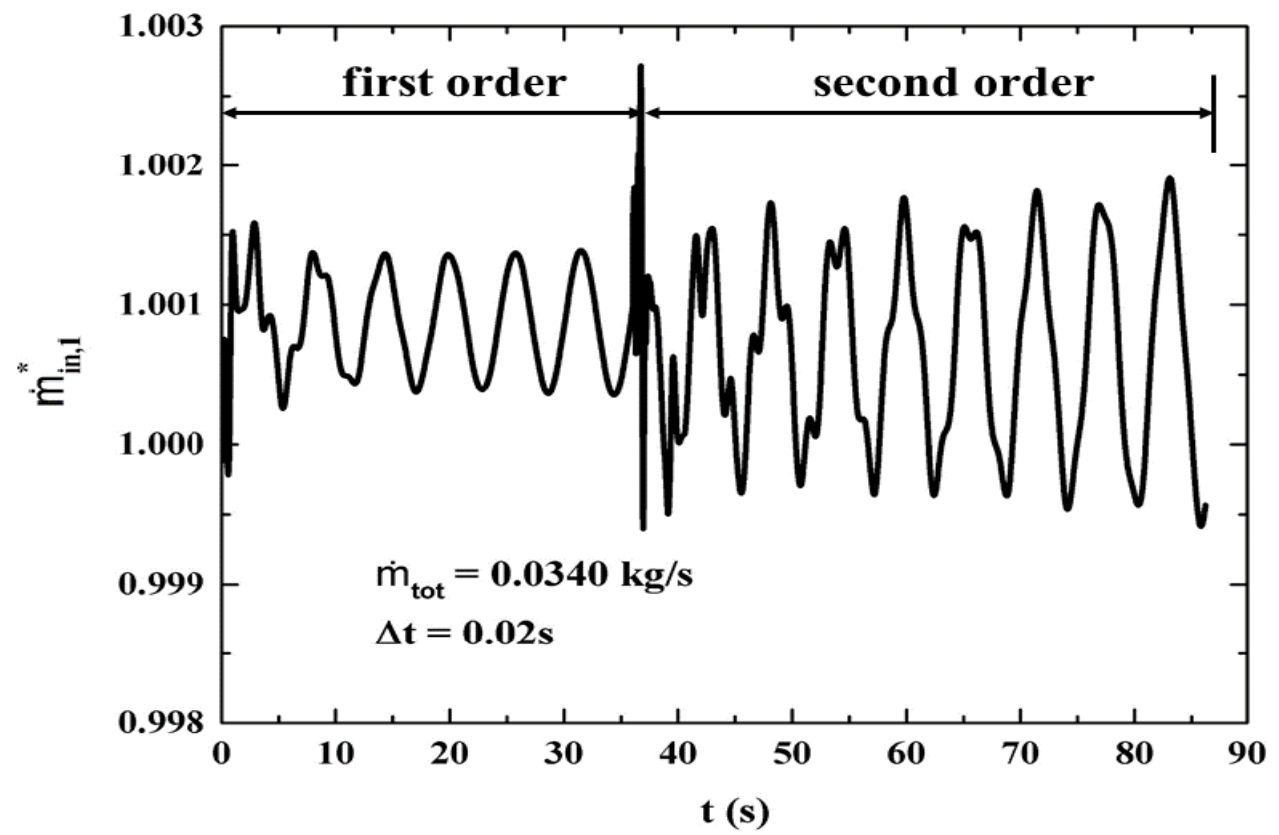

(b) Test 2 at a total inlet mass flow rate of $0.0340 \mathrm{~kg} / \mathrm{s}$

Figure 5.9: The normalized channel 1 inlet mass flow transient responses under Case 1 flow conditions with different transient schemes 
To further examine the consistency of the two transient schemes, the threshold mass flow rate of Case 1 was sought by performing the above two restart tests: Test 1 and Test 2 . In those tests, the behaviour in the second part of the transient run was used to indicate the onset of instability. The transient behaviour for these tests is summarized in Table 5.16.

Table 5.16: Restart test results at different total inlet mass flow rates for Case 1

\begin{tabular}{|c|c|c|c|c|}
\hline \multirow{2}{*}{$\dot{m}(\mathrm{~kg} / \mathrm{s})$} & \multicolumn{2}{|c|}{ Test 1 } & \multicolumn{2}{c|}{ Test 2 } \\
\cline { 2 - 5 } & $\begin{array}{c}\text { initial part: } \\
\text { second order }\end{array}$ & $\begin{array}{c}\text { second part: } \\
\text { first order }\end{array}$ & $\begin{array}{c}\text { initial part: } \\
\text { first order }\end{array}$ & $\begin{array}{c}\text { second part: } \\
\text { second order }\end{array}$ \\
\hline 0.0340 & stable & unstable & unstable & unstable \\
\hline 0.0342 & stable & stable & stable & unstable \\
\hline 0.0344 & stable & stable & stable & stable \\
\hline
\end{tabular}

Table 5.16 shows that, for Test 1 , the First Order Transient scheme predicts that the onset of case 1 instability occurs between total inlet mass flow rates of $0.0340 \mathrm{~kg} / \mathrm{s}$ and 0.0342 $\mathrm{kg} / \mathrm{s}$; therefore, the threshold mass flow rate is taken as $0.0341 \mathrm{~kg} / \mathrm{s}$. For Test 2 , however, the Second Order Transient scheme predicts that the onset of case 1 instability occurs between total inlet mass flow rates of $0.0342 \mathrm{~kg} / \mathrm{s}$ and $0.0344 \mathrm{~kg} / \mathrm{s}$; therefore, the threshold mass flow rate is taken as $0.0343 \mathrm{~kg} / \mathrm{s}$. In addition, it is noteworthy that, in Test 2 at total inlet mass flow rate of $0.0342 \mathrm{~kg} / \mathrm{s}$, the Second Order Transient scheme predicts an unstable transient behaviour when it continues from a stable transient response predicted by the First Order Transient scheme. This indicates that the unstable transient response predicted by the Second Order Transient scheme in Figure 5.9 (b) is not triggered by the unstable behaviour at the initial part with the First Order Transient scheme. 
The threshold mass flow rate of Case 1 obtained by performing restart tests was also compared with the results without restart (see Figure 5.8), as summarized in Table 5.17.

Table 5.17: Instability boundary of Case 1 under different test conditions

\begin{tabular}{|l|c|c|c|}
\hline & Test 1 & $\begin{array}{c}\text { without restart } \\
\text { (pure first order) }\end{array}$ & difference \\
\hline$\dot{m}_{\text {thold }, C F X}$ for Case $1(\mathrm{~kg} / \mathrm{s})$ & 0.0341 & 0.0341 & $0.00 \%$ \\
\hline \multicolumn{3}{|c|}{} \\
\hline & Test 2 & $\begin{array}{c}\text { without restart } \\
\text { (pure second order) }\end{array}$ & difference \\
\hline$\dot{m}_{\text {thold,CFX }}$ for Case $1(\mathrm{~kg} / \mathrm{s})$ & 0.0343 & 0.0327 & $4.89 \%$ \\
\hline
\end{tabular}

Table 5.17 indicates that the First Order Transient scheme is independent of the application of restart, for exactly the same instability boundary $(0.0341 \mathrm{~kg} / \mathrm{s})$ is predicted. The Second Order Transient scheme, however, is sensitive to the initial conditions and deviates from the Case 1 instability boundary by $4.89 \%$ when a restart is used. In addition, the Case 1 threshold mass flow rate predicted was close between the two transient schemes $(0.0343 \mathrm{~kg} / \mathrm{s}$ vs. $0.0341 \mathrm{~kg} / \mathrm{s})$ only when the Second Order Transient scheme started from the first order results. Therefore, the threshold mass flow rate of $0.0341 \mathrm{~kg} / \mathrm{s}$ for Case 1, predicted by the First Order Transient scheme, is consistent and reliable.

To sum up findings of transient scheme effects, two main disadvantages of the Second Order Transient scheme are noticed:

- More numerical noise in the transient response.

- Predictions of the instability boundary depend on the initial conditions.

Therefore, a researcher should be cautious about the use of the Second Order Backward Euler Transient scheme when performing transient numerical simulations for oscillatory 
flow in parallel channels with supercritical water. More numerical investigations should be conducted to further verify these findings. Throughout this study, the First Order Backward Euler Transient scheme was adopted because its predictions were more consistent and was considered to be more reliable.

An attempt was made to find out the possible reasons why in transient computations for instability analyses the two transient schemes behave so differently and why the Second Order Backward Euler Transient scheme works so inconsistently. It is thought that the plena connecting the two parallel channels could be a factor. To test this theory, equivalent single channel transient analyses would be required.

To be equivalent with the boundary condition of the two parallel-channel system, for single channel instability study, the total stagnation pressure drop of channel should be kept constant during transient analyses, and this pressure drop has to be exactly the same total stagnation pressure drop from corresponding steady-state analyses. However, as stated before, it is presently not possible to specify outlet total pressure in CFX. Therefore, this attempt was discontinued. 


\section{CHAPTER 6}

\section{SUMMARY, CONCLUSIONS, AND RECOMMENDATIONS}

\subsection{Summary}

In this study, a numerical simulation was performed to investigate the oscillatory instability of upward flow in two heated parallel channels with supercritical water, using a RANS model in CFD ANSYS CFX. This study is mainly aimed at assessing the ability of a commercial CFD code to predict instability thresholds of supercritical flow in parallel channels and to match instability experiments.

Grid and time step independent studies were conducted first to choose the mesh and time step to be used for later stability analyses. It was found that the CFX code is sensitive to the time step used, while spatial grid size refinement does not have a dramatic effect on the instability threshold prediction. After the decision of optimal mesh and time step, instability boundaries of nine experimental cases were modeled by the CFX code using the standard $k-\varepsilon$ turbulence model. The 1-D non-linear SPORTS code was also used to determine instability boundaries for comparison purposes. These new numerical results were then compared with experimental data as well as previously reported numerical results for the same experiment. Comparisons showed that numerical simulation results of this study agree overall well with the experiments. In addition, certain discrepancies among different numerical studies were noticed, and possible reasons were examined and reported. A previous conclusion that CFD results yield a better prediction of the instability boundary than a 1-D solution is not supported in this study. 
A series of senstivity studies were carried out to verify the CFD numerical results, as well as further assess the sensitivity of CFD to model supercritical flow instability. These studies included the effects of changing the outlet plenum volume, the turbulent Prandtl number, the turbulence inlet conditions, the outlet $\mathrm{K}$ factor, the maximum iterations per time step, and the transient scheme. Test results showed that within a certain range, the variation of outlet plenum volume, turbulent Prandtl number, turbulence inlet conditions, and outlet $\mathrm{K}$ factor affects the instability boundary in heated parallel channels slightly. However, the maximum iterations per time step have a noticeable influence on the instability thresholds prediction. Unless the maximum iterations per time step is at least a value, converged transient responses of mass flow rate cannot be achieved. For the transient scheme effect study, results of the First Order Backward Euler and the Second Order Backward Euler Transient schemes are compared, showing that the First Order Backward Euler Transient scheme provides more consistent and reliable results and is, therefore, recommended to be used for the predictions of supercritical flow instability in parallel channels.

\subsection{Conclusions}

From the results of this numerical study, the following conclusions are drawn:

- The agreements between numerical results of this study (both 1-D and 3-D) and experimental data show that 3-D CFX code and 1-D SPORTS code are capable of predicting the onset of supercritical flow instabilities in two heated parallel channels. 
- Although the same experiment was simulated, numerical results of this study deviate somewhat from the numerical results reported by previous investigators. For 3-D CFX numerical simulation differences, the different time step size applied is thought to play the key role in creating the discrepancy. In previous 3-D CFX simulation, investigators adopted a large time step such that temporal convergence was not achieved. Therefore, although previous 3-D CFX numerical results are closer to the experiment, it is suspected that their results would change if a smaller time step size was used. For 1-D numerical simulation differences, different boundary condition imposed at the inlet and outlet of channels is believed to be the cause of discrepancies. Previous 1-D simulation imposed equal static pressure boundary condition at the channel inlet and outlet, whereas it should be equal stagnation pressure. In conclusion, both previous 1-D and 3-D numerical simulations exhibit problems. For the differences between new 1-D and 3-D numerical results, different outlet boundary condition and different ways to compute the frictional pressure drop are thought to be the main reasons, and the former one is thought to be the key reason.

- For eight out of nine experimental cases, the 1-D SPORTS code gives a better prediction than the 3-D CFX code. Hence, it appears that the 1-D results are better than the 3-D CFX results. This conclusion is different from the one stated by Xi et al. (2014) that 3-D CFX code would predict the onset of flow instability better than 1-D code. However, a further comparison of the result between 1-D and 3-D CFX predictions needs to be made when the outlet total pressure can be specified in CFX. 
- Spatial grid size refinement does not have a dramatic influence on the instability boundary, whereas there is a high sensitivity of the CFX code to the time step size, and a larger time step can stabilize the system.

- Enlarging the outlet plenum volume by ten times, increasing or decreasing the turbulent Prandtl number by 0.1 , increasing or decreasing the turbulence intensity at the inlet by two times, and increasing or decreasing the outlet $\mathrm{K}$ factor of individual channel by $5 \%$ do not have considerable effects on the instability boundaries of tested cases. All of the variations made on instability thresholds of tested cases are within $2 \%$.

- The number of maximum iterations per time step during transient analyses has a significant influence on the transient behaviour of channel mass flow rate, and further affects the stability boundary prediction. Until the maximum iterations per time step reaches a certain value, properly converged transient responses are achieved.

- Some noisy transient responses were observed when the Second Order Transient scheme was used. Compared with the First Order Transient scheme, transient responses of the Second Order Transient scheme are not smooth, and it also takes a much longer time to capture an identifiable oscillation pattern. Furthermore, the Second Order Transient scheme does not generate consistent and reliable results. Therefore, the First Order Transient scheme is suggested to be used in the future. 


\subsection{Recommendations}

The following recommendations are made for future studies:

- Repeat this numerical study with the SST turbulence model to verify if similar numerical results can be obtained. Past experience indicates that the SST turbulence model predicts heat transfer characteristics more precisely than $k-\varepsilon$ turbulence model. Hence, the influence of improved heat transfer prediction on instability thresholds should be studied. The effect of changing the turbulent Prandtl number should also be repeated for the SST model.

- The findings of transient scheme effect in this study should be further verified by more numerical simulations, not only in parallel channels but also in other models such as single channel (if possible), rod bundles, and natural circulation loops.

- Investigate the effect of spatially varied $P r_{t}$ on the instability threshold. Different correlations for spatial variation of $P r_{t}$ have already been proposed, so spatially varied $\operatorname{Pr}_{t}$ number can be tested to observe its effects on flow instability prediction.

- Other fluids such as $\mathrm{CO}_{2}$, Helium, and Methane can also be tried to investigate their flow instability boundary in parallel channels with a 3-D CFX code. 


\section{REFERENCES}

Ambrosini, W., 2009. Discussion on the stability of heated channels with different fluids at supercritical pressures. Nuclear Engineering and Design 239(12), pp.2952-2963.

Ambrosini, W., 2011. Assessment of flow stability boundaries in a heated channel with different fluids at supercritical pressure. Annals of Nuclear Energy 38(2-3), pp.615627.

Ambrosini, W. and Sharabi, M., 2008. Dimensionless parameters in stability analysis of heated channels with fluids at supercritical pressures. Nuclear Engineering and Design 238(8), pp.1917-1929.

Ampomah-Amoako, E., Akaho, E.H.K., Nyarko, B.J.B. and Ambrosini, W., 2013. Analysis of flow stability in nuclear reactor subchannels with water at supercritical pressures. Annals of Nuclear Energy 60, pp.396-405.

Ampomah-Amoako, E., Akaho, E.H.K., Nyarko, B.J.B. and Ambrosini, W., 2013. CFD analysis of the dynamic behaviour of a fuel rod subchannel in a supercritical water reactor with point kinetics. Annals of Nuclear Energy 59, pp.211-223.

Ampomah-Amoako, E. and Ambrosini, W., 2013. Developing a CFD methodology for the analysis of flow stability in heated channels with fluids at supercritical pressures. Annals of Nuclear Energy 54, pp.251-262. 
ANSYS, Inc., 2013. ANSYS CFX-Solver Theory Guide.

Archana, V., Vaidya, A.M. and Vijayan, P.K., 2015. Numerical modeling of supercritical $\mathrm{CO}_{2}$ natural circulation loop. Nuclear Engineering and Design 293, pp.330345.

Barth, T.J. and Jespersen, D.C., 1989. The design and application of upwind schemes on unstructured meshes. AIAA Journal 0366(13).

Brook, B.W., Alonso, A., Meneley, D.A., Misak, J., Blees, T. and van Erp, J.B., 2014. Why nuclear energy is sustainable and has to be part of the energy mix. Sustainable Materials and Technologies 1-2, pp.8-16.

Chatoorgoon, V., 1986. SPORTS - A simple non-linear thermalhydraulic stability code. Nuclear Engineering and Design 93(1), pp.51-67.

Chatoorgoon, V., 2001. Stability of supercritical fluid flow in a single-channel natural-convection loop. International Journal of Heat and Mass Transfer 44(10), pp.1963-1972.

Chatoorgoon, V., 2008. Supercritical flow stability in horizontal channels. Nuclear Engineering and Design 238(8), pp.1940-1946. 
Chatoorgoon, V., 2016. Personal communication.

Chatoorgoon, V., Voodi, A. and Fraser, D., 2005. The stability boundary for supercritical flow in natural convection loops: Part $\mathrm{I}: \mathrm{H}_{2} \mathrm{O}$ studies. Nuclear Engineering and Design 235(24), pp.2570-2580.

Chatoorgoon, V., Voodi, A. and Upadhye, P., 2005. The stability boundary for supercritical flow in natural-convection loops: Part II: $\mathrm{CO}_{2}$ and $\mathrm{H}_{2}$. Nuclear Engineering and Design 235(24), pp.2581-2593.

Chen, L., Deng, B.L. and Zhang, X.R., 2013. Experimental study of trans-critical and supercritical $\mathrm{CO} 2$ natural circulation flow in a closed loop. Applied Thermal Engineering 59(1-2), pp.1-13.

Debrah, S.K., Ambrosini, W. and Chen, Y., 2013. Assessment of a new model for the linear and nonlinear stability analysis of natural circulation loops with supercritical fluids. Annals of Nuclear Energy 58, pp.272-285.

Dutta, G., Zhang, C. and Jiang, J., 2015. Analysis of parallel channel instabilities in the CANDU supercritical water reactor. Annals of Nuclear Energy 83, pp.264-273. 
Ebrahimnia, E., 2014. Numerical stability and heat transfer analyses of supercritical water flowing upward in vertical heated pipes (M.Sc. thesis). Dept. of Mechanical Engineering, University of Manitoba.

Ebrahimnia, E., Chatoorgoon, V. and Ormiston, S.J., 2016. Numerical stability analyses of upward flow of supercritical water in a vertical pipe. International Journal of Heat and Mass Transfer 97, pp.828-841.

Grotjans, H. and Menter, F.R., 1998. Wall functions for general application CFD codes. ECCOMAS 98 Proceeding of the Fourth European Computational Fluid Dynamics Conference, pp.1112-1117.

Haaland, S.E., 1983. Simple and explicit formulas for the friction factor in turbulent pipe flow. Journal of Fluids Engineering 105(1), pp.89-90.

Hou, D., Lin, M., Liu, P.F. and Yang, Y.H., 2011. Stability analysis of parallelchannel systems with forced flows under supercritical pressure. Annals of Nuclear Energy 38(11), pp. 2386-2396.

Jain, P.K. and Rizwan-uddin, 2008. Numerical analysis of supercritical flow instabilities in a natural circulation loop. Nuclear Engineering and Design 238(8), pp.1947-1957. 
Jain, R. and Corradini, M.L., 2006. A linear stability analysis for naturalcirculation loops under supercritical conditions. Nuclear technology, 155(3), pp.312-323.

Launder, B. E., and Sharma, B. I., 1974. Application of the energy-dissipation model of turbulence to the calculation of flow near a spinning disc. Letters in Heat and Mass Transfer 1(2), pp.131-137.

Lemmon, E.W., Huber, M.L. and McLinden, M.O., 2013. NIST reference fluid thermodynamic and transport properties-REFPROP. NIST Standard Reference Database 23-Version 9.1.

Liu, P.F., Hou, D., Lin, M. Kuang, B. and Yang, Y.H., 2014. Stability analysis of parallel-channel systems under supercritical pressure with heat exchanging. Annals of Nuclear Energy 69, pp.267-277.

Lomperski, S., Cho, D., Jain, R. and Corradini, M.L., 2004. Stability of a natural circulation loop with a fluid heated through the thermodynamic pseudo-critical point. United States: American Nuclear Society - ANS, La Grange Park (United States).

March-Leuba, J., and Rey, J.M., 1993. Coupled thermohydraulic-neutronic instabilities in boiling water nuclear reactors: a review of the state of the art. Nuclear Engineering and Design 145, pp.97-111. 
Nuclear Energy Institute, 2016. Nuclear Energy around the World - World Statistics. [online] Available at: http://www.nei.org/Knowledge-Center/NuclearStatistics/World-Statistics [Accessed 2016].

OECD Nuclear Energy Agency for the Generation IV International Forum, 2014. Technology Roadmap Update For Generation IV Nuclear Energy Systems - January 2014.

Ortega Gómez, T., Class, A., Lahey Jr., R.T. and Schulenberg, T., 2008. Stability analysis of a uniformly heated channel with supercritical water. Nuclear Engineering and Design 238(8), pp.1930-1939.

Patankar, S., 1980. Numerical heat transfer and fluid flow. CRC press.

Rhie, C.M. and Chow, W.L., 1983. Numerical study of the turbulent flow past an airfoil with trailing edge separation. AIAA Journal 21(11), pp.1525-1532.

Sharabi, M., Ambrosini, W. and He, S., 2008. Prediction of unstable behavior in a heated channel with water at supercritical pressure by CFD models. Annals of Nuclear Energy 35(5), pp.767-782.

Sharabi, M., Ambrosini, W., He, S., Jiang, P.X. and Zhao, C.R., 2009. Transient three-dimensional stability analysis of supercritical water reactor rod bundle subchannels 
by a Computational Fluid Dynamics code. Journal of Engineering for Gas Turbines and Power 131(2), p.22903(6).

Sharma, M., Pilkhwal, D.S., Vijayan, P.K., Saha, D. R. and Sinha, K., 2010. Steady state and linear stability analysis of a supercritical water natural circulation loop. Nuclear Engineering and Design 240(3), pp.588-597.

Sharma, M., Vijayan, P.K., Pilkhwal, D.S. and Asako, Y., 2013. Steady state and stability characteristics of natural circulation loops operating with carbon dioxide at supercritical pressures for open and closed loop boundary conditions. Nuclear Engineering and Design 265, pp.737-754.

Sharma, M., Vijayan, P.K., Pilkhwal, D.S. and Asako, Y., 2014. Natural convective flow and heat transfer studies for supercritical water in a rectangular circulation loop. Nuclear Engineering and Design 273, pp.304-320.

Tilak, A.K. and Basu, D.N., 2015. Computational investigation of the dynamic response of a supercritical natural circulation loop to aperiodic and periodic excitations. Nuclear Engineering and Design 284, pp. 251-263.

T'Joen, C. and Rohde, M., 2012. Experimental study of the coupled thermohydraulic-neutronic stability of a natural circulation HPLWR. Nuclear Engineering and Design 242, pp.221-232. 
Wagner, W., Cooper, J. R., Dittmann, A., Kijima, J., Kretzschmar, H.J., Kruse, A., Mares, R., Oguchi, K., Sato, H., Stocker, I., Sifner, O., Takaishi, Y., Tanishita, I., Trubenbach, J. and Willkommen, Th., 2000. The IAPWS industrial formulation 1997 for the thermodynamic properties of water and steam. Journal of Engineering for Gas Turbines and Power 122(1), p.150.

Worldometers.info, 2016. World Population Clock - Worldometers. [online] Available at: http://www.worldometers.info/world-population/ [Accessed 17 Aug. 2016].

Xi, X., Xiao, Z., Yan, X., Li, Y.L. and Huang, Y.P., 2014. An experimental investigation of flow instability between two heated parallel channels with supercritical water. Nuclear Engineering and Design 278, pp.171-181.

Xi, X., Xiao, Z., Yan, X., Xiong, T. and Huang, Y.P., 2014. Numerical simulation of the flow instability between two heated parallel channels with supercritical water. Annals of Nuclear Energy 64, pp.57-66.

Xiong, T., Yan, X., Huang, S.F., Yu, J.C. and Huang, Y.P., 2013. Modeling and analysis of supercritical flow instability in parallel channels. International Journal of Heat and Mass Transfer 57(2), pp.549-557. 
Xiong, T., Yan, X., Xiao, Z.J., Li, Y.L., Huang, Y.P. and Yu, J.C., 2012. Experiment study on flow instability in parallel channels with supercritical water. Annals of Nuclear Energy 48, pp.60-67.

Zhang, L., Cai, B., Weng, Y., Gu, H., Wang, H., Li, H. and Chatoorgoon, V., 2016. Experimental investigations on flow characteristics of two parallel channels in a forced circulation loop with supercritical water. Applied Thermal Engineering 106, pp.98-108.

Zhao, J., Saha, P. and Kazimi, M.S., 2005. Stability of supercritical water-cooled reactor during steady-state and sliding pressure start-up conditions. In: The 11th International Topical Meeting on Nuclear Reactor Thermal-Hydraulics (NURETH-11), p.106, Popes' Palace Conference Center, Avignon, France, October 2-6.

Zuber, N., 1966. An analysis of thermally induced flow oscillations in the nearcritical and super-critical thermodynamic region. Report NASA-CR-80609, Research and Development Center, General Electric Company, Schenectady, NY, USA, May 25, 159 pp. 